\title{
SELEÇÃO RECORRENTE COM ENDOGAMIA EM DUAS POPULAÇŌES DE MILHO: AVALIAÇÃO QUANTITATIVA E PERSPECTIVAS PARA SELEÇÃO DE HIBRIDOS
}

\author{
FRANEISCO TERASA IUNIOR
}

Engertheiro Agrónomo

Orientador: Prof. Dr. JOSE BRANCO DE MIRANDA FILHO

Disserta̧ăo afresentada a
Escola Superior de Agricultura
"Luiz de Gueiroz", da Univer-
sidade de Săo Paulo, para
obtençă do titujo de Mestre
em Agronomia, Erea de Concen-
traçăo: Genetica e Melhora-
mento de Plantas.

PIRACICABA

Estado de São Pauio - Brasil

Maio de 1993 
Ficha catalogrtica preparade pela sefáde livroe da Diviszo de Eibiateda e Documentafäo-FCLOLLSF

Terasawe Junior, Francisco

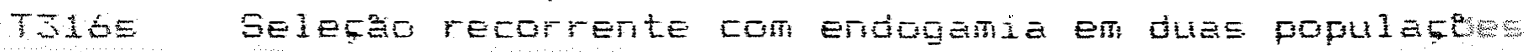
de milho: avaluaba quantitativa e perspectivas para selefac de hibridoc. Firacicabe, 1993. $167 \mathrm{p}$.

DiSS- (HEStrE) - ESALQ

Eitiliggrefía.

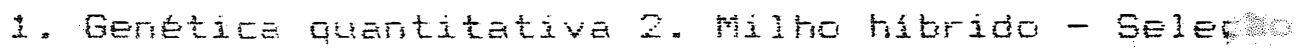
3. Nilto - Mejtioramento I. Escale Superiar de Agricul tura luiz de OuEiroz, Fireatcabe 
SELEĢO RECORRENTE COM ENDOGAMIA EM DUAS PQPULAĢES DE MILHO: AVALIAGZO QUANTITATIVA E PERSPECTIVAS PARA SELECTO DE HI BRIDOS

$$
\text { Francisco Terasawa Junior }
$$

Aprovada em: 24.06 .93

Comissăo Julgadora:
Dr. Roberto de Rissi
CIBA-SEMENTES
Prof. Dr. Lazaro Iose Chaves
UFG
Prof. Dr. Jose Braneo de Miranda Filho ESALQJUSP

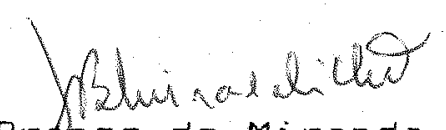

Prof. Dr. Jose Bratico de Miranda Filho 
DEDICO

A

FRANCISCO

pelo exemplo de homem

e de profissional

ANA CIRTE

por toda a sensibilidade

e beleza interiar

JOSE MALIRICIO

pela verdadeira amizade

DANIELA THAIS

pela alegria e pureza. 
IFEREC O

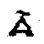

LVGIA VITORIA

pelo nosso amor e felicidade. 


\section{AGRADECT MENTOS}

A Deus, presente en tados os mamentos.

A minha familia, pela educaça fornecida e pelo constante incentivo.

Ao Prof. Jose Branco de Miranda Filho, pela valiosa orientaça, pela amizade e pela confiança depositada.

Ao Conselho Nacional de Pesquisa e Desenvolvimento, CNPq, pela bolsa de estudos concedida.

AFT - Pesquisa e Sementes, pelo suporte financeiro durante o curso.

Ao Prof. Dr. Roland Yencorsky, pela efetiva contribuiça a este trabalho.

Aos engentheiros agronomos Marcos Kamikoga e Bento Manoel Ferreira, pelo auxilio na condução dos experimentos e obtença dos dados.

A equipe tecnica da ICI/Contibrasil pelos dados experimentais concedidas.

Aos professores e funcionarios do Departamento de Genetica, e em especial a Sra. Carmen Pilotto, Sr. Antonio Miotto, Sr. Marcos Cella, e Sr. Trajano de oliveira Filho, pela sempre pronta colaboraçăo pela amizade. 
A Sra. Silvana Gregório, pelo auxlito na elaboração das referências bibliográficas.

A Prof: Lygia Vitória Galli pelas sugestôs na redaça.

A Daniel Doprado Barbosa, pelo apoio na elaboração dos gráficos.

A Daniela Thais Terasawa pela colaboração na fase final.

Aos colegas de curso, em especial a Ido José Pellicano, Benedita Aparecida da Silva, Cilaudia Silva e Mónica Rosa Bertão, pela amizade. 
INDICE

Pagina

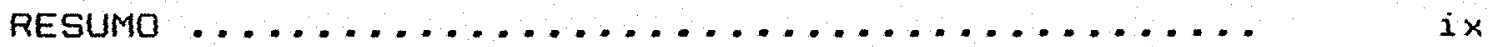

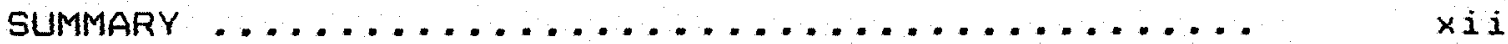

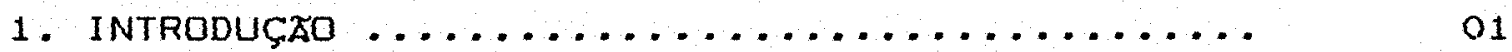

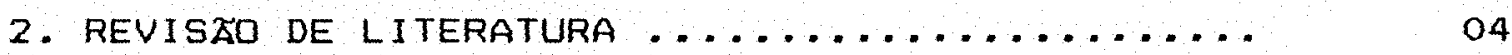

2.1. Seleço recorrente ................

2.2. Seleção recorrente com progenies endoga-

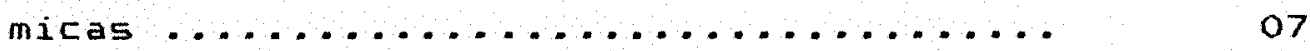

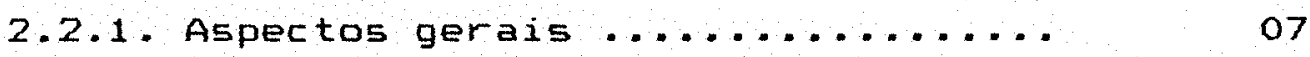

2.2.2. Resultados comparativos a outros processos seletivos .............. 14

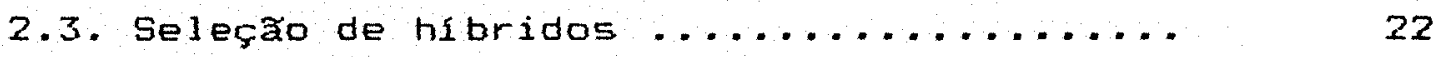

2.4. Variaça genetica ............... 2 .

3. MATERIAL E METODOS ...................

3.1. Caracterização das popul açôes ........ 35

3.2. Avaliaçao das progenies $51 \ldots \ldots \ldots \ldots . . . \ldots$

3.2 .1 . Material ................ 36

3.2.2. Execuçăo experimental ........ 37

3.2.3. Analises estatisticas ......... 39

3.2.4. Estimativas de parametras genetico-estatisticos .................. 45

3.2.5. Depresså por endogamia ....... 50

3.2.6. Distribuiçס̈es fenotipicas observa-

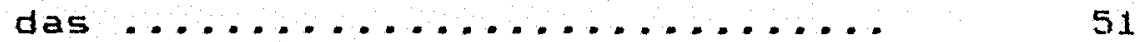

3.3. Avaliação dos "testcrosses" reclprocos .. 51

3.3.1. Material ................ 51

3.3.2. Execucão experimental ........ 53

3.3.3. Analises estatrsticas ......... 54 
Página

3.3.4. Estimativas de parametros genetico-estatisticos ............. 57

3.3.5. Depressão por endogamia ........ 60

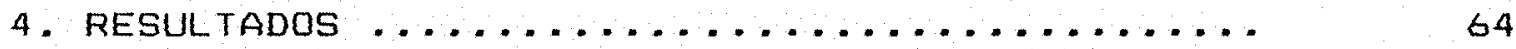

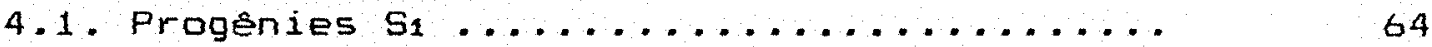

4.1 .1 . Valores medios ..................64

4.1.2. Distribuiçoses observadas....... 68

4.1.3. Analises agrupadas por local .... 69

4.1 .4 . Analises conjuntas ............ 70

4.1.5. Estimativas de variancia e coeficientes de herdabilidade ......... 71

4.1.6. Progressos esperados com a seleçao 75

4.2. Resultados dos "testcrosses" reclprocos . 76

4.2.1. Valores medios e amplitudes dos

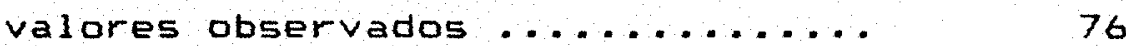

4.2.2. Análises de variancia ......... 78

4.2.3. Estimativas ............... 80

4.2.4. Progressos esperados com a seleça de híbridas .................. 81

4.2.5. Distribuição esperada de híbridos e "testcrosses" ............... 83

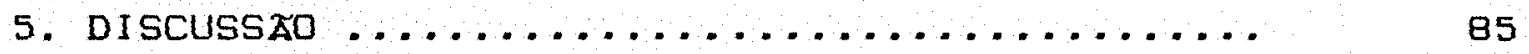

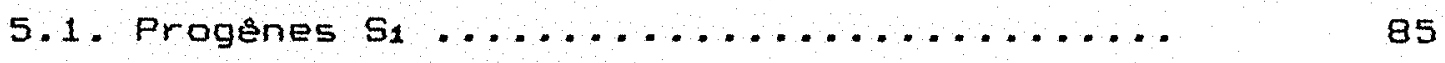

5.1.1. Valores medios e distribuiçós observadas ...................

5.1.2. Parametros genetico-estatisticos... 93

5.2. Anslise dos "testcrosses" reclprocos ..... 97

5.2.1. Valores médios e distribuiços observadas .............................. 98

5.2.2. Partiça da variabilidade geneti-

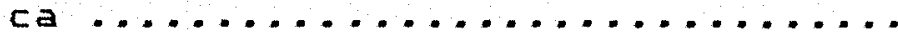


5.2.3. Estimativas de parámetros genéticaestatisticos .................. 103

5.2.4. Seleção recorrente reciproca ...... 105

5.2.5. Seleçán de nibridos ............ 111

6. CONCLUSOES ........................ 117

REFERENCIAS BIBLIOGRAFICAS .............. 119

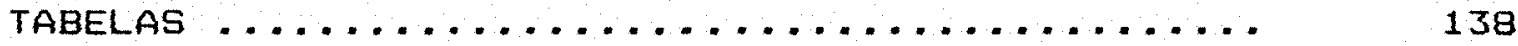

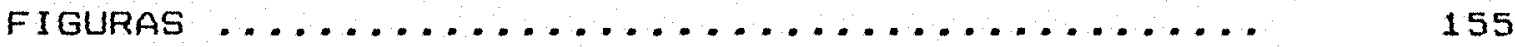

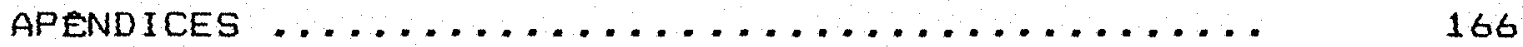


SELEÇZ̃O RECORRENTE COM ENDOGAMIA EM DUAS POPULAÇCES DE MILHO: AVALIAÇスO QUANTITATIVA E PERSPECT IVAS PARA SELEGAO DE HI BRIDOS

Autor: Francisco Terasawa Junior Orientador: Prof. Dr. Jose Branco de Miranda Filtho

\section{RESUMO}

- presente trabaltio refere-se a: i) avaliaçă de progenies $S_{1}$ no quarto ciclo de selefăo recorrente com endogamia nas populaçoes de milho ESALQ PB-2 C3 e ESALQ pB-3 c3, com enfase na determinação da depressăo por endogamia; iil avaliaçăo de "testcrosses" recfprocos de progenies $S_{2}$ derivadas de ESALG PB-2 C2 e ESALQ PB-3 C2, inferindo sobre a performance esperada de hibridos de 1 intiagens endogamicas.

No primeiro conjunto de experimentos, foram avaliadas 200 progenies de cada população em dois locais: Ponta Grossa (PR) e Rondonópolis (MT); as populaçós base não endogamicas $\left(S_{0}\right)$ o hibrido comercial c511 foram incluidos. Para as populaçBes bases ESALG PB-2 e ESALQ PB-3, a depressao por endogamia $\left[D E=\left(\bar{S}_{2}-\bar{S}_{0}\right) / \bar{S}_{0}\right]$ estimada foi de $-40,0 \%$ e $-44,0 \%$ para produca de graos (PG), $-8,1 \%$ e $-8,0 \%$ para altura de planta (AP) e $-8,9 \%$ e $-8,2 \%$ para altura de espiga (AE), respectivamente; os desvios $\left(S_{1}-\bar{S}_{0}\right) / \bar{S}_{0}$ foram apresentados graficamente, com limites inferiores de: 
$-1,5 \%$ e $-12,4 \%$ para $P G ;+13,4 \%$ e $+15,6 \%$ para AP; e $+18,0 \%$ e +16,6\% para $A E$. Estimativas da media de uma amostra aleatória de lintias homozigotas, sao tambem apresentadas. As estimativas de variancia genetica aditiva para ESALQ PB-2 (C3) E ESALQ PB-3 (C3) foram: 211 e 130 para $P G(g / p 1), 231$ e 243 para AP (cm), e 131 e 105 para AE (cm), sob a suposição de igualdade de frequencias alelicas $(p=q=0,5$ para locos segregantes) e para as relaçes de $\alpha_{A}^{2}$ : $\sigma_{D}^{2}$ iguais a 2:1 para PG e 5:1 para AP e AE. Os coeficientes de variaçăo genetica foram da ordem de $15 \%, 7 \%$ e $9 \%$ para PG, $A P, A E$, respectivamente para as duas populaçBes.

No segundo conjunto de experimentos, 171 "testcrosses" reciprocos (T) foram avaliados en um local (Cravinhos, SP), compondo 80 cruzamentos de ESALQ PB-2Q $\times$ ESALQ PB-3 O (T12) e 91 cruzamentos de ESALQ PB-3q $\times$ ESALG PB-26 (T21), onde as fameas sao representadas por progenies $S_{2}$ individuais e os machos pela mistura de polen das progenies $S_{2}$ da populaçăo reclproca; o híbrido comercial C511 foi incluf do como testemunha. As estimativas das medias do hiorido interpopulacional, em relação a testemuntia, foram $97 \%, 102 \%$ e $106 \%$ para PG, AP e $A E$, respectivamente. Para a interpopulaçăo, as estimativas de variancia aditiva foram 304, 240 e 144 para PG $\left(\mathrm{g}^{\prime} \mathrm{P}^{1}\right)$, AP $(\mathrm{cm})$ e AE $(\mathrm{cm})$, respectivamente. Os progressos esperados com a seleça de híbridos simples (HS), hibridos triplos (HT) e hibridos duplos (HD) de 1 inhagens completamente endogamicas foram, respectiva- 
mente: $27,2 \%, 21,0 \%$ e $15,0 \%$, para a relaçao $\left(\sigma_{A}^{2}: \sigma_{D}^{2}\right)=1: 1$; e $23,0 \%, 18,0 \%$ e $13,0 \%$ para a relaçæo 2:1. Os progressos esperados com a seleçă de híbridos så também apresentados para altura de planta, altura de espiga e para híbridos de linhagens com endogamia parcial. As medias preditas dos melhores "testcrosses" (progenies $S_{2}$ ), HS, HT, HD (1intiagem $F=1)$ foram iguais a $130 \%, 154 \%, 145 \%$ e $137 \%$, respectivamente, a produção da testemunina cs11, para $\left(\alpha_{A}^{2}: \alpha_{D}^{2}\right)=1: 1$. 
RECURRENT SELECTION WITH INBREEDING IN TWO MAIZE POPULATIONS: QUANTITATIVE EVALUATION AND PERSPECTIVES FOR HYBRID SELECTION

Author: Francisco Terasawa Junior Adviser: Prof. Dr. Jose Branco de Miranda Filto

\section{SUMMARY}

The present work was carried out for: i) evaluation of $S_{1}$ progenies in the fourth cycle of recurrent selection with inbreeding in the maize populations ESALQ $P B-2$ C3 and ESALQ $P B-3$ C3, with emphasis for inbreeding depression determination; ii) evaluation of reciprocal testcrosses of $S_{2}$ progenies derived from ESALQ PB-2 C2 and ESALQ PB-3 C2, followed by inferences on the expected performance of hybrids from inbred 1 ines.

In the first set of experiments, $200 \mathrm{~s}_{1}$ progenies from each population were evaluated at two locations: Ponta Grossa (PR) and Rondonspolis (MT); the noninbred ( $S_{0}$ ) base populations and the hybrid check C-511 were included. For the base populations ESALQ PB-2 and ESALQ PB-3, the inbreeding depression $\left[I=\left(\bar{S}_{1}-\bar{S}_{0}\right) / \bar{S}_{0}\right]$ was estimated as $-40.0 \%$ and $-44.0 \%$ for grain yield (GY), $-8.1 \%$ and $-8.0 \%$ for $\mathrm{Plant}$ height $(\mathrm{PH})$ and $-8.9 \%$ and $-8.2 \%$ for ear height $(E H)$, respectively; the deviations $\left(S_{1}-\bar{S}_{0}\right) / \bar{S}_{0}$ were 
shown graptically and the lower 1 imits were $-1.5 \%$ and $-12.4 \%$ for $G Y,+13.4 \%$ and $+15.6 \%$ for $\mathrm{PH}$ and $+18.0 \%$ and $+16.0 \%$ for EH. Estimates of the expected mean of a random sample of homozigous lines, are also shown. The estimates of the additive genetic variance for ESALQ PB-2 (C3) and ESALQ PB-3 (C3) were: 211 and 130 for $G Y(g / p 1), 231$ and 243 for $\mathrm{PH}$ (cm) and 131 and 105 for $E H(\mathrm{~cm})$, under the assumption of equal allel frequency $(p=q=0,5$ for segregating $10 c i)$ and ratios of $\sigma_{A}^{2}: 0_{D}^{2}$ of $2: 1$ for GY and $5: 1$ for $P H$ and $E H$. The genetic coefficients of variation were of the order of $15 \%$, $7 \%$ and $9 \%$ for GY, $\mathrm{PH}$ and $\mathrm{EH}$, respectively, for both populations.

In the second set of experiments, 171 reciprocal testcrosses (T) were evaluated at one location (Cravintios, SP), comprising 80 crosses of ESALQ PB-2q $x$ ESALQ PB-30 (T12) and 91 crosses of ESALQ PB-3qX ESALQ PB-20 (T21) where the females are represented by individual $S_{2}$ progenies and the males by a mixture of $s_{2}$ progenies for each population; the hybrid check C-511 was included. The estimates of the interpopulation hybrid means relative to check mean were $97 \%, 102 \%$ and $106 \%$ per GY, PH and EH, respectively. For the interpopulation the estimates of the additive genetic variance were 304,240 and 144 for GY $(\mathrm{g} / \mathrm{p})$ ), PH ( $\mathrm{cm})$ and $\mathrm{EH}(\mathrm{cm})$, respectively. The expected gain from selection for grain yield of single-crosses (SC), three-way crosses (TC) and double crosses (DC) from 
completely homozygous 1 ines were, respectively: $27.2 \%, 21.0 \%$ and $15.0 \%$ for the ratio $\left(\sigma_{A}^{2}: \sigma_{D}^{2}\right) 1: 1$; and $23.0 \%, 18.0 \%$ and 13.0\% for the ratio 2:1. Expected gains for hybrid selection are a 150 shown for $\mathrm{PH}$ and $\mathrm{EH}$ and for hybrids from partially homozygous lines. The predicted mean of the best testcrosses (S, progenies), SC, TC and DC (inbred 1 ines $F=1$ ) outyielded the check (C-511) mean by $130 \%, 154 \%, 145 \%$ and $137 \%$, respectively, for the ratio $\left(\sigma_{A}^{2}: o_{D}^{2}\right)=1: 1$. 


\section{INTRODUÇÃO}

A possibilidade de integração de programas de seleça recorrente a metodos de obtençao de hibridos, melhorando as populaçes-fonte de linhagens, tem sido sugerida na literatura, uma vez demonstrada a presenga de suficiente variabilidade genetica nas populaçoes (ROBINSON et alii, 1955) e confirmada a tendencia de estabelecimento de platos em programas de media e longa duraçá (COMSTOCK, $1964)$

Desta forma, a avaliaçao e recombinaça de progenies endogamicas em programas de selecão recorrente tem se mostrado uma boa opça para o mel horamento populacional, pois além de promover gantios nas populaçoes base, proporciona a reduça na depressáo por endogamia, permitindo a selecão de linhagens mais vigorosas. Este aspecto e de alta relevancia, especialmente em programas de obtença de hibridos simples e triplos, nos quais está envolvidas linhagens endogamicas na produção do hlorido final. 
Quando analisado o progresso obtido na capacidade de combinaçăo, entretanto, estudos teoricos e resultados experimentais tem indicado a superioridade dos esquemas de selecáo recorrente reciproca sobre os metodos intrapopulacionais. No primeiro caso, a pratica da seleça visa diretamente o comportamento do hibrido interpopulacional, atuando preferencialmente tanto sobre a capacidade geral como especl fica de combinaça lcomstock et $2111,19491$.

outro ponto importante 2 a possibilidade de estimação dos componentes aditivos da variancia interpopulacional, atraves da seleçáo recorrente reclproca, permitindo a prediçá do progresso esperado com a seleçá, bem como a determinação das distribuiçoes esperadas dos hibridos a serem obtidos, assumindo-se um valor hipotetico para a variancia dominante. A analise destes resultados, em associação ao contecimento das performances "per se" das linhagens endogamicas parentais s, desta forma, um bom indicativo do potencial das duas populaçoes para obtenção de hibridos.

No sentido de aumentar a integração seleça recorrente - selecão de hibridos, bem como de avaliar o potencial das duas populaçoes ESALQ PB-2 e ESALQ PB-3 neste contexta, traçaram-se os seguintes objetivos para a presente estudo: 
a) Avaliar a performance "per se" das pOpul açBES ESALQ PB-2 (C3) e ESALQ PB-3 (C3) em conjunto com as progenies $S_{1}$ delas derivadas, relativas ao quarto ciclo de seleça com progenies endogámicas.

b) Predizer a media do conjunto de linthagens totalmente endogamicas que serão extraidas da ESALQ $P B-2$ (C3) ESALQ PB-3 (C3).

C) Determinar as medias e os componentes de variancia referentes aos "testcrosses" reciprocos de linhagens $S_{2}$, derivados de ESALQ PB-2 (C2) e ESALQ PB-3 (C2).

d) Predizer a performance esperada dos diversos tipos de hibridos a serem obtidos do cruzamento ESALQ PB-2 (C2) × ESALQ PB-3 (C2). 


\section{REVISÃO DE LITERATURA}

\subsection{Seleça Recorrente}

Seleção recorrente, denominaçăo proposta por HULL (1945), refere-se a um conjunto de metodologias conduzidas de maneira clclica, baseada na seleçao e intercruzamento de individuos. O melhoramento e promovido de forma continua, sendo função do aumento gradativo da freqüencia de alelos favoraveis na populaçao (PATERNIANI \& MIRANDA FILHO, 1987).

Segundo HALLAUER (1980), cada ciclo de recorrencia e composto por tres fases: a) abtenção de genotipos; b) avaliaçăo e seleçao de genotipos; c) recombinação de genotipos, sendo que, em alguns métodos como a seleção massal, por exemplo, estas fases podem estar sobrepostas em uma ou duas fases.

MOLL \& STUBER (1974) dividiram os metodos de selecáo recorrente em dois grupos: metodos intrapopulacionais, visando o mel horamento "per se" das populaçöes e metodos interpopulacionais, onde a selecă visa o melhoramento do híbrido interpopulacional. Apesar de possulrem objetivos principais distintos, espera-se que tanto o meltio- 
ramento intrapopulacional como o interpopulacional promovam respostas positivas nas populaçoes "per se" bem como em combinaçes his bridas, haja visto a maior importancia de efeitos aditivos sobre caracteres quantitativos em milho (HALLAUER, 1984 ; HALLAUER \& MIRANDA FILHO, 1988).

São varios os processos de seleção recorrente descritos na literatura, sendo que revisoes sobre os diversos metodos podem ser encontrados em PENNY et al $i$ (1963), LONNQUIST ( 1965 ) e mais recentemente em PATERNIANI \& MIRANDA FILHO (1987), HALAUER \& MIRANDA FILHO (1988); HALLAUER Et a 1 i (1988) e PANDEY \& GARDNER (1993). NESte 1 tem serăo abordados alguns fatores que afetam a eficiencia da seleçao recorrente, tomando-se por base a expressão do progresso esperado com a seleção, a qual permite também estabelecer comparaçbes entre os diferentes processos seletivos (EBERHART, 1970 ; PATERNIANI, 1980; HALLAUER \& MIRANDA FILHO, 1981, MIRANDA FILHO, 1985, PATERNIANI, 1990). A expIES5ão Chave proposta por EBERHART (1970) \& a seguinte:

$$
G s=\frac{1}{y} \cdot P \cdot d s \cdot H, \text { onde: }
$$

Gs: progresso esperado com a seleção por ano;

p: valor associado ao grau de controle parental exercido; ds: diferencial de seleçao, representado pela diferença entre a média de individuos selecionados e a media populaciona $1\left(\bar{x}_{5}-\bar{x}\right)$; para a selecáa truncada ds $=\mathrm{k} . \alpha_{F}$, onde $k$ e o diferencial de seleção estandartizado, função da intensidade de seleção aplicada; $\sigma_{F}$ e desvio padrão fenotlpico da unidade de seleção; 
$H:$ coeficiente de herdabilidade estimado por $\sigma_{g}^{2} / \sigma_{f}^{2}$, onde $\sigma^{2}$ e a variancia genetica aditiva e $\sigma_{f}^{2}$ a variancia fenotipica daunidade de selecão;

y: número de anos necessários por ciclo de seleçao.

Partindo-se de um material geneticamente variável, a magnitude da variancia aditiva exploravel e função do metodo de seleção adotado. o número de anos necessários para um eiclo de seleçao (y) varia em funçao do metodo e da possibilidade de utilizaça de geraçes de inverno, nas fases de obtenção e recombinação das progenies. A redução do valor de y, atraves de plantios no inverno e colocada por EBERHART (1970) como fator importante para mel horar a eficiencia do método. Propbe-se, tambem, o emprego de maior número de locais para avaliação, en detrimento do número de repetiçbes por local e do tamanto da parcela. o uso de altas intensidades de seleçao, pode acarretar, entretanto, possiveis problemas de deriva genética e aumentos na endogamia da população, associados ao baiko tamantio efetivo popu1aciona 1. Segundo VENCQUSKY (1987), o tamantio efetivo mantido em programas de seleção recorrente e funçăo do número e do tipo de progenies recombinadas.

Nos 1 tens 2.2 .1 e 2.2 .2 será estabelecidas comparaçbes entre os metodos de seleçáo com progenies endogamicas e demais processos seletivos, considerando-se aspectos tesricos es resultados descritos na literatura. 
2. 2. Seleça recorrente com progenies endogamicas

\subsubsection{Aspectos gerais}

A utilizaçao do metodo de seleçao recorrente com progenies endogámicas tem sido relatada desde a decada de 60, em milho, com trabaltios de BUJANOWSKI (1967) PENNY et alii (1967) visando resistencia a Ustilago maydis (carvão da espiga) e "European Corn Borer", respectivamente. Malor entase a este esquema de seleção, contudo, tem sido dada nas Ul timas duas décadas. Uma das razBes colocadas por HALLAUER et alii (1988) seria a maior importancia dos efeitos aditivos com dominancia completa e parcial, do que outros tipos de efeitos génicos em popul açoes de milho.

A relação entre os tipos de ação genica controlando o carater e os metodos de mel horamento adotados foi discutida por COMSTOCK (1964). Na ausencia de sobredominancia, a seleçăo com proganies endogamicas mostrou-se o metodo mais eficiente em alterar as frequencias genicas da populacão.

Comparado aos demais processos seletivos, o metodo de seleção com progenies endogamicas apresenta o maior coeficiente de variancia aditiva exploravel na seleçă, com valor igual a 1 para progenies 5, e 1,5 para progenies $S_{2}$ (COMSTOCK, 1964; EMPIG et a1ii, 1972; HALLAUER, 1980, HALLAUER \& MIRANDA FILHO, 1981). Alem da variancia 
aditiva, computado na expressão do progresso com a seleção o componente Ds, definido por COCKERHAM (1983) como a covariancia entre os efeitos aditivos e dominantes dos homozigotos. As expressbes do progresso com a seleça de progenies endogamicas $\left(S_{1} \in S_{2}\right)$ ao fornecidas por SOUZA Jr. (1989), onde:

$$
\begin{aligned}
& G_{\left(S_{1}\right)}=\frac{1}{\sigma_{x_{1}}}\left[\sigma_{A}^{2}+\frac{1}{2} D_{1}\right] \\
& G s_{\left(S_{2}\right)}=\frac{1}{\sigma_{x_{2}}}\left[\frac{3}{2} \sigma_{A}^{2}+\frac{5}{4} D_{1}\right]
\end{aligned}
$$

Em se tratando de uma covariancia, o componente $D_{1}$ pode assumir valores positivos, negativos ou nulo, sendo função das frequencias genicas na população e do grau de dominancia do carater. Em populaçBes onde a frequencia de alelos desfavoraveis superior a frequencia de alelos favoraveis, bem como em algumas situaçoes especlticas aonde prevalece a sobredominancia, o componente $D_{1}$ e negativo, reduzindo a variancia genetica exploravel com a seleção (COORS, 1988; FERNANDES, 1990). SUa magnitude em populaçBes de milti, contudo, $s$ pouco contiecida. Resultados experimentais de cooRs (1988), no sintetico 3 L Comp, revelaram estimativa de $D_{1} e$ de magnitude semelhante a variancia aditiva, en termos absolutos, para produçao de graos.

Com respeito ao tamantio efetivo populacional (Ne), entre os metodos intrapopulacionais, os menores valores de Ne são obtidos para a selecaao recorrente com proge- 
nies endogamicas, comparando-se o mesmo número de progénies selecionadas. Para a seleçăo com progenies $S_{1}, 0$ tamantio efetivo populacional equivale ao número de progénies recombinadas ( $N e \cong N$ ), sendo inferior en relaçăo a seleção com progénies de irmáos germanos (Ne $\cong 2 N$ ) e com progenies de meios irmás (Ne $\cong$ 4N) (VENCOVSKY, 1987).

Como salientado por HALLAUER (1984), a maioria dos programas de seleção recorrente com recombinação de progenies endogamicas tem adotado altas intensidades de seleçã, restringindo o tamanho efetivo populacional. Alem da perda fixaça aleatoria de alelos devido a deriva genetica, podem ser gerados problemas devido ao acrescimo da endogamia da população.

Em estudos anteriores, BAKER \& CURNOW (1969) determinaram que valores de tamanho efetivo da ordem de 35 a 40 seriam suficientes para assegurar progressos tanto a curto quanto a longo prazo, em programas de seleçao recorrente. SMITH (1983) mostrou efeitos evidentes da deriva genetica, em populaçBes mantidas com tamantio efetivo igual a 10. O nlvel de endogamia populacional (F) e estimado pela relação: $F=1 / 2 N e$ (FALCONER, 1960 ).

Ds efeitos depressivos causados pelo acrescimo de $1 \%$ na endogamia, en populaçóes de milho, foram determinados por HALLAUER \& MIRANDA FILHO (1981), obtendose reduç̧es medias de $50 \mathrm{~kg} / \mathrm{ha}$, para produção de grãos, 0,40 cm para altura de planta e $0,30 \mathrm{~cm}$ para altura de espiga. 
Foram assumidos decrescimos lineares com o aumento da endogamia populacional.

Entre os caracteres avaliados em milho, a produção de grăos tem se mostrado o mais senslvel aos efeitos da endogamia (JONES, 1918, 1939; HALLAUER \& SEARS, 1973; GOOD \& HALLAUER, 1977, MARQUES, 1988). Jones (1939), citado por HALLAUER \& MIRANDA FILHO (1981), relatou decrescimos na produçăo da ordem de $79 \%$ apos 30 geraç̧es de autofecundaçă, com valores crescentes de depressão por endogamia ate a $20^{a}$ geração. As medias de altura de planta, no entanto, foram reduzidas em 29\%, estabilizando-se por volta da 5 a geraçao de autofecundação. Tendências semel hantes foram encontradas por HALLAUER \& SEARS (1973) e GOOD \& HALLAUER (1977), sUbmetendo a população BSSS a sucessivas geraçäres de autofecundação. Tais resultados sao atribuldos aos maiores niveis de dominancia genica, aliados a alta complexidade do carater produça de grãos.

A relação entre depressão por endogamia e heterozigose, como colocado por MOLL \& STUBER (1974) foi corroborada por MEGHII et alii (1984) avaliando hibridos oriundos de tres eras de meltoramento (1930, 1950 e 1970), en conjunto com suas 1 intiagens parentais e suas respectivas geraçBes $F_{2}$. Ao lado de acrescimos da ordem de $2.000 \mathrm{~kg} / \mathrm{ha}$ na heterose $\left(F_{1}-\bar{P}\right)$, a depressao por endogamia $\left(\bar{F}_{1}-\bar{F}_{2}\right)$ foi elevada em $1250 \mathrm{~kg} / \mathrm{ha}$, com o transcorrer das decadas de mel horamento. Resultados semelhantes foram obtidos por 
LAMKEY \& SMITH (1987), avaliando a depressao por endogamia em sinteticos representativos de sete eras de melhoramento (antes de 1930 e as 6 decadas subsequentes). A melhoria na performance das populaçoes So, de seus "bulks" de S1, bem como os aumentos na diferenga $\left(S_{0}-S_{2}\right)$ com 0 decorrer das decadas foram atribuidos a dois fatores: a) maior número de locos das populaçbes segregantes; b) baixos valores de frequencia de alelos favoráveis $(\bar{p}<0,5)$ nas populaçoes originais, sendo aumentadas nas populaçes mais modernas.

Cabem aqui algumas colocaçBes do ponto de vista teórico. Os progressos obtidos nas performances populacionais não necessariamente conduzem a uma redução na depressão por endogamia da população (SOUZA Jr., 1985; FERNANDES, 1990). o progresso obtido nas lintiggens f função da covariancia $\sigma_{A_{F} A_{0}}$ (SOUZA Jr, 1985) e não diretamente da variancia aditiva. Este autor, utilizando.o modelo de um $10 c o$ com dois alelos e considerando dominancia completa, determinou acrescimos na depressão quando a frequencia do alelo favoravel (P) foi inferior a do alelo desfavoravel (q); em situaça oposta, obteve-se decrescimo na depressao por endogamia.

Um aspecto positivo a utilizacao do metodo de selecão com progenies endogámicas e a possibilidade de se selecionar contra alelos letais e deleterios presentes na populaçăo, reduzindo sua carga genetica e possibilitando, assim, a extração de linhagens mais vigorosas (HALLAUER, 
1980, HALLAUER \& MIRANDA FILHO, 1981). As pOpU1 açBEs de milho disponfveis no Brasil apresentaram, de um modo geral, acentuada carga genetica, refletindo em altos valores de depressa por endogamia (Tabela 1 ).

Ao lado da importancia do melhoramento das populaçßes "per se" via seleça o recorrente (MIRANDA FILHO, 1985; PATERNIAI, 1985), s salientado POF HALLAUER (1990) a necessidade de um direcionamento destas metodologias visando uma maior integração em programas de desenvolvimento de linhagens e hibridos. Apesar de ser enquadrado dentro dos métodos intrapopulacionais, a seleção recorrente com progenies endogamicas apresenta-se como uma boa alternativa para o melhoramento das populaçaes brasileiras, pois além de enfatizar a extracão de lintigens mais vigorosas, compativel com programas para obtenção de lintagens, utilizadas em hIbridos (HALLAUER, 1980; MIRANDA FILHO, 1981; HALLAUER, 19901.

Um programa integrado, desta natureza, foi SUgeridO pOR MIRANDA FILHO (1981), avaliando progénies $S_{2} e$, posteriormente, os "testcrosses" das progenies selecionadas. Utilizando-se duas geraçoes por ano, cada cielo de seleçá e completado em dois anos, alternando-se assim, as avaliaçás para performance "per se" e capacidade de combinação, ano a ano. Oesquema detalhado e apresentado por MIRANDA FILHO (1981) E MARQUES (1988). 
Tabela 1. Estimativas percentuais da depressão por endogamia e intervalo de variaça do desvio $100 \cdot\left(\bar{s}_{1}-\bar{s}_{0}\right) / s_{0}$ em várias populaçธes, para produção de grãos.

\begin{tabular}{|c|c|c|c|}
\hline Popul açes & Media & $\begin{array}{l}\text { Intervalo } \\
\text { de variaça }(\%)\end{array}$ & Referencia \\
\hline Varias popul açOes & $-45,8$ & - & (1) \\
\hline Varias popul açoes & $-40,5$ & - & (2) \\
\hline CMS OS C & $-42,5$ & $-18,6$ a $-66,0$ & (3) \\
\hline CMS $05 \mathrm{C}_{1}$ & $-38,9$ & $-17,9 \geq-58,4$ & (3) \\
\hline Centralmex & $-36,7$ & $-11,6$ a $-67,4$ & (4) \\
\hline ESALQ PB-2 $\mathrm{C}_{2}$ & $-43,7$ & $-15,2$ a $-76,3$ & (5) \\
\hline$E S A L Q P B-3 C_{2}$ & $-49,4$ & $-22,5$ a $-76,1$ & (5) \\
\hline SUWAN - DMR & $-42,4$ & - & (6) \\
\hline Composto Thai & $-42,3$ & - & (6) \\
\hline EE 1 & $-46,2$ & $+30,2$ a $-91,4$ al & (7) \\
\hline EC4 & $-46,2$ & $-9,4$ a $-81,7$ 의 & (7) \\
\hline
\end{tabular}

(1) VIANA et alii (1982); (2) LIMA et alii (1984); (3) MORO (1982); (4) MOTA (1974); (5) MARQUES (1988); (6) LIMA Et alii (1982); (7) NASS (1992).

á Comunicação pessoal. 


\subsubsection{Resultados comparativos a outros processos} seletivos

Qs metodos de seleção recorrente com progenies endogamicas têm, de um modo geral, se mostrado eficientes no meltoramento do carater produção de grăos. Comparado a outros processos seletivos, entretanto, consistente superioridade do metodo e detectada apenas na reducăo da depressao por endogamia da populaça, aumentando a produtividade de seus "bulks" de $S_{1}$ e de suas progenies de autofecundação (GENTER \& ALEXANDER, 1966; BURTON et ali1, 1971; WEST et a $1 \mathrm{i} i, 1980$, entre outros), conforme a Tabela 2 . A maior redução na depressão por endogamia com a seleçă de progenies endogamicas deve-se ao fato do metodo enfatizar a contribuição dos locos homozigotos (HALLAUER et alii, 1988), aumentando a possibilidade de fixação genica.

TANNER \& SMITH (1987) determinaram que a depressão por endogamia, apus oito ciclos de selecão com progenies "testcrosses" (SRTC), foi similar a quatro ciclos de seleção com progenies $S_{1}$ (SRS,), na variedade BKS. WEST et alii (1980) e, posteriormente, ODHIAMBO \& COMPTON (1989), obtiveram diferencas significativas nas performances dos "bulks" de $S_{1}$, comparando programas de seleçao recorrente com progênies $S_{1}$ (SRS ${ }_{1}$ ) a seleção recorrente reciproca com progenies de irmãos germanos (SRRIG) nas populaşos NBS, NSS, NKS. HORNER et alii (1985) concluiram que o metodo 
SRS $_{2}$ resultou em menores depressbes por endogamia, ao lado de maiores produçBes preditas da populaçăo totalmente endogama $(F=1)$, quando comparado a seleção com "testcrosses" , em FSBA E FSBB.

Cabe salientar que o metodo com avaliaços de "testcrosses" (SRTC), ben como programas de seleção recorrente reclproca (SRR) Utilizam progenies endogamicas para fins de recombinação, possibilitando assim, a exposição de alelos deleterios recessivos, durante esta fase. Entretanto, metodologias que não envolvem autofecundaçao durante qualquer fase do ciclo de recorrencia, tenderam a manter a carga genetica presente na população. MULAMBA et alii (1983), avaliando os efeitos da seleção massal em BSK, detectaram decrescimos de produção das progenies $S_{2}$, apos 14 ciclos de seleçao. A populaça "per se", entretanto apresentou progressos da ordem de $0,5 \%$ ao ciclo (Tabela 2).

Com relação ao melhoramento da população "per se", resultados divergentes tem sido descritos na literatura comparando a eficiencia da seleção com progenies endogámicas a outros processos seletivos (Tabela 2). Considerada apenas a proporçao de variancia aditiva exploravel, a seleçao com progenies endogámicas deveria resultar em progressos significativamente superiores a selecáo com outros tipos de fams lias (HALLAUER, 1980, HALLAUER \& MIRANDA FILHO, 1981). Fatores como baixo tamanto efetivo mantido nas populaç̧es, a 
maior eficiencia na fixação genica, a possivel presença de variancia não aditiva em alguns locos (particularmente em germoplasmas elites) a magnitude e sinal do componente $D_{1}$ poderiam explicar parte dos resultados insatisfatórios obtidos com o metodo (HALLAUER, 1984; HALLAUER \& MIRANDA FILHO, 1988, HALLAUER et a Iii, 1988; SOUZA Jr., 1989).

BURTON et alii (1971) reportaram a maior eficiencia da seleção com progenies $S_{1}$ do que o uso de progenies "testcrosses", apos quatro ciclos de seleça em Bks. Resul tados opostos seriam obtidos por HORNER et alii (1973), comparando os metodos SRS 2 e SRTC, na população Flórida 767. A seleçăo com progenies $S_{2}$ acarretou uma reduçao significativa da produtividade "per se" da populaça, durante os dois primeiros ciclos de seleção. o nivel de endogamia populacional foi acrescido em $31,6 \%$, ao final de cinco ciclos de SRS, superando em $50 \%$ o valor apresentado por SRTC.

WEST et alii (1973) relataram a superioridade de dois ciclos de STS, quando comparada a SRRIG, em aumentar a produçao das populaçbes "per se". Em trabalio posterior, completados cinco ciclos de seleção, ODHIAMBO \& COMPTON (1989) nå detectaram diferengas significativas entre os dois metodos. Foram observados efeitos da deriva genetica, causados en parte, pelo baixo número de progénies recombinadas $(\mathrm{Ne}=10)$. 
Tabela 2. Resultados comparativos de diversos ciclos de seleçäo empregando se diferentes medotologias de seleção recorrente.

\begin{tabular}{|c|c|c|c|c|c|c|}
\hline \multirow{2}{*}{ Populaçäo } & \multirow{2}{*}{$\begin{array}{l}\text { Método } \\
\text { de } \\
\text { seleçāo }\end{array}$} & \multirow{2}{*}{$\begin{array}{l}N^{8} \\
\text { ClClos }\end{array}$} & \multicolumn{3}{|c|}{$\begin{array}{l}\text { Progressos obtidos } \\
\text { por ciclo }(\%)\end{array}$} & \multirow{2}{*}{ Referéncia } \\
\hline & & & $\begin{array}{l}\text { per } \\
\text { se' }\end{array}$ & $\begin{array}{r}\text { Média } \\
\mathrm{S}_{1}\end{array}$ & $\begin{array}{l}\text { Capac. } \\
\text { combin. }\end{array}$ & \\
\hline \multirow{2}{*}{ CES } & SRT & 2 & - & 9,0 & - & GENTER \& ALEXANDER (1966) \\
\hline & $\mathrm{SRS}_{1}$ & 2 & - & 15,7 & - & \\
\hline \multirow{2}{*}{ VLE } & SRT & 2 & $-0,7$ & - & 0,8 & GENTER (1973) \\
\hline & $\mathrm{SRS}_{1}$ & 2 & 1,2 & - & 0,6 & \\
\hline \multirow[b]{2}{*}{ VCBS } & SRT & 2 & 1,4 & - & 2,3 & GENTER ( 1973$)$ \\
\hline & $\mathrm{SRS}_{1}$ & 2 & 7,2 & - & 3,3 & \\
\hline \multirow{2}{*}{ BSK } & SRT & 4 & 1,6 & 3,0 & 1,4 & BURTON et alii ( 1971$)$ \\
\hline & $\mathrm{SRS}_{1}$ & 4 & 4,1 & 9,7 & 2,7 & \\
\hline \multirow{3}{*}{ BSK } & SM & 14 & - & $-0,86$ & - & MULAMBA et alii (1983) \\
\hline & SRT & 8 & - & 7,9 & - & \\
\hline & $\mathrm{SRS}_{1}$ & 8 & - & 8,7 & - & \\
\hline \multirow{2}{*}{ BSK } & SRT & 8 & 4,0 & 5,2 & - & TANNER \& SMITH $(1987)$ \\
\hline & $\mathrm{SRS}_{1}$ & 8 & 2,9 & 6,1 & - & \\
\hline \multirow{2}{*}{ NBS } & SRRIG & 2 & $-0,7$ & 1,8 & - & WEST et aIII (1980) \\
\hline & $\mathrm{SRS}_{1}$ & 2 & 6,0 & 12,2 & - & \\
\hline \multirow{2}{*}{ NSS } & SRRIG & 2 & 2,2 & $-2,8$ & - & WEST et alii (1980) \\
\hline & $\mathrm{SRS}_{1}$ & 2 & 4,4 & 11,7 & - & \\
\hline \multirow{2}{*}{ NKS } & SRRIG & 2 & 4,4 & 4,8 & - & WEST et alii (1980) \\
\hline & $\mathrm{SRS}_{1}$ & 2 & 8,3 & 12,4 & - & \\
\hline
\end{tabular}


Tabela 2. Continuação...

\begin{tabular}{|c|c|c|c|c|c|c|}
\hline \multirow{2}{*}{ Populaçäo } & \multirow{2}{*}{$\begin{array}{l}\text { Método } \\
\text { de } \\
\text { seleçāo }\end{array}$} & \multirow{2}{*}{$\begin{array}{l}N^{8} \\
\text { clelos }\end{array}$} & \multicolumn{3}{|c|}{$\begin{array}{l}\text { Programas obtidos } \\
\text { por ciclo }(\%)\end{array}$} & \multirow{2}{*}{-Referência } \\
\hline & & & $\begin{array}{l}\text { per } \\
\text { se' }\end{array}$ & $\begin{array}{l}\text { Media } \\
S_{1}\end{array}$ & $\begin{array}{l}\text { Capac. } \\
\text { combin. }\end{array}$ & \\
\hline \multirow{2}{*}{ NBS } & SRRIG & 5 & - & 0,8 & - & \multirow{2}{*}{$\begin{array}{l}\text { ODHIAMBO \& COMPTON } \\
\text { (1989) }\end{array}$} \\
\hline & $\mathrm{SRS}_{1}$ & 5 & - & 1,9 & - & \\
\hline \multirow[t]{2}{*}{ NSS } & SRRIG & 5 & - & 4,7 & - & \multirow{2}{*}{$\begin{array}{l}\text { ODHIAMBO \& COMPTON } \\
(1989)\end{array}$} \\
\hline & $\mathrm{SRS}_{1}$ & 5 & - & 6,8 & - & \\
\hline \multirow{2}{*}{ NKS } & SRRIG & 5 & - & 2,8 & - & \multirow{2}{*}{$\begin{array}{l}\text { ODHIAMBO \& COMPTON } \\
\text { (1989) }\end{array}$} \\
\hline & $\mathrm{SRS}_{1}$ & 5 & & 7,4 & - & \\
\hline \multirow{2}{*}{ BSSS } & SRRMI & 10 & 3,8 & 4,6 & - & \multirow{2}{*}{ HELMS (1986) } \\
\hline & $\begin{array}{l}\mathrm{SR}_{\mathrm{T}}+\mathrm{S}_{1} \\
+\mathrm{S}_{2} \mathrm{I}\end{array}$ & 11 & 3,5 & 5,8 & - & \\
\hline \multirow{2}{*}{$\mathrm{BS} 13^{\mathrm{a}}$ - } & SRT & 7 & 5,3 & 4,9 & - & \multirow[t]{2}{*}{ HELMS (1986) } \\
\hline & $S R\left(s_{1}-s_{2}\right)$ & ) 4 & $<0,1$ & 4,4 & - & \\
\hline \multirow{2}{*}{$\mathrm{Fla} .767$} & SRT & 5 & - & - & $3,4^{c /}$ & \multirow[t]{2}{*}{ HORNER (1973) } \\
\hline & $\mathrm{SRS}_{2}$ & 5 & - & - & 2,4 & \\
\hline$F S B A=$ & SRTS $_{2}$ & $0-3$ & - & - & 4,6 & \multirow[t]{2}{*}{ HORNER $(1985)$} \\
\hline FSBB & $\mathrm{SRS}_{2}$ & $0-3$ & - & - & 4,0 & \\
\hline FSBA $D /$ & $\mathrm{SRTS}_{2}$ & $3-4$ & - & - & $4,7=$ & \multirow[t]{2}{*}{ HORNER et alii (1989) } \\
\hline FSBB & $\mathrm{SRS}_{2}$ & $3-4$ & - & - & 3,0 & \\
\hline 3LComp & $S R\left(M I+S_{1}\right)$ & 4 & 4,0 & 9,8 & 0,8 & COORS (19B8) \\
\hline
\end{tabular}

a/ Os quatro ciclos de seleção com progénies endogâmicas sucederam aos 7 cị clos de seleçấo baseados em testcrosses.

b/ Estimativas médias para as duas populações.

Cl Média das testcrosses com diferentes testadores.

* Seleção recorrente com progênies $S_{1}\left(S R S_{1}\right)$, seleção recorrente recíproca de meios irmãos (SRRMI); seleção recorrente com testcrosses (SRT). 
TANNER \& SMITH (1987) relataram tendencia semel hante quanto a performance da populaça bSK "per se". Após quatro ciclos de seleção maiores produtividades foram obtidas com SRS, sendo que, ao final de oito ciclos, o metodo SRTC mostrou-se mais eficiente em aumentar a media do carater. Foram estimados os decrescimos na produtividade devido ao reduzido tamantio populacional, sendo da ordem de 2,24 t/ha e 1,15 t/ha nas populaços conduzidas por sf is is eS, e SRTC, respectivamente, apos oito ciclos de selecáo. As maiores reducbes acarretadas pelo metodo SR (s, e s s foram atribuldas a maior eficiencia do metodo en eliminar alelos letais e deleterios recessivos, e a recombinaçáo de progenies $S_{2}$ no setimo e oitavo ciclo de seleçăo.

A possibilidade de mel horamento na capacidade de combinação da população, atraves de esquemas de seleção com progenies endogamicas tem sido relatada na literatura, baseada nas evidencias da maior importancia de efeitos geneticos, controlando caracteres quantitativos.

GENTER \& ALEXANDER (1962) discutiram o potencial da avaliaçao de progenies $S_{1}$ na identificaçá de genótipos mais produtivos, quando em combinaços híbridas. Posteriormente, GENTER \& ALEXANDER(1966) sugeriram que a seleçá visual para caracteres agronómicos associada a ava1 iaçós para produtividade em progenies $S_{1}$, poderiam se mostrar mais eficientes do que a utilização de "testcrosses", em geraçzes precoces de autofecundaçao.As con- 
clusరes dos autores basearam-se em avaliaçชes "per se" das progenes $5_{1}$. Resultados posteriores, entretanto, nao tem mostrado consistente superioridade da seleça com progenies endogamicas em aumentar a capacidade de combinação das popu1 açBes.

BURTON et a1 i (1971) E GENTER (1973) constataram que a SRS foi significativamente mais eficiente que SRTC em aumentar a capacidade de combinaçåo das populaçoes BSK e VCBS com quatro e dois ciclos, respectivamente. Entretanto, HORNER et ali1 (1973) avaliando a populaçăo Flórida 767 , relataram a menor eficiencia da SRS, comparada a SRTC, empregando tanto testadores de base genetica ampla, como restrita. Os autores acreditam que o metodo SRS não foi eficiente em fixar alelos dominantes favoraveis, na população. Mais recentemente, TANNER \& SMITH (1987) nåo detectaram diferengas significativas entre oito ciclos de SR ( $S_{1}$ e $S_{2}$ ) e SRTC, no mel horamento da capacidade combinatoria da populaçăo BSK. Foram utilizados, neste estudo, os mesmos testadores empregados no programa SRTC.

Resultados interessantes foram reportados por COORS (1989) avaliando a performance do sintetico $3 L$ Comp, após quatro ciclos de seleção combinada envolvendo progénies de meios-irmãos e progénies s, avaliadas e selecionadas simultaneamente. A ausencia de mel horamento na capacidade de combinação da populaçao foi relacionada a estimativa grande e negativa do componente $0_{1},-309(\mathrm{~g} / \mathrm{pl})^{2}$, 
de valor absoluto superior a variancia aditiva, 293 $(g / p l)^{2}$, para produção de graos. Sob estas condiçoes, o autor conclui que o melhoramento simultaneo das lintragens "per se" e de sua combinação en "tescrosses" pode se tornar diffeil.

As conclusBes de COORS (1988) poden elucidar algumas respostas negativas obtidas no melhoramento da capacidade de combinação, quando praticada a seleçáo com progenies endogámicas. Sabe-se que a relação de parentesco entre progenies $S_{1}$ e seus "testerosses" não é apenas fungão da variancia dos efeitos aditivos $\left(\sigma_{A}^{2}\right.$, mas tambem da covariancia entre os efeitos aditivos e dominantes dos homozigotos (D) . AO nivel intrapopulacional, COCKERHAM \& WEIR (1984) determinaram que a covarisncia genetica entre progenies $S_{1}$ e progenies de meios-irmăos intrapopulacionais $(F=0)$ e a seguinte: $\operatorname{Cov}(S, M I)=\frac{1}{2} \sigma_{A}^{2}+\frac{1}{4} D_{1}$.

Outras hipoteses, entretanto, tem sido formuladas a fim de explicar a menor eficiencia da selecão com progênies endogámicas em mel horar a capacidade de combinação e a performance en cruzamentos hi bridos. HORNER et alii (1989) argumentam sobre a importáncia da ação gênica recl proca de combinação das populaçoes FSBA e FSBB. Segundo HALLAUER et alii (1988) a possibilidade de sobredominancia en alguns locos, principalmente em fontes de germoplasma elite, não pode ser descartada. 
ação genica aditiva e năo aditiva lincluindo sobredomináncia e efeitos de ligaçă deven estar envolvidos na superior resposta apresentada pela SRRIG, comparada a SRG, em aumentar a performance do hibrido interpopulacional, bem como da heterose manifestada no cruzamento das populaçaes selecionadas. Estes resultados poderiam ser esperados, uma vez que os metodos de seleça recorrente reciproca enfatizam a performance do híbrido interpopulacional, capitalizando tanto a capacidade geral como a especl fica de combinacăo, conforme proposto por COMSTOCK et alii (1949).

\section{3. Seleção de Híbridos}

Desde que o sistema endogamia-hibridação proposto por SHULL (1908, 1909 ) mostrou-se viavel de ser aplicado comercialmente (JONES, 1918), vários aspectos conceituais e metodologias tem, ao longo do tempo, contribui do para aumentar a eficiencia da seleça entre hioridos. As primeiras contribuiçes relevantes referem-se ao uso de testcrosses para avaliaça da capacidade de combinaçá (DAVIS, 1927 ), a possibilidade de prediça de medias de hi bridos duplos (JENKINS, 1934) e a introduçao do teste precoce para capacidade de combinação (JENKINS, 1935; SPRAGUE, 1946; LONNQUIST, 1950).

As definiçóes dos efeitos da capacidade geral e especlfica de combinação, associados a esquemas 
diale1icos (SPRAGUE \& TATUM, 1942) constitulram-se a base para o desenvolvimento de novas metodologias especificas para avaliação da performance de conjuntos de lintiagens e populaçoes de polinização livre (GRIFFINGS, 1956, FYFE \& GILBERT, 1963; GARDNER \& EBERHART, 1966, MIRANDA FILHO \& GERALDI, 1980, 1984, GERALDI \& MIRANDA FILHO, 1988). NEStE contexto, o esquema de eruzamento dialelico parcial EIRCUIantE (KEMATHORNE \& CURNOW, 1961 ) adaPtadO POT MIRANDA FILHO para o nivel interpopulacional (informação pessoal) tem se mostrado eficiente para a avaliaçã da capacidade de combinação em linhagens provenientes de duas populaçoes (GONÇALVES, 1987 ; DANTE, 1988; DANTAS, 1992).

Do ponto de vista conceitual, os trabal hos de COMSTOCK (1961) e COMSTOCK (1964) forneceram as bases teoricas que proporcionaram o mejhor entendimento do sistema endogamia-hibridação.

COCKERHAM (1961), relacionando a variabilidade genética expressa entre hibridos e o progresso esperado com a seleçăo, demonstrou o maior potencial da seleção sobre híbridos simples, comparada a hibridos triplos e duplos, para a mesma popul ação de referéncia e iqual ni vel de endogamia dos parentais. A vantagem da selecão de hi bridos simples é amplificada com o aumento do grau de dominancia e na presença de variação epistatica. Segundo o autor, o maior nLvel de endogamia das lintragens parentais e refletido em acrescimos na variabilidade genetica entre hi bridos. 
Baseado na superioridade de til bridos simples sobre hibridos triplos e duplos (COCKERHAM, 1960), bem como na eficiencia do teste precoce para capacidade de combinacao SPRAGUE (1946); LONNQUIST (1950), HALLAUER (1967) e LONNQUIST \& WILLIAMS (1967) propuseram uma metodologia para isolamento e teste de hloridos simples, onde sá avaliadas progenies de irmás germanos (hi bridos duplos "cripticos") a cada geração de autofecundaçao das linhagens. Esta tecnica mostrou-se efetiva no desenvolvimento de hl bridos simples de a ta produtividade (HALLAUER, 1973) e na geração de linhagens com alta capacidade geral e especifica de combinação (HOEGEMEYER \& HALLAUER, 1976). NO Brasil, estudOs sobre a eficiencia do metodo de híbridos cripticos tem sido relatadOS IMAGNAVACA, 1977, ZINSLY et a11i, 1977; MIRANDA FILHO, 1979, GERARDI et a 11 i, 1986).

Alén do método de hibridos cripticos, outras metodologias tém sido propostas a fim de selecionar linhagens com maior capacidade de combinação durante o processo de autofecundação, tais como: avaliação de progenies cruzadas com uma linhagem especi fica e a seleção de testcrosses reciprocos interpopulacionais, enfatizando a selesão sobre efeitos aditivos (SOUZA Jr. \& MIRANDA FILHO, 1981).

Um aspecto interessante nas metodologias propostas por HALLAUER (1967), LONNQUIST \& WILLIAMS (1967), HALLAUER (1970) E SOUZA Jr. \& MIRANDA FILHO (1981) reside na possibilidade de prediça do comportamento de hibridos de 
lintiagens derivadas das populaçbes em estudo, baseado nas formulaçBEs de COCKERHAM $(1961)$.

Entretanto, estudos desta natureza, envolvendo prediçoes da performance de hibridos com base em seus componentes de variação genetica são raros, na literatura. Tais avaliaçós podem ser úteis na determinação de populaçós base para programas de desenvolvimento de hloridos, como complemento a performance media no ho brido intervarietal. Resultados da 1 iteratura demonstraram que o comportamento medio de um cruzamento intervarietal não pode ser correlacionado a variabilidade genetica presente dentro deste eruzamento. MIRANDA FILHO et alii (1984) obtiveram para a interpopul ação "ESALQ PB-1 × BR-105", produção media de 130 (g/pl) e variancia entre progénies de irmăos-germanos da ordem de $86,4(g / p 1)^{2}$. Em trabaltho anterior, MIRANDA FILHO (1979) obteve media de 125,8 (g/pl) e variancia entre progenies de irmás germanos igual a 248,1 (g/pl $)^{2}$ no hu brido "Piranão UD-2 x Piranão VF-1". Já, para o cruzamento entre "ESALQ PB-2" x "ESALQ PB-3", tais valores foram de $108,6(\mathrm{~g} / \mathrm{P} 1)$ e $167,5(\mathrm{~g} / \mathrm{pl})^{2}$, respectivamente (GERALDI et a 111,1986$).$

Cabe salientar que a variabilidade genetica expressa entre progenies de irmás germanos ou hubridos cripticos $\left(S_{0} \times S_{0}\right)$ e equivalente a variaçá manifestada entre habridos duplos de lintiagens totalmente endogámicas, para a mesma populaçao (VENCovsky et alis, 198B). A pre- 
dição da performance de outros tipos de hibridos, avaliandose apenas um tipo de progenie, exige, contudo, a formulação de hipoteses para a relação $\sigma_{D}^{2} / \sigma_{A}^{2}$.

SOUZA Jr. et alii (1980), utilizando deste artificio, determinaram os progressos esperados com a sele૬ão de hibridos simples, triplos e duplos, derivados de intiagens totalmente endogamicas, para o cruzamento entre "ESALQ VF-1" e "ESALQ VD-2". As variancias geneticas entre híbridos foram determinadas fazendo-se analogia aos componentes intrapopulacionais, como apresentados por COCKERHAM (1961).

Em estudo posterior, SOUZA Jr. (1987) decompos a variáncia genetica entre hloridos, ao nivel interpopulacional, discutindo suas consequencias sobre os progressos esperados com a selecáo. Um dos pontos interessantes enfatizado por SouzA Jr. e a viabilidade de utilização de hitoridos simples e triplos modificados, em substituiçã aos respectivos hibridos de linhagens totalmente endogámicas. A possibilidade de seleça de hibridos simples de linhagens parcialmente endogamicas ( $S_{2}$ pu $S_{3}$ ) e sugerida como opfão a utilização de hloridos duplos e triplos de linhagens totalmente endogamicas.

A utilizaçăo de hloridos de linhagens parcialmente endogamicas foi inicialmente proposta por WELLHAUSEN (1954) E LOEFFEL (1964; 1971) avaliando hIbridos entre progenies $S_{1}$ com o intuito de amenizar os efeitos 
depressivos da endogamia sobre lintias macho e femea. Entretanto, a utilizaçao de progenies $S_{2}$, ao inves de $S_{1}$, tem se mostrado como mel hor opção, haja visto os majores progressos esperados com a seleçao de hibridos $S_{2} \times S_{2}$, a maior uniformidade genetica destes híbidos (STANGLAND \& RUSSELL, 1981) e a possibilidade de manutença das caracteristicas das lintiagens "per se" e de sua capacidade de combinação, atraves de sucessivas geraçaes de cruzamentos paternais ("Sib-crossEs") (CARLONE \& RUSSELL, 1988, 1989).

Segundo RUSSELL $(1974), 79,1 \%$ do avanço de produtividade durante o periodo de 1930 a 1970 foi devido a fatores de natureza genética, correspondendo a um acréscimo de $3020 \mathrm{~kg} / \mathrm{ha}$. En trabaltho anterior, Frey (1971) citado por RUSSELL (1974) calculou progressos da ordem de $49 \%$ na comparação entre híbridos cultivados no persodo de 1926 a 1968. Mais recentemente, MEGHJI et alii (1984) apresentaram comparaçoes entre híbridos duplos representativos das décadas de 1930 (Era 1), 1950 (Era 2) e hibridos simples cultivados na decada de 1970 (Era 3), obtendo progressos significativos com a substituicao de hibridos duplos por hloridos simples, conforme esperado (COCKERHAM, 1961). DEtectou-se, contudo, ausencia de melhoramento na produtividade entre as Eras 1 e 2, correspondente ao perído designado como "plat8", pela literatura ISPRAGUE \& EBERHART, 1977; HALLAUER et a 11 i, 1988). 
A tendencia do estabelecimento de "platos", em programas de híbridos, pode ser esperada, caso a extraçăo de linhagens não esteja associada a um processo dinamico de melhoramento populacional. Teoricamente a probabilidade de obtença de genotipos superiores permanece constante, sob sucessivas amostragens em uma mesma população (COMSTOCK, 1964). A conduçăo de processos de seleçăo recorrente apresenta-se, assim, como boa opção para a integraçăo com programas de desenvolvimento de hl bridos, aumentando a cada ciclo a probabilidade de obtenção de genótipos superiores.

\section{4. Variaçao genetica}

A estimaçåo dos componentes de variaçăo genetica e sua utilizaçăo em programas de mel horamento tem sido abundantemente enfocada na literatura, dada a sua efetiva contribuiça tanto nas fases de planejamento inicial, como de execução em $5 i$ do programa.

Em miltio, os resultados tem demonstrado suficiente variabilidade para caracteres de planta e de espiga (HALLAUER \& MIRANDA FILHO, 1988). Amplas reVisBes, apresentando estimativas de variancia genetica aditiva em populaçBes brasileiras podem ser encontradas em RAMALHO (1977), SAMPAIO (1986), MARQUES (1988), NASS (1992), entre outros. 
Em estudo apresentado por VENCOUSKY et alii (1988) envolvendo cinquenta e oito ensaios de progenies de meios irmãos, derivados de varias populaç̧es brasileiras, obtiveram-se valores de variancia aditiva oscilando de 41 $(g / p 1)^{2}$ a $753(g / p 1)^{2}$, com media igual a $309(g / p l)^{2}$, para - carater produça de grãos. HALLAUER \& MIRANDA Fo (1988), relatam estimativas medias de variancia aditiva iguais a $468(g / p 1)^{2}$, para produção de grăos, $213 \mathrm{~cm}^{2}$ para altura de planta e $153 \mathrm{~cm}^{2}$ para altura de espiga, correspondendo a $62 \%$, $84 \%$ e $93 \%$ da variaçáo genetica total. Estes valores demonstram a predominancia de efeitos aditivos sobre dominantes na expressá destes caracteres.

Para estimaçã dos componentes de variancia genetica tem sido utilizados os delineamentos $I$ e II propostos por COMSTOCK \& ROBINSON (1948, 1952) bem como outros esquemas especificos de cruzamentos. controlados. No Brasil, o processo de estimaçao do componente aditivo tem sido, na maioria dos casos, atraves da avaliaçao de progenies de meios-irmãos (RAMALHO, 1977). Esquemas envolvendo progenies endogamicas tambem tem sido reportadas para estimação da variancia aditiva (MARQUES, 1988; MEIRELLES \& MIRANDA FILHO, 1986), as5umindo-5e, porém, um valor hipotetico para a variancia dominante $\left(\sigma_{\text {b }}^{2}\right)$ e igualdade de frequencias genicas na popul ação estudada $(p=q=0,5)$. Nesta condiça, conforme discutido no item 2.1, os componentes $\mathrm{D}_{1}$ e $\mathrm{D}_{2}$ igualam-se a zero, e a variação 
genetica total entre progenies endogamicas passa a ser funçăo apenas de seus componentes aditivo e dominante (COCKERHAM, 1983). A importancia do conhecimento das estimativas $D_{1} e D_{2}$ é tanto maior quanto o grau de dominancia do carater, uma vez que na ausencia de dominancia seus valores são nulos.

Em programas de melhoramento, a estimação dos componentes de variação genetica, alem de permitir a quantificação da eficiencia da seleçăo, atraves da estimação do progresso esperado (Gs) e por $5 i$ so um indicativo da viabilidade ou nå da conduçåo de futuros ciclos, em programas de seleção recorrente.

Estudos teoricos demonstram que a pratica da Seleçă nåo necessariamente conduz a uma redução da variancia aditiva, sendo esta funçzo da estrutura genetica da população, da natureza do caráter e do. tamantio efetivo mantido nos ciclos de seleça. Segungo FALCONER (1960), para o caso de um loco com dois alelos e dominancia completa (d=a) a variancia genetica aumenta gradativamente com o incremento na freqúencia do alelo favoravel (p) ate o limite próximo a 0,25 , reduzindo-se a partir deste valor.

A nivel experimental, os resultados tem revelado uma acentuada reduça na variabilidade genética decorrido o primeiro ciclo de seleçã, mantendo-se mais ou menos constantes nos demais ciclos (PATERNIANI, 1967; HALLAUER \& MIRANDA FILHO, 1988). Isto se deve ao fato de 
que, no primeirociclo, utilizada a variabilidade genetica livre presente na população, sendo posteriormente liberada de forma gradativa a variabilidade genetica potencial, atraves da permuta genética dentro de blocos poligênicos (PATERNIANI, 1967 ; WEBEL \& LONNQUIST, 1967; PATERNIANI, 1968). Justificam-se desta forma os ganhos continuos relatados na literatura, mesmo em programas de longa duração IPATERNIANI \& MIRANDA FILHO, 1987, HALLAUER ET a1 ii, 1988 ).

Com relação aos componentes interpopulacionais tornou-se necessária a sua estimaşăo apos a introdução da seleça recorrente reclproca (COMSTOCK et ali1, 1949), com trabal hos iniciais de STUBER et alii (1966), GOODRICH et alis (1975) e OBILANA et alii, (1979), utilizando os delineamentos I e I I (COMSTOCK \& ROBINSON, 1948,1952 ).

Com a proposição de novas metodologias de seleção recorrente reci proca, avaliando progénies de meiosirmãos (PATERNIANI \& VENCOUSKY, 1978), amp1iou-se o número de estimativas dos componentes aditivos $\int_{A_{12}}^{2}$ e $\sigma_{A_{21}}^{2}$, abrangendo um maior numero de populaçoes (PATERNIANI \& VENCOVSKY, 1978; MIRANDA FILHO \& PATERNIANI, 1983; SOUZA JH. \& MIRANDA FILHO, 1986 ; PELLICANO, 19901.

No Brasil, os delineamentos a e b sugeridos por MIRANDA FILHO (1982) permitiram a estimaçã dos componentes $\sigma_{A_{1} A_{2}} \sigma_{A_{2} A_{1}} e \phi$, responsáveis, respectivamente, pelo ganto indireto nas populaçbes "per se" e na heterose do hi - 
brido intervarietal, quando praticados os esquemas de sele5ăo reciproca propostos por PATERNIANI \& VENCOUSKY (1977, 1978).

Un resumo das estimativas $\alpha_{A_{(12}}^{2}$ em populaçBes brasileiras, apresentado por PELLICANO (1990) e NASS (1992) demonstrou valores variando de $86,39(\mathrm{~g} / \mathrm{pl})^{2}$ en ESALQ PB-1 1 BR 105, assumida a hipotese $H_{1}=\sigma_{D_{\text {, }}^{2}}^{2}=\sigma_{A_{(12}}^{2}$ (MIRANDA FILHO et a 111,1986$)$ a $497,12(9 / \mathrm{pl}\}$, em PIRANAO VF-1 $\times$ PIRANAO UD-2, supondo-se $\alpha_{\text {D, }}^{2}$, $=0$ (MIRANDA FILHO, 1979 ). Quanto ao componente dominante $\left(\sigma_{\left.D_{12}^{2}\right)}^{2}\right)$, poucos resultados tem sido apresentados na literatura. OBILANA et alii (1979), utilizando o delineamento II, estimaram 17 $(g / p l)^{2}$ para a interpopulaçă BS10 x BS11, correspondendo a apenas $14 \%$ da estimativa de variancia aditiva nas mesmas populaçชes. Posteriormente, MARTINS (1986), avaliando um esquema dialelico parcial de um conjunto $f i \times o$ de lintiagens dE PIRANAO VF-2B E PIRANAO UF-1B obteVE o Valor de 45,35 $(g / p 1)^{2}$ para o o $o_{(12}^{2}$, equivalendo a $19 \%$ da estimativa de $\sigma_{A(12)}^{2}$ Estes resultados são bastante inferiores aos valores da relação $\sigma_{D}^{2} / \alpha_{A}^{2}$ descritos a nivel intrapopulacional (HALLAUER \& MIRANDA FILHO, 1988 ).

Varios autores tem estimado a variação genetica total entre progenies de meios-irmás interpopulacionais, uma vez que ela representa a variabilidade esperada entre híbridos duplos derivados destas populaçoes (AJUDARTE NETO, 1978; MIRANDA FILHO, 1979; MIRANDA FILHO et 
alii, 1986; GERALDI et alii, 1986). Demonstrada inicialmente por COCKERHAM (1961), a variabilidade genetica entre hibridos para um conjunto de lintiagens totalmente endogamicas foi assim expressa, a nivel intrapopulacional:

$$
\begin{aligned}
& \sigma_{\mathrm{HS}}^{2}=\sigma_{A}^{2}+\sigma_{D}^{2} \\
& \sigma_{\mathrm{HT}}^{2}=\frac{3}{4} \sigma_{A}^{2}+\frac{1}{2} \sigma_{D}^{2} \\
& \sigma_{\text {HD }}^{2}=\frac{1}{2} \sigma_{A}^{2}+\frac{1}{4} \sigma_{D}^{2}
\end{aligned}
$$

Em trabal ho mais recente, SouZA Jr. (1988) estendeu esta definição ao nivel interpopulacional, decompondo a variaçao genética entre híbridos oriundos de Inhagens com diferentes niveis de endogamia e entre hitridos de progenies. Para o caso de híbridos de linhagens, a principal madificaça ocorreu com hibridos triplos, uma vez que a variabilidade genetica dependera do sentido do cruzamento. Para o caso de diferentes valores de $\sigma_{A}^{2} e_{12} \alpha_{A}^{2}$, sugere-se que o parental macho do hi brido (1 inhagem) derive da população a qual esteja associada a maior das duas estimativas. Segundo SoUZA Jr. (1988) a variabilidade genetica entre hibridos foi assim decomposta: 


$$
\begin{aligned}
& \sigma_{H S_{(12)}}^{2}=\frac{(1+F)}{4}\left(\sigma_{A_{12}}^{2}+\sigma_{A_{21}}^{2}\right)+\frac{(1+F)^{2}}{4} \sigma_{D_{(12)}^{2}} \\
& \sigma_{H_{12}}^{2}=\frac{(1+F)}{8} \sigma_{4,2}^{2}+\frac{(1+F)}{4} \sigma_{21}^{2}+\frac{(1+F)^{2}}{8} \sigma_{D_{\text {(12) }}^{2}} \\
& \sigma_{\text {HT }}^{2}=\frac{(1+F)}{4} \sigma_{A_{12}}^{2}+\frac{(1+F)}{8} \sigma_{A_{21}^{2}}^{2}+\frac{(1+F)^{2}}{8} \sigma_{D_{(12)}} \\
& \sigma_{\text {HD }}^{2}=\frac{(1+F)}{8}\left(\sigma_{A_{12}}^{2}+\sigma_{A_{21}}^{2}\right)+\frac{(1+F)^{2}}{16} \sigma_{D_{(12)}}
\end{aligned}
$$

Associado a media do cruzamento intervarietal, o conhecimento da variabilidade genética entre hioridos, estima diretamente a performance esperada dos mel hores hibridos da interpopulação. Tal informaçao e de especial valor em programas de seleçăo recorrente reciproca, uma vez que o progresso obtido no híbrido intervarietal não representa necessariamente o mesmo gantio sobre os melhores hi eridos derivados da interpopulação. Uma drástica redução na variabilidade poderia, desta forma, representar uma queda no limite de produção dos hibridos superiores, mesmo se considerando os gantios no cruzamento intervarietal obtidos pela seleção recorrente reciproca. 


\section{MATERIAL E MÉTODOS}

3.1. Caracterização das popul açßos

No presente trabaliho utilizaram-se duas populaçBes de milho de ampla base genetica, ESALQ PB-2 e ESALQ PB-3 denominados originalmente de Composto Dentado Planta Baixa e Composto Flint Planta Baixa, respectivamente. Tais populaçós resultaram dos cruzamentos do Composto Dentado e do Composto flint com sete variedades de porte de planta reduzidO (MIRANDA FILHO, 1974 ).

o mel hor amento das duas populaçoes foi conduzido de forma independente. Realizou-se, inicialmente, 1 ciclo de seleção massal estratificada, seguindo-se de 3 ciclos de seleção recorrente intrapopulacional com progenies endogámicas. As unidades de seleção e recombinação foram progenies $S_{1}$ nos dois primeiros ciclos e progenies $S_{2}$ no terceiro ciclo de selecao. Foram geradas, nos respectivos ciclos de seleção, as populaçßes: ESALQ PB-2 (CA) e ESALQ $P B-3$ (C1); ESALQ PB-2 (C2) E ESALQ PB-3 (C2); ESALQ PB-2 
(Ca) e ESALQ PB-3 (C3), estas avaliadas anteriormente por MARQUES $(1988)$.

o presente estudo, envolvendo progenies extraldas de diferentes ciclos de seleçă, foi dividido em duas partes:

1 - Avaliação de progenies $S_{1}$ das populaçós ESALQ PB-2 (C9) E ESALQ PB-3 (C3), correspondendo a quarto ciclo de seleção com progenies endogámicas.

2 - Estudos envolvendo "testerosses" reciprocos de progenies $S_{2}$, derivadas das populaçoes ESALQ $P B-2$ (C2) E ESALQ PB-3 (C2) para fins de avaliar a capacidade reciproca de combinação.

3. 2. Avaliação das progenes $S i$

\section{2.1. Material}

Utilizaram-se, nesta fase, 200 progenes $S_{1}$ extraidas de cada populaçå, ESALQ PB-2 (C3) e ESALQ PB-3 (C3), referentes ao quarto ciclo de seleça ro recorrente com progenies endogamicas. Como testemuntias foram empregados 0 híbrido comercial C511, de ciclo normal e porte intermediario, e as respectivas popul açbes não endogámicas (s $)$. 


\subsubsection{Execução experimental}

A obtençáo das progenies realizou-se no campo experimental da ESALQ, municlpio de Piracicaba (SP), no ano de 1989, geração de inverno. Foram semeadas cerca de 1000 sementes por campo de antofecundaçăo. Obtiveram-se, apos descarte de campo e laboratorio, 200 espigas $S_{1}$ por população, as quais foram avaliadas em progenies no ano $\operatorname{agr} 1001$ a $1989 / 1990$

Os experimentos foram conduzidos em dois $10-$ cais com caracteristicas edafoclimaticas contrastantes: Estação Experimental da FT - Pesquisa e Sementes, Ponta Grossa (PR), Estação Experimental da CoOPACEL, Rondonopolis (MT). o delineamento experimental adotado foi látice (10x10) parcialmente balanceado, com 3 repetiçoes. Foram instalados quatro experimentos por local: os experimentos 1.1 e 1.2 referem-se à populaçå ESALQ PB-2 (C3); os experimentos 1.3 e 1.4 a populaçá ESALQ PB-3 (Ca). As testemuntias, representadas pelas populaçós năo endógamas (S.) e pelo hibrido C511, foram plantadas alternadamente a cada dez parcelas nas repetiços.

As parcelas constitul ram-se de uma fileira de 3, Om de comṕrimento, com espaçamento entre fileiras de 1 , om. Este tamantio de parcela tem se mostrado adequado para avaliação de caracteres de media e baixa herdabilidade (CHAVES \& MIRANDA FILHO, 1992). Foram semeadas 22 sementes por 
fileira, obtendo-se após o desbaste, 15 plantas por parcela, espaçadas a 0,20 , en media. A densidade populacional correspondente 6 de 50.000 plantas/hectare.

A semeadura nos experimentos foi realizada dentro do perfodo indicado pela pesquisa local. As adubaçós de base e cobertura, foram feitas cerca de 7 dias antes da semeadura e aos 30 dias apos a emergencia, respectivamente, segundo as indicaçBes das análises de solo locais.

Foram tomados dados dos seguintes caracteres:

"stand" final, altura de planta, altura de espiga e produçăo de grăs. Para os caracteres altura de planta e espiga coletaram-se dados de cinco plantas por parcela, cerca de trinta dias após o florescimento. O carater produção de grãos foi avaliado atraves do peso total de grãos da parce1a. Os dados foram corrigidos para um "stand" ideal de quinze plantas por parcela, pelo metodo de covariancias sugerido por MIRANDA FILHO, citado por VENCOVSKY \& BARRIGA (1992). Os dados de "stand" final foram tomados por ocasiao da colneita, sendo utilizados apenas para fins de correção, nas análises de produção.

A colneita dos experimentos 1.3 e 1.4 , em Rondonópolis, mostrou-se prejudicada pela excessiva precipitação pluviometrica, havendo defasagem de cerca de duas semanas quando comparados aos experimentos 1.1 e 1.2 . Isto acarretou en um aumento no número de plantas acamadas e espigas doentes, conforme observaçoes de campo. 


\subsubsection{Análises estatisticas}

a) Analises de vartancla individuals e agrupadas por local

As analises de variancia foram realizadas segundo o procedimento de COCHRAN \& COX (1957), para delineamentos em 1atice. Analisaram-se tres caracteres: produção de grãos, altura de planta e altura de espiga. Foi adotado - seguinte modelo matematico:

$$
\gamma_{i j k}=\mu+p_{i}+q_{j}+b_{k / j}+e_{i j k}
$$

onde:

$Y_{i j k}=$ media das progénie $i$ no bloco k da repeticăo j;

$\mu=$ media geral do experimento, fixa; $E(\mu)=\mu ; E(\mu)^{2}=\mu^{2}$

$p_{i}=$ efeito aleatorio da progenie $i\left(i=1,2, \ldots k^{2}\right)$;

$E\left(P_{i}\right)=O_{i} E\left(p_{i}\right)^{2}=\sigma_{p}^{2}$

$q_{j}=$ efeito aleatório da repetiça j $(j=1,2 \ldots . r)$;

$E\left(q_{j}\right)=O_{i} \quad E\left(q_{j}\right)^{2}=\sigma_{r}^{2}$

$b_{k, j}=$ efeito aleatorio do bloco k dentro da repeticão $j$ $(k=1,2, \ldots K) ; E\left(b_{k, j}\right)=0 ; E\left(b_{k, j}\right)^{2}=\sigma_{b}^{2}$

$e_{i j k}=$ erro experimental associado a parcela ik, dentro da repetiça $j ; e_{i j k} \cap N\left(0, \alpha^{2}\right) ; E\left(e_{i j k}\right)=O ; E\left(e_{i j k}\right)^{2}=\alpha^{2}$

Para os caracteres altura de planta e altura de espiga foram tomados dados ao nlvel de plantas individuais, o que possibilitou a determinação dos QM dentro de parcelas, o qual e um estimador direto da variancia feno- 
tipica dentro de progenies $\left(o_{d}^{2}\right)$. Seu calculo foi realizado de forma independente, posteriormente introduzido na analise. Os dados de produção de grãos foram tomados ao nivel de totais de parcelas, sem observação ao nIvel de plantas individuais.

As analises de variancia para os caracteres altura de planta e altura de espiga, seguem o modelo proposto por VENCOUSKY (1987) para antises realizadas com medias de parcelas. Os esquemas foram adaptados para delineamentos em latice parcialmente balanceados (Tabela 3 ).

Tabela 3 . Esquemas de análises de variância realizados com médias de parcelas, para delineamentos em latice.

\begin{tabular}{|c|c|c|c|c|}
\hline FV & $G L$ & QM & $F$ & $E(Q M)$ \\
\hline Blocos/Repetiçoes & $r-1$ & -- & -- & - \\
\hline Progenies ajustadas & $k^{2}-1$ & Q1 & $\left(Q_{1}\right) /\left(Q_{2}\right)$ & $\alpha_{d}^{2}$ \\
\hline Erro intrablocos & $(K-1)(r k-K-1)$ & $Q_{2}$ & & $\alpha_{d}^{2}, n+$ \\
\hline Dentro & $(n-1)(r)\left(k^{2}\right)$ & Q3 & & $\alpha_{d}^{2}$ \\
\hline
\end{tabular}

Total

$$
\left(n \cdot r \cdot k^{2}\right)-1
$$


Para o carater froducão de grăos, o processo de correçăo para stand ideal acarretou a perda de 1 grau de liberdade para o reslduo. A estrutura das análises seguiu os modelos apresentados na literatura para experimentos em látice. (MIRANDA Fo, 1987), adaptando-se para o caso de latices parcialmente balanceados (Tabela 4).

Tatela 4. Esquema geral de arílise de variancia para delineamentos em latice, com as esperangas dos quadrados médios $E(Q M)$.

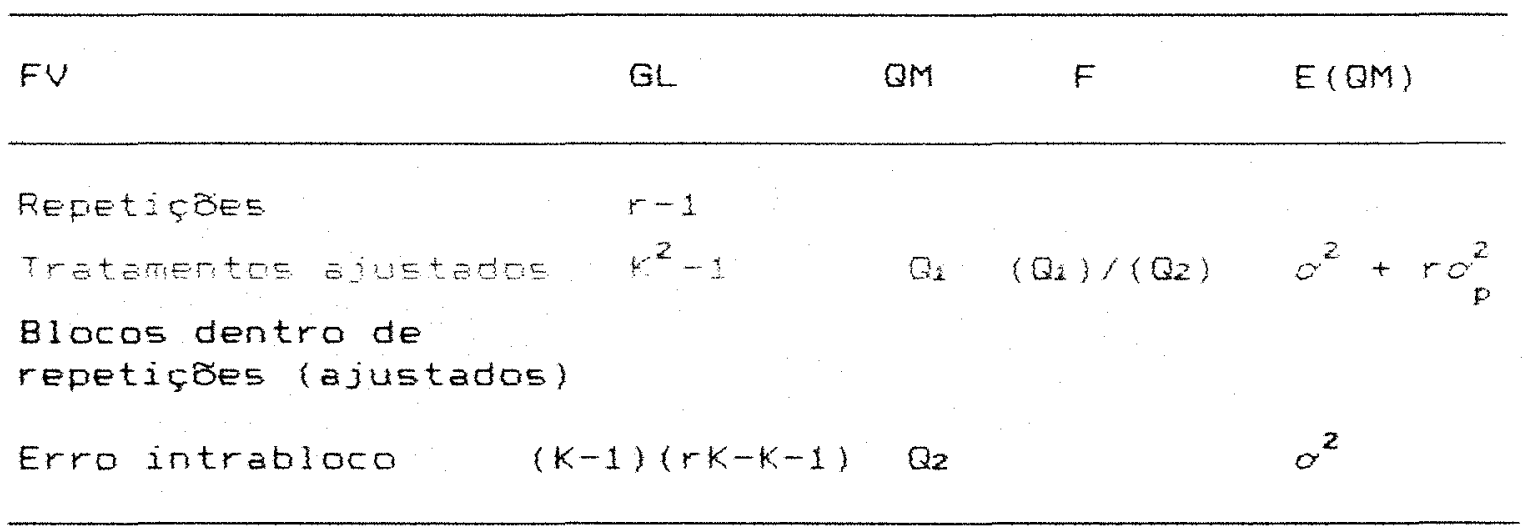

Para todos os caracteres foram determinados os coeficientes de variaça ambiental (CV), os coeficientes de variaçăo genetica $\left(C V_{Q}\right\rangle$ e os indices de variaçăo experimental $(\theta)$, onde

$$
\begin{gathered}
C V_{E}=100 \frac{\hat{\alpha}}{\bar{x}} ; \quad C V_{Q}=100 \frac{\hat{\sigma}_{p}}{\bar{x}} ; \quad \theta=\frac{C_{Q}}{C V_{e}} \\
\text { sendo: } \sigma=\left(\frac{\sigma^{2}}{n}+\sigma_{e}^{2}\right)^{1 / 2} \text { para os caracteres altura de } \\
\text { planta e altura de espiga. }
\end{gathered}
$$


As análises individuais foram agrupadas em cada local, levando-se em conta a população de origem. Foram agrupados os experimentos 1.1 e 1.2 , e 1.3 e 1.4 , relativos as populaçós ESALQ PB-2 (Cэ) e ESALQ PB-3 (C3), respectivamente. Manteve-se basicamente a estrutura das analises individuais (Tabelas 3 e 4 ). Os graus de liberdade foram duplicados e os quadrados medios correspondem a média aritmetica dos QM individuais, para as respectivas fontes de variaçăo.

\section{c) Analises conjuntas}

Foram realizadas as análises conjuntas, para cada experimento, utilizando-se as medias ajustadas das progenies, para os dois locais. Analisaram-se os caracteres altura de planta, altura de espiga e produção de grãos, para os quatro latices (10)10). Agruparam-se, posteriormente, as analises conjuntas dos experimentos 1.1 e 1.2 , referentes a populaçå ESALQ PB-2 (C3), e 1.3 e 1.4 , referentes a população ESALQ PB-3 (Ca). Adotou-se o seguinte modelo matemático misto, para as análises conjuntas:

$$
Y_{i j l}=\mu+p_{i}+r_{j(l)}+a_{l}+(p a)_{i l}+e_{i j l}
$$

onde:

$\mu:$ media geral do experimento; fixa; $E(\mu)=\mu, E(\mu)^{2}=\mu^{2}$

$p_{i}$ : efeito aleatorio da progenie $i \quad(i=1,2, \ldots, 1)$;

$$
E\left(p_{i}\right)=0 ; E\left(p_{i}\right)^{2}=\sigma_{p}^{2}
$$


$r_{j(l)}:$ efeito aleatorio da repetiçăo $j(j=1, \ldots, r)$, dentro do ambiente $1 ; E\left(r_{j / l}\right)=0 ; E\left(r_{j / l}\right)^{2}=\alpha_{r}^{2}$ $a_{1}$ : efeito fixo do ambiente $1(1=1,2) ; E\left(a_{1}\right)=a$; $E\left(a_{l}\right)^{2}=a^{2}$

(pa) ${ }_{i l}$ : efeito aleatorio da interaço entre a progenie $i$ e o ambiente $1 ; E\left((p a)_{i l}\right)=0 ; E\left((p a)_{i l}\right)^{2}=\alpha_{p a}^{2}$ $e_{i j l}$ : erro efetivo associado a medias ajustadas da progênie i, na repetiçao j, para o local 1;

$$
\begin{aligned}
& e_{i j l} \cap N\left(0, \alpha_{\theta l}^{2}\right) ; E\left(e_{i j l}\right)=0 \\
& E\left(e_{i j l}\right)^{2}=\sigma_{\theta l}^{2}
\end{aligned}
$$

Foi considerarado ambientes como efeito fixo devido as condiçes edafoclimaticas contrastantes, entre os locais de avaliação.

As analises conjuntas, para.0s 3 caracteres, seguiram a estrutura apresentada por STEEL \& TORRIE (1960), para experimentos em fatorial, adotando-se modelos mistos (Tabela 5). Como fonte residual utilizou-se a media do erro efetivo en cada local, os quadrados medios foran estimados a partir de totais de progenies ajustadas por local. 
Tabela 5. Esquema de análise de variancia para experimentos em fatorial, adotando-se modelos mistos.

FV GL GM F $\quad$ G $(\mathrm{GM})$

$$
\begin{aligned}
& \begin{array}{l}
\text { Repetiçoes } \quad(r-1) \cdot 1 \\
\text { ambiente }
\end{array} \\
& \text { Progenies(P) } n-1 \quad Q_{1} Q_{1} / Q_{4} \quad \sigma_{01}^{2}+r 1 \sigma_{P}^{2} \\
& \text { Ambientes(A) } 1-1 \quad Q_{2} \quad *_{1} \quad \sigma_{\text {or }}^{\theta^{1}}+r\left(\frac{P}{1-1}\right) \alpha_{p a}^{2}+n 1 \alpha_{r}^{2}+r n v_{0} \\
& P \times A \quad(n-1)(1-1) \quad Q_{3} Q_{3} / Q_{4} \alpha_{o f}^{2}+\left(\frac{1}{1-1}\right) \alpha_{p o}^{2} \\
& \text { Erro efetivo }(r-1)(n-1)(1) Q_{4}
\end{aligned}
$$

$*_{1}: F\left(Q_{2}\right)=\frac{Q_{2}+Q_{4}}{Q_{1}+Q_{3}}$

al os graus de libertade do numerador e denominador foram calculados segundo SATTERTHWAITE (1946).

$\left(\frac{1}{1-1}\right)$ : fator de correça para modelos mistos;

As analises conjuntas agrupadas por população mantiveram a estrutura basica das analises conjuntas individualizadas por experimento, apresentando algumas alteraçoes: os graus de liberdade foram duplicados e os quadrados medios ajustados correspondem a media dos quadrados medios individuais, para as respectivas fontes de variação. 
3.2.4. Estimativas de parámetros geneticoestatisticos

Obtiveram-se, a partir das análises individualizadas por local (Tabelas 5 e 6 ) as estimativas dos parametros $\sigma_{p}^{2}$ e $\sigma^{2}$ para os trss caracteres avaliados, em ambos locais de avaliaçao: Ponta Grossa (PR) e Rondonopolis (MT), sendo que:

$$
\begin{aligned}
& \hat{\sigma}_{p}^{2}=\frac{\left(Q_{2}-Q_{2}\right)}{r} \hat{\alpha}^{2}=Q_{2} \\
& \hat{\sigma}_{p}^{2}=\frac{\left(Q_{1}-Q_{4}\right)}{r 1} \hat{\sigma}_{G 1}^{2}=Q_{4}
\end{aligned}
$$

Partindo-se destas estimativas primarias, foram estimados os componentes da variancia genetica entre progenies. COCKERHAM \& MATZINGER (1985) definiram os componentes da variação genetica entre progenies endogamicas, para um loco com dois alelos, onde:

$$
\begin{aligned}
\sigma_{A}^{2}= & 2 p q[a+(q-p) d]^{2} \\
& =\text { variancia genetica aditiva associada aos efeitos medios } \\
& \text { dos genes: } \\
\sigma_{D}^{2}= & (2 p q d)^{2} \\
& =\text { variancia genetica dominante, associada aos efeitos das } \\
& \text { interaçoes alélicas; }
\end{aligned}
$$




$$
\begin{aligned}
D_{1}= & -2 p q(q-p)[a+(q-p) d] d \\
& =\text { covariancia media entre os efeitos aditivos dos a }] \text { elos } \\
& \text { e os efeitos de dominancia dos homozigotos; }
\end{aligned}
$$

$D_{2}=4 p q[(q-p) d]^{2}$

- variancia genetica dos efeitos de dominancia dos tromozigotos:

onde:

a: metade da diferenca entre os valores genotipicos dos homozigotos;

d: desvio genotipico dos heterozigotos, em relação a media genotipica dos homozigotos;

p: frequencia do alelo favoravel;

q: frequencia do alelo desfavoravel.

Considerando-se progenies $S_{1}$ a variancia genetica entre progenies $\left(\alpha_{p}^{2}\right)$ e assim decomposta (LAMKEY \& HALLAUER, 1987; SOUZA Jr,, 1988):

$$
\sigma_{p}^{2}=\sigma_{A}^{2}+\frac{1}{4} \sigma_{0}^{2}+D_{1}+\frac{1}{8} D_{2}
$$

Assumiu-se no presente trabaltio, $p=q=0,5$, em ambas populaçós, para os tres caracteres avaliados. Neste caso tem-se $D_{1}=D_{2}=0$, sendo que:

$$
\sigma_{p}^{2}=\sigma_{A}^{2}+\frac{1}{4} \sigma_{D}^{2} \quad \text { (HALLAUER, 1980) }
$$


Partindo-se desta equaçăo estimaram-se os componentes geneticos intrapopulacionais, $\sigma_{A}^{2}$ e $\sigma_{D}^{2}$, para os caracteres avaliados (Tabela 6). As hipoteses assumidas $\left(H_{i}\right)$ para a relaçao $\sigma_{D}^{2} / \alpha_{A}^{2}$ variaram em função da natureza do carater, seguindo tendencias encontradas na literatura. Para os caracteres altura de planta e altura de espiga, em milito, a relasao $\alpha_{D}^{2} / \alpha_{A}^{2}$ tem oscilado en torno de 0,20 (HALLAUER \& MIRANDA FILHO, 1988), para produção de grãos este valor de variado de 0,5 a 1,0 . obtiveram-se assim as estimativas $\alpha_{A_{1}}^{2} \sigma_{A_{2}}^{2}$, referentes as popul açBes ESALQ PB-2 (Ca) e ESALQ PB-3 (Ca), respectivamente, para os dois locais de avaliaร̧a.

A variancia da interaçáo entre progenies e ambientes $\left(\sigma_{p a}^{2}\right.$ ) pode ser decomposta de maneira analoga a $\sigma_{p}^{2}$, em $\alpha_{A E}^{2}+\frac{1}{4} \alpha_{D E}^{2}$ (HALLAUER \& MIRANDA FILHO, 1988). DadOS experimentais, contudo, ná se mostram conclusivos a ponto de permitir extrapolaçoes para a relação $\sigma_{D E}^{2} / \sigma_{A E}^{2}$ ISILVA, 19741.

As estimativas de ${ }^{2}$, obtidas das análises individualizadas por local estão inflacionadas pela interação entre a variancia aditiva e o ambiente $\left(\sigma_{A E}^{2}\right)$. por outro lado, as estimativas de $\alpha^{2}$, provenientes das analises conjuntas estão isentas desta interação (REZENDE, 1989; PELLICANO, 1990). As variancias fenotipicas entre progenies $s_{1}\left(\sigma_{f}^{2}\right)$ e os coeficientes de herdabilidade ao nivel de médias de progenies $\left(h \frac{2}{x}\right)$ foram determinados para cada 
local, individualmente, e para os dois locais, em conjunto (Tabela 6).

Tabela 6. Hipoteses (H) assumidas para a relação $\sigma_{0}^{2} / \sigma_{A}^{2}$, para os caracteres produção de grãos, altura de planta e altura de espiga, e suas implicaçoes nos conteúdos de $\alpha_{p}^{2}$.

\begin{tabular}{|c|c|c|c|}
\hline rater & $H_{1} * \sigma_{D}^{2} / \sigma_{A}^{2}$ & $\alpha_{A}^{2} / \sigma_{p}^{2}$ & $\sigma_{D}^{2} \sigma^{2}$ \\
\hline $\begin{array}{l}\text { Produçao de grãos } \\
\text { (g/pl) }\end{array}$ & $\begin{array}{l}H_{1}=0,5 \\
H_{2}=1,0\end{array}$ & $8 / 9$ & $\begin{array}{l}4 / 9 \\
4 / 5\end{array}$ \\
\hline Altura de plante $(\mathrm{cm})$ & $H_{3}=0,2$ & $20 / 21$ & $4 / 21$ \\
\hline Alture de espiga $(\mathrm{cm})$ & $\mathrm{H}_{3}=0,2$ & $20 / 21$ & $20 / 21$ \\
\hline
\end{tabular}

* $p=q=0,5 ; 2$ alelos por 1000

o progresso com a selecáo de progenies $S_{1}$, foi calculado para a produçao de grăos, adotando-se uma intensidade de seleção de $20 \%$ ( $k=1,3998$ ) (VENCOUSKY, 1987 ). Os componentes da variação genetica responsaveis pelo progresso com a seleção de progenies $S_{1}$ são $\sigma_{A}^{2}+\frac{1}{2} D_{A}$ (SOUZA Jr., 19891 . o coeficiente de D, aproveitavel na selecáo difere do coeficiente expresso na variancia entre progenies $S_{1}$

HALLAUER \& MIRANDA FILHO (1988) definiram UM desvio $\beta$ que soma-se a variancia aditiva, na expressá do desvio da variancia aditiva devido principalmente a efeitos 
de dominancia. Para casos de frequencias genicas $p=q=0,5$ - valor de $\beta=0$, e progresso e apenas funcáa da $\alpha_{A}^{2}$.

Consideraram-se as seguintes condiçoes para cálculo do progresso com seleça: a) ganto direto no proprio ambiente de seleção (Gs); b) gantio medio dos dois locais quando a seleça e praticada na media dos mesmos (Gs-), (Tabela 7). No primeiro caso o progresso e função de o ${ }^{2}$, determinada para os dois locais. No segundo caso Gs é funçăo de $\alpha_{A}^{2}$, extral da da análise conjunta, e isenta da interaçå $\sigma_{A E}^{2}$.

Tabela 7. Equaçoes para estimação dos progressos esperados no proprio local de seleçao (Gs), progressos médios com a seleção na média dos locais (Gs, (K) ) e das variancias fenotipicas herdabilidades ao ni vel de medias, para as duas condiçbes.

Local $\alpha_{f(x)}^{2} \quad h \frac{2}{x}^{*} \quad$ Gs

\begin{tabular}{|c|c|c|c|c|}
\hline$P G, R O$ & $\frac{\alpha^{2}}{r}$ & $+\alpha_{p}^{2}$ & $\sigma_{A}^{2} / \sigma_{r(x)}^{2}$ & $G s=k \cdot h^{2}(\bar{x}) \cdot o_{f(x)}$ \\
\hline $\begin{array}{l}\text { Media de } \\
\text { locais** }\end{array}$ & $\frac{\alpha_{\theta 1}^{2}}{r 1}$ & +0 & $\sigma_{A}^{2} / \sigma_{f(x)}^{2}$ & $G s=k \cdot h^{2}(\bar{x})$ \\
\hline
\end{tabular}

$*: p=q=0,5 \therefore D_{1}=2 \beta=0$

** estimativas obtidas da análise conjunta 


\subsubsection{Depressão por endogamia}

Determinou-se a depressao por endogamia para as populaçశes ESALQ PB-2 (C3) e ESALQ PB-3 (C3), nos dois locais de avaliação, para os tres caracteres em estudo. A depressão por endogamia (DE) foi estimada como um desvio, percentual, em relação média da populaçăo não endogama. A depressão media foi assim calculada:

$$
\overline{\mathrm{DE}}(\%)=100 \cdot \frac{\left(\bar{S}_{1}-\bar{S}_{0}\right)}{\bar{S}_{0}} \text {, onde: }
$$

$\overline{\mathrm{DE}}(\%)$ : depressá por endogamia media;

$\bar{s}_{0} \quad$ : media da população $S_{0}$

$\vec{s}_{1} \quad$ media das progenies $S_{1}$.

Para cada progenie $S_{\mathfrak{A}}$ obteve-se seu desvio percentual em relação a media da populaça $S_{0}$ (DE).

Estimaram-se os componentes de medias das duas populaçסes $(\mu, a, d)$, de modo que:

$$
\begin{array}{r}
\mu+a=2 \bar{S}_{1}-\bar{s}_{0} \\
d=2\left(\bar{S}_{0}-\bar{s}_{1}\right)
\end{array}
$$

$\mu=$ media dos homozigotos;

$a=\Sigma(2 p-1) . \alpha$, e representa a contribuigão dos locos em homozigose na media do carater (VENCOVSKY, 1987).

$d=\Sigma 2 p(1-p) \delta$, e refere-se a contribuição dos locos em heterozigose para a media do carater. 


\title{
3.2.6. DistribuiçB̃es fenotipicas abservadas
}

\begin{abstract}
As distribuiços de frequencias observadas das progenies endógamas $\left(S_{1}\right)$, bem como seus valores de $D E$ foram apresentadas em forma de histogramas, juntamente com as medias e amplitudes de variação, para os caracteres produçå de grăos, altura de planta e altura de espiga. Considerou-se o intervalo entre classes ao redor de 0,50
\end{abstract}

3. 3. Avaliaçăo dos "Testcrosses" reciprocos

\subsubsection{Material}

Este estudo envolveu "testcrosses" reclprocos de progenies $S_{2}$, oriundos das populaçBes ESALQ PB-2 (Ca) e ESALQ PB-3 (C2), utilizando-se, como testador, a mistura de progénies $S_{2}$ da populaçao reclproca. Foram obtidas e avaliadas 80 progenies "testcrosses" referentes a populaça ESALQ PB-2 (C2) e 91 referentes a ESALQ PB-3 (C2).

Dentro de cada populaçăo, a amostra de progênies avaliadas constituiu-se de uma mistura de "testcrosses" aparentados e nao aparentados, onde as progenies mães $\left(S_{2}\right)$ foram extraldas sequndo o esquema genealogico (Figura 1 ). 


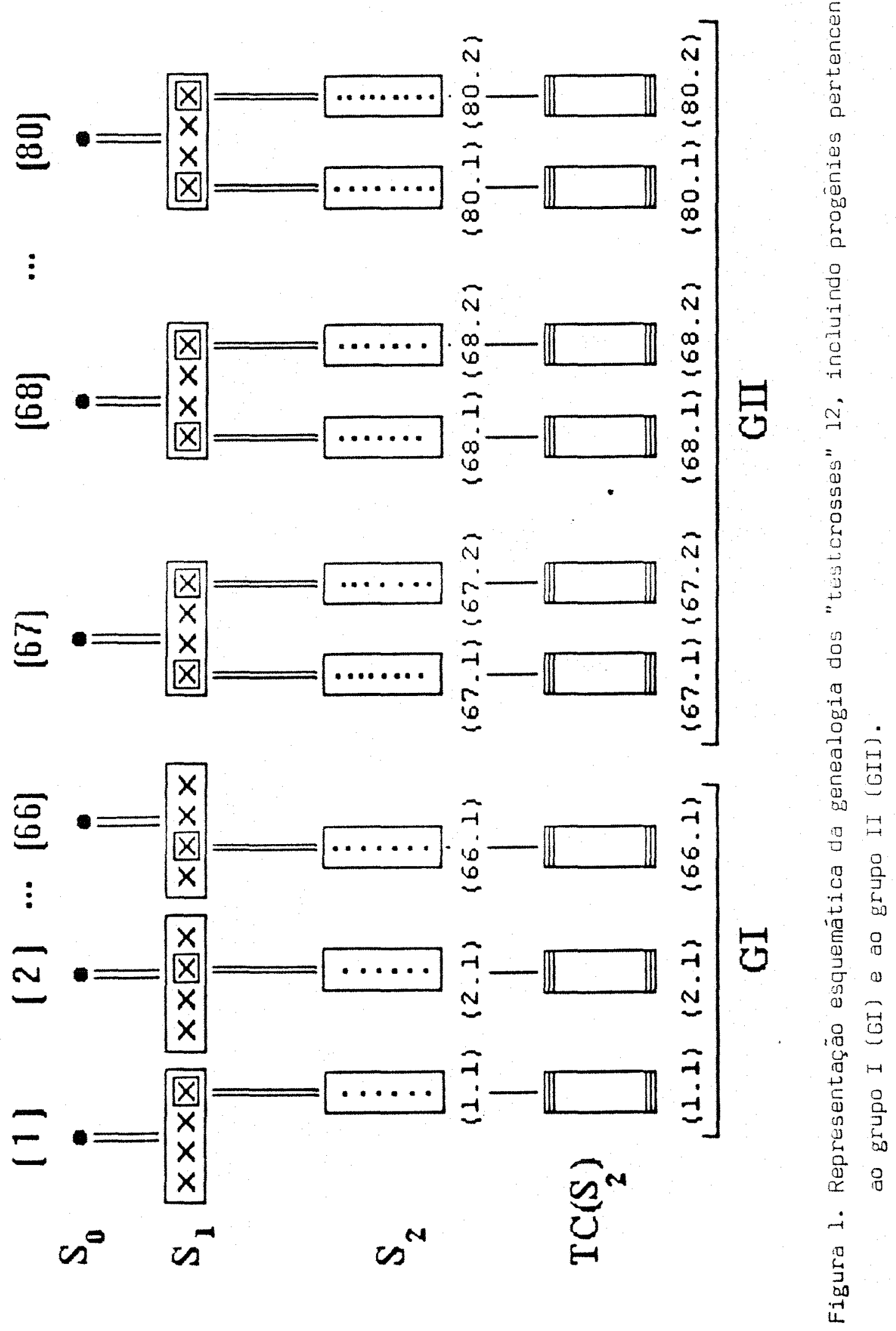




\section{3.2. Execusăo experimental}

Os "testcrosses" foram obtidos no campo experimental da ESALQ, no ano de 1987. Os experimentos foram conduzidos na estacão experimental da Contibrasil, municipio de Cravintios (SP), no ano agrfeola de $1988 / 1989$. Adotou-se o del ineamento experimental de blocos ao acaso, con tres repetiçBes. Como testemunha foi utilizado o híbrido comercial C511, intercalado a cada dez progenies.

As parcelas constitulram-se de uma fileira de 4, om de comprimento, com espacamento de $1,0 \mathrm{~m}$ entre fileiras. Foram semeadas 2 sementes por cova, visando após 0 desbaste, uma densidade populacional de 50.000 plantas por hectare.

Foram tomados dados de produção de grãos, "stand" final, altura de planta e altura de espiga. para os caracteres altura de planta e altura de espiga, coletaramse dados de apenas uma planta, representativa da média da parcela. Para produção de grãos tomaram-se dados de totais de parcela. A correção para "stand" ideal de vinte plantas foi realizada pelo metodo de covariancia proposto por Miranda Filho, eitado por VENCOVSKY \& BARRIGA (1992). 


\section{3. 3. Analises estatisticas}

As análises de variáncia preliminares foram executadas segundo delineamentos em blocos casualizados, cujo modelo matematico $\&$ o que segue:

$$
Y_{i j}=\mu+t_{i}+r_{j}+e_{i j} \text { onde: }
$$

$Y_{i j}$ : média do tratamento i na repetiça $j$;

$\mu$ : media geral do experimento, fixa; $E(\mu)=\mu ; E(\mu)^{2}=\mu^{2}$;

$t_{i}:$ efeito do tratamento $i(i=1.2, \ldots, 1)$, desdobrado em:

$$
\begin{aligned}
p_{i}= & \text { efeito aleatorio da progenie "testcross" } \\
& (i=1,2, \ldots I-1) \text {; } E(p)=0 ; E\left(p_{i}\right)^{2}=\alpha_{P}^{2} \\
s_{i}= & \text { efeito fixo da testemuntia }(i=I) ; E\left(s_{i}\right)=5 \\
& E\left(s_{i}\right)^{2}=s^{2} \\
e_{i j}= & \text { erro experimental associado a parcela ij; } \\
& e_{i j} \cap N\left(0, \alpha^{2}\right), E\left(E_{i j}\right)=0 ; E\left(e_{i j}\right)^{2}=\alpha^{2}
\end{aligned}
$$

As progenies "testcrosses", na analise de variancia, foram decompostas em tres grupos, en funça da relaça de parentesco entre elas (Figura 1):

i) grupo I = conjunto de "testcrosses" de progenies $S_{2}$ oriundas de plantas $S_{0}$ distintas;

ii) grupo II : conjunto de "testcrosses" onde pares de progenies $S_{2}$ derivam da mesma planta $S_{0}$

iii) grupo III: conjunto de "testcrosses" onde sub-grupos de tres progeries $S_{2}$ derivam da mesma planta $S_{0}$ 
o experimento 2.1 , relativo a progenies da populaçå ESALQ PB-2 (C2) contém apenas progenies pertencentes aos grupos I I I; no caso da população ESALQ PB-3 (C2) experimento 2.2 , progenies dos tres grupos estão presentes.

A estrutura das análises de variancia para os experimentos 2.1 e 2.2 să apresentados nas Tabelas 8 e 9. Os desdobramentos do efeito de progenies seguiram o esquema hierarquico.

Tabela 8. Esquema de analise de variancia para o experimento 2.1 , juntamente com as esperanças dos quadrados medios $E(Q M)$.

\begin{tabular}{|c|c|c|c|c|}
\hline$F V$ & GL & QM & $E(Q M)$ & $E(Q M) \stackrel{b}{-}$ \\
\hline Blocos ${ }^{a}-/$ & 2 & & & \\
\hline Tratamentos & 80 & & & \\
\hline Testcrosses & 79 & & & \\
\hline GI & 65 & $Q_{1}$ & $\sigma^{2}+r \cdot \sigma_{0 x}^{2}$ & $\alpha^{2}+(9 / 8) \alpha_{A}^{2}$ \\
\hline GII & 6 & $Q_{2}$ & $\alpha^{2}+r \cdot \alpha_{d p I I}^{2}+n \cdot r \cdot \alpha_{p I I}^{2}$ & $\sigma^{2}+(15 / 8) \sigma^{2}$ \\
\hline dGI I & 7 & Q3 & $\sigma^{2}+r \cdot \sigma_{\text {dpII }}^{2}$ & $\alpha^{2}+(3 / 8) \alpha_{12}^{2}$ \\
\hline GI vS GII & 1 & & & \\
\hline $\begin{array}{l}\text { Testerosses } \\
\text { vs. Testem. }\end{array}$ & 1 & & & \\
\hline REsI dUO & 183 & Q4 & $\sigma^{2}$ & $\alpha^{2}$ \\
\hline
\end{tabular}

Tota 1

a l para altura de planta e altura de espiga $r=2 \therefore$ $G L(B] O C O 5)=1 ; G L(R e s I d u O)=95$.

D_ ésperanças validas para produçáo de gráos $(r=3)$ 
$\sigma_{p 1}^{2}$ : variancia genetica entre progenies pertencentes ao grupo 1 ;

$\sigma_{p I I}^{2}$ : variancia genetica entre pares de progenies aparentadas, pertencentes ao grupo II;

$\sigma_{\text {dpI }}^{2}$ : variancia genetica entre progenies derivadas da mesma planta $S_{0}$, dentro do grupo II:

$\alpha^{2}$ : variancia residual, composta pela:

- variancia devido a interaçáa entre blocos e tratamentos (160 g1)

- variancia entre parcelas da testemuntia, dentro da mesma repetigå (24,g1)

$r$ número de repetiçoes;

$n$ : número de progenies derivadas da mesma planta $S_{0}$.

Tabela 9. Esquema de análise de variancia para o experimento 2.2 , juntamente com as esperanças dos quadrados medios E(QM).

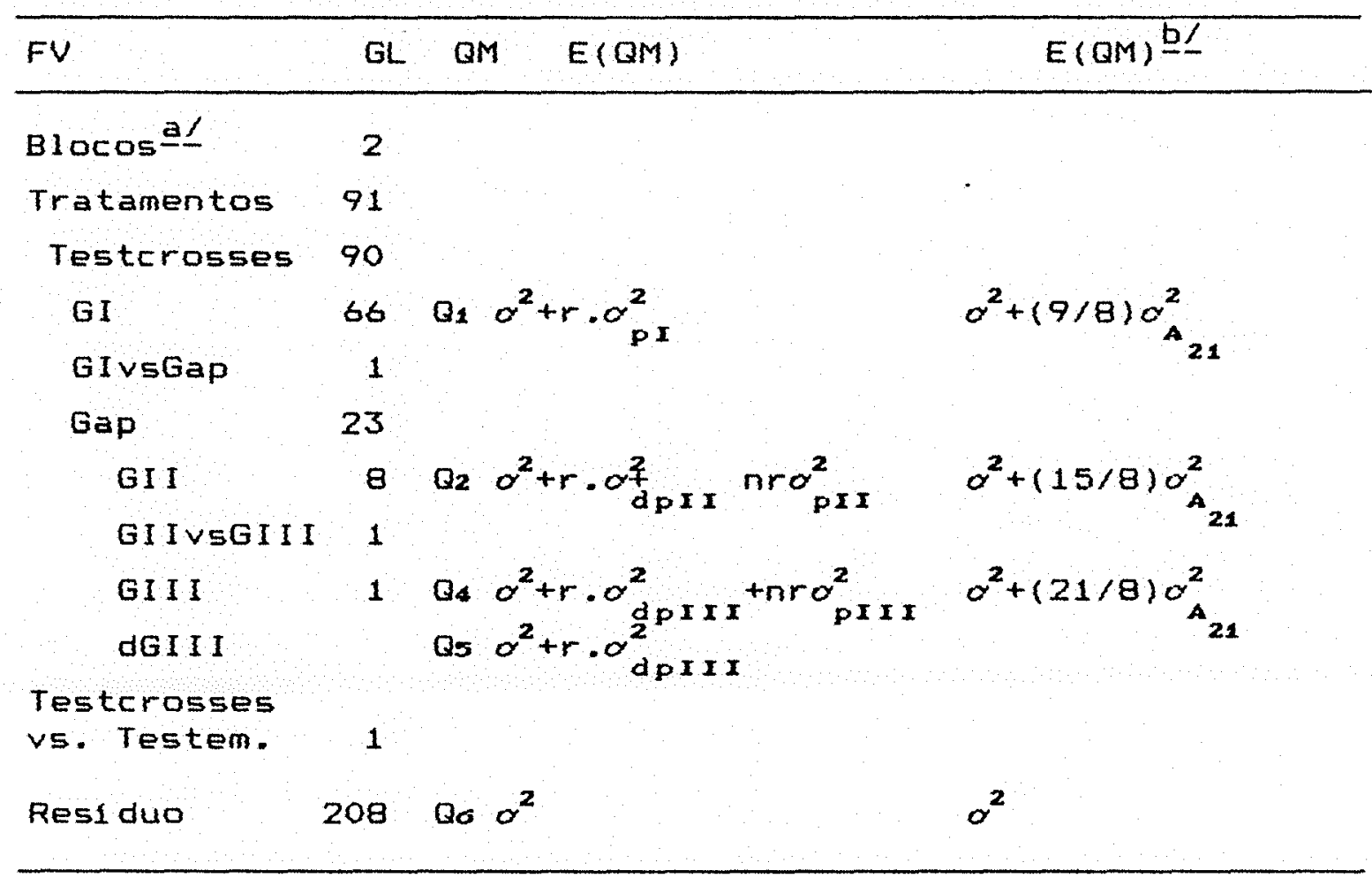

al: para altura de planta e altura de espigas $r=2 \therefore$ $G L(B 10 c 0 s)=1 ; G L(R e s 1 d u o)=108$

b/: esperanças válidas para o carater produção de grãos ( $r=3$ ) 
$G_{\text {ap }}$ : conjunto de progénies aparentadas, pertencentes ao grupo II e grupo III;

$\sigma_{\text {pxy }}^{2}$ variancia genetica entre progenies derivadas da mesma planta $S_{0}$ dentro do grupo III;

$n, m$ : número de progenies derivadas da mesma planta $S_{0}$ $\{n=2, m=3\}$.

A variancia genetica entre progenies de meios irmás interpopulacionais e função apenas dos componentes $d_{A_{12}}^{2}=\sigma_{A_{21}}^{2}$, analogos da variancia aditiva ao nivel interpoPUIaCIONa1 (HALLAUER \& MIRANDA FILHO, 1981, VENCOVSKY, 1987). Determinou-se, assim, o conteudo da variancia presente nos componentes $\alpha_{\text {pI }}^{2} \alpha_{\text {pII }}^{2} \alpha_{\text {dpII }}^{2}$ observa-se, assim:

$$
\begin{aligned}
& \sigma_{p I}^{2}=(3 / B) \sigma_{A_{12}}^{2} \text { ou }(3 / 8) \sigma_{A_{21}}^{2} \\
& \alpha_{\text {PII }}^{2}=\sigma_{\text {PIII }}^{2}=(1 / 4) \sigma_{A_{12}^{2}}^{2} \text { ou }(1 / 4) \sigma_{A_{21}^{2}}^{2} \\
& \sigma_{\mathrm{dpII}}^{2}=\sigma_{\mathrm{dpIXI}}^{2}=(1 / 8) \sigma_{A_{12}}^{2} \text { ou }(1 / 8) \sigma_{A_{21}}^{2}
\end{aligned}
$$

3. 3. 4. Estimativas de parametros geneticoestatisticos

a) Metodologia

Os parametros genético-estatisticos foram estimados pelo metodo dos quadrados minimos ponderados, onde o fator de ponderaçăo (f) corresponde ao inverso da raiz qudrada da varisncia de cada quadrado medio: 


$$
\begin{aligned}
& f i=\frac{1}{\sqrt{V\left(Q M_{i}\right)}} \text {, sendo que: } \\
& V\left(G M_{i}\right)=\frac{2\left(G M_{i}\right)^{2}}{9^{1+2}} \text { (VELLO \& VENCOUSKY, 1974) }
\end{aligned}
$$

A matriz dos pesos (P) e uma matriz diagonal, sendo que os fatores de ponderação (f) ocupam as diagonais, e as demais posiçßes são tomadas por zeros (SILVA, 1974). As matrizes $X$ e $Y$ ponderadas foram obtidas multiplicando-se: P.X, P.Y, respectivamente. Este tipo de ponderação tem como vantagem a homogeneizaçăo dos erros associados aos quadrados medios, tornando a variancia de cada quadrado medio ponderado igual a unidade (OBILANA, 1977). Isto torna-se mais relevante quando os quadrados medios envolvidos apresentam diferentes magnitudes e estão associados a diferentes graus de liberdade.

Apos a ponderação, a resolução do sistema é identica ao metodo dos quadrados ms nimos não ponderados, onde:

$$
\beta=(x \cdot x)^{-1} \cdot(x \cdot Y) \text {, sendo } \beta \text { a matriz das esti- }
$$
mativas.

A precisão das estimativas, $V(\hat{\beta})$, foi obtida atraves da expressão:

$$
V^{-1}=P^{\cdot} \cdot P \quad \text { (SILVA, } 1974 ; \text { OBILANA, } 1977 \text { ). }
$$




\section{b) Estimação}

Entre as equaçoes disponi veis para compor o sistema, foram selecionadas aquelas que nå gerassem al guma tendenciosidade as estimativas. Desprezou-se os quadrados medios entre progenies aparentadas, dentro de grupos (QM dgI QM dgIII', devido ao efeito da selecáo dentro das progenies $S_{1}$ Tamben foi exclus do o quadrado medio entre grupos de

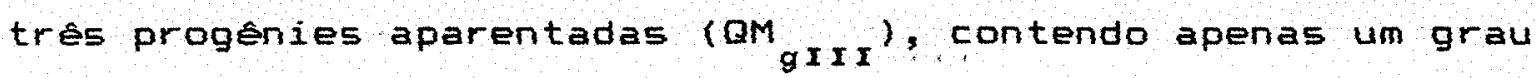
de liberdade.

Foram agrupados em apenas uma matriz os experimentos relativos a "testcrosses" oriundos das duas populaçós. o quadrado medio residual que compos a matriz $Y$ corresponde a média dos QM residuais dos experimentos 2.1 e 2.2 , ponderados por seus respectivos graus de liberdade. A sequir, så apresentadas as estruturas das matrizes $X, \beta, Y$, P, para os caracteres produção de grãos, altura de planta e altura de espiga.

$$
\begin{aligned}
& x^{* 1} \\
& \begin{array}{ccc}
9 / 8 & 0 & 1 \\
15 / 8 & 0 & 1 \\
0 & 7 / 8 & 1 \\
0 & 15 / 8 & 1 \\
0 & 0 & 1
\end{array} \mid
\end{aligned}
$$

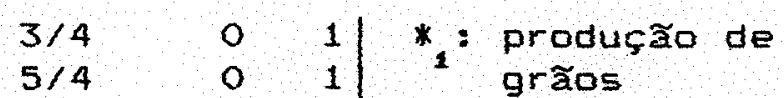

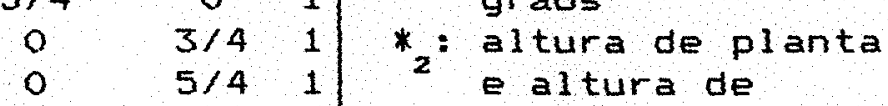

$$
\begin{aligned}
& \begin{array}{ccc}
0 & 5 / 4 & 1 \\
0 & 0 & 1
\end{array} \mid \begin{array}{ll}
2 & \text { e altura de } \\
\text { espiga } &
\end{array}
\end{aligned}
$$

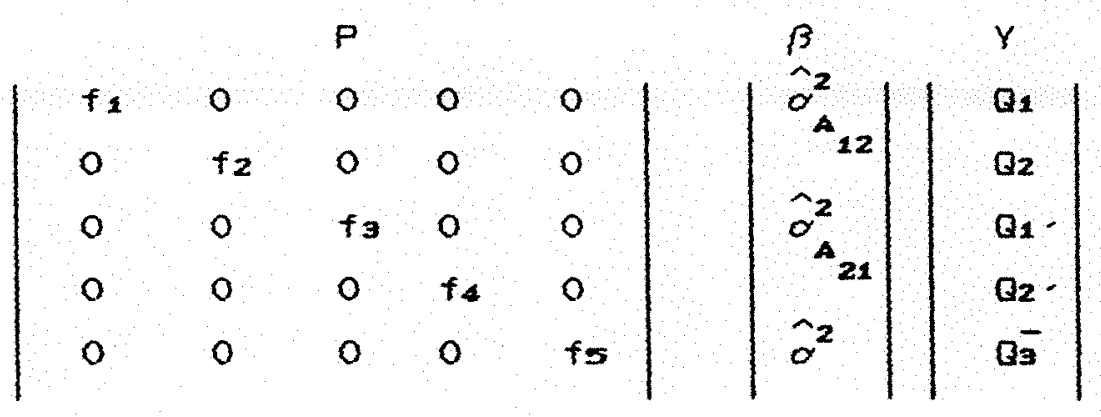




\subsubsection{Progressos esperados com a seleção}

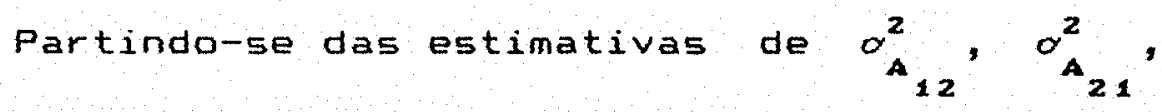
$\alpha^{2}$, foram calculados os progressos esperados com a seleção de hibridos simples (HS), hibridos triplos (HT) e hIbridos duplos (HD), entre as populaçßes ESALQ PB-2 (C2) e ESALQ PB-3 ( $C_{2}$ ), para o carater produção de gráos. A expressão que determina o progresso com a seleção de hibridos a a seguinte:

$$
G s=k \cdot o_{g H}^{2} / \sigma_{x}
$$

$\sigma_{\text {gh }}^{2}$ : variancia genetica expressa entre híbridos;

$\sigma_{\bar{x}}$ : desvio padráo fenotipico entre medias de hibridos.

As variancias geneticas expressas entre hibridos simples (HS ${ }_{(12)}$ ), hiloridos duplos (HD (12) $)_{\text {e }}$ nsoridos triplos (HT, ${ }_{12}, H_{21}$ ) sä apresentados a seguir (SOUZA Jr, , 1988).

$$
\begin{aligned}
& \sigma^{2}{ }_{(12)}=\frac{(1+F)}{4}\left(\sigma_{A_{12}}^{2}+\sigma_{A_{21}}^{2}\right)+\frac{(1+F)^{2}}{4} \sigma_{D_{(12)}} \\
& \alpha_{H T_{12}}^{2}=\frac{(1+F)}{8} \sigma_{A_{12}}^{2}+\frac{(1+F)}{4} \sigma_{A_{21}}^{2}+\frac{(1+F)^{2}}{8} \sigma_{D_{(12)}} \\
& \sigma_{\mathrm{HT}}^{2}=\frac{(1+F)}{4} \sigma_{A_{12}}^{2}+\frac{(1+F)}{8} \sigma_{A_{21}}^{2}+\frac{(1+F)^{2}}{8} \sigma_{D_{(12)}}^{2}
\end{aligned}
$$


$o_{H D_{(12)}}^{2}=\frac{(1+F)}{8}\left(\sigma_{A_{12}}^{2}+\sigma_{A_{21}}^{2}+\frac{(1+F)^{2}}{16} \sigma_{D_{(12)}}^{2}\right.$

sendo que:

HT 12 : hibridos triplos formados pelo cruzamento de um HS da popul ação 1 com uma lintiagem da popul ação 2

HT 21 hIbridos triplos provenientes do cruzamento de um HS da popul ação 2 com uma lintiagem da popul ação 1.

Foram formuladas as seguinte s hipoteses $\left(\mathrm{H}_{i}\right)$ baseadas em resul tados apresentados na lit eratura, para a relaçao $\sigma_{D}^{2} \int_{(12)} \alpha_{(12)}^{2}$ (HALLAUER \& MIRANDA FILHO, 1988):

$$
\begin{aligned}
& H_{1}: \alpha_{D_{(12)}}^{2} / \alpha_{A_{(12)}}^{2}=1 \\
& H_{2}: \sigma_{D_{(12)}}^{2} \alpha_{A_{(12)}}^{2}=0,5 \\
& H_{3}: \sigma_{D_{(12)}^{2}}^{2} / \sigma_{\left.A_{(12}\right)}^{2}=0,2 \\
& \sigma_{\left.A_{12}\right)}^{2}=\frac{1}{2}\left(\sigma_{A_{12}}^{2}+\sigma_{A_{21}}^{2}\right)
\end{aligned}
$$

(HALLAUER \& MIRANDA FILHO, 1988 )

As variancias geneticas entre ho bridos são, assim, apresentadas na Tabela 10 en funçao apenas dos componentes $\alpha_{A_{12}^{2}}^{2}=\sigma_{A_{21}}^{2}$. Foram considerados trés niveis de endogamia para as linhagens: $S_{2}(F=1 / 2), S_{3}(F=3 / 4)$, $S_{\infty}(F=1)$. o coeficiente de endogamia (F) refere-se a geraça anterior de autofecundação. 


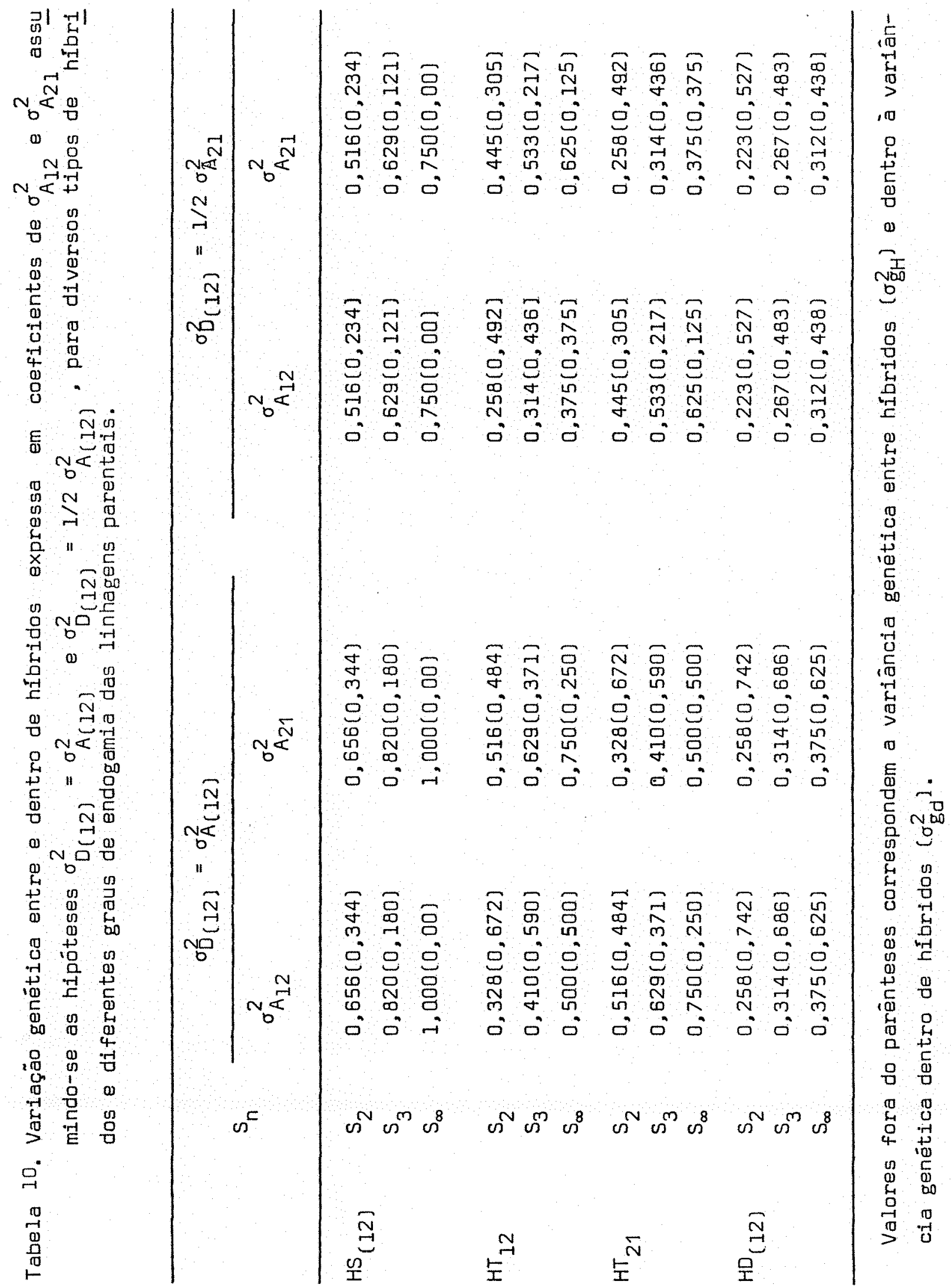


Para fins de predição do progresso com a seleção, manteve-se constante o componente ambiental $E$, determinando-se a variancia genetica dentro ( ${ }_{g}^{2}$ ), para cada tipo de híbrido. Assim a expressão geral para cálculo da variancia fenotipica entre medias de hibridos e a seguinte:

$$
\sigma_{f x}^{2}=\frac{\sigma_{g d}^{2}}{k \cdot r}+\frac{E}{r}+\sigma_{g}^{2}
$$

Na Tabela 10 să apresentados os componentes de variancia genetica dentro de cada tipo de hibrido, em termos de $\alpha_{A_{12}}^{2} e \alpha_{A_{21}}^{2}$, considerando-se as hipoteses $\left(H_{1}, H_{2} e\right.$ $\mathrm{H}_{3}$ 


\section{RESULTADOS}

\section{1. Progenies $S_{1}$}

\subsubsection{Valores Medios}

As performances medias das progenies $S_{1}$ das popul açóes não endógamas (S,', bem como do híbrido comercial C511 estão condensados na Tabela 11, para os dois locais de avaliação e os três caracteres avaliados, quais sejam, produça de graos (PG), altura da planta (AP) e altura de espiga (AE), apresentados ao nivel de plantas individuais.

Como esperado, 0 efeito de ambientes mostrou-se bastante pronunciado, sendo que as medias referentes ao local 1 (Ponta Grossa) apresentaram-se sempre superiores ao local 2 (Rondonopolis). Em media, verificou-se em ponta Grossa uma superioridade de $120 \%$ em produçăo de grãos $(g / p 1), 15,2 \%$ na altura de planta $(\mathrm{cm})$ e $18,4 \%$ em altura de espiga $(\mathrm{cm})$.

Na media dos dois locais, as populaçßes não endogamas ESALQ PB-2 (C3), populą̧ăo 1, e ESALQ PB-3 (C3), 
população 2, mostraram produçzes similares, com valores iguais a $175 \mathrm{~g} / \mathrm{pl}$ e $160 \mathrm{~g} / \mathrm{pl}$, respectivamente, equivalendo a cerca de $93 \%$ da produção da testemuntia (Tabela 11). Este percentual manteve-se da mesma ordem en Ponta Grossa, com produços em torno de $2209 / \mathrm{pl}$ en ambas as populaçoes. Em Rondonopolis as medias foram de 123 g/pl e $98 \mathrm{~g} / \mathrm{pl}$ para as populasão 1 e 2 , respectivamente,correspondendo, em cada caso a 103 e $93 \%$ da produção do hu brido comercial c511. os resultados inferiores apresentados pela populaça 2 podem ser devido aos problemas de ordem experimental envolvendo os experimentos 1.3 e 1.4 , comentados no 1 tem 3.2 .2 .

Com respeito aos caracteres altura de planta e altura de espiga, o hibrido comercial sempre apresentou valores inferiores as populaç̧es nå endógamas. Para al tura de planta as medias de Ponta Grossa foram da ordem de 245 cm/pl em ambas populaçBes, superando a testemuntia em torno de $5 \%$. Em Rondonópolis as medias de $220 \mathrm{~cm}$ para a popul ação 1 , e 205 cm para a populaçă 2 , representaram acrescimos de 7 e $2 \%$, comparados ao his orido $\mathrm{cs} 11$.

Para o carater altura de espiga, foram obtidos em Ponta Grossa valores en torno de $150 \mathrm{~cm}$ nas populaçes 1 e 2 , superando a testemuntha em 15 e $10 \%$, respectivamente. Em Rondonopolis, tais percentuais foram de $13 \%$ e $5 \%$ com medias de $120 \mathrm{~cm}$ e $110 \mathrm{~cm}$ para a populaç̧es 1 e 2 , respectivamente. 
Com relação as progennies endogámicas (S,), as produçós obtidas em Ponta Grossa foram da ordem de $140 \mathrm{~g} / \mathrm{pl}$ para ambas populaçoes, correspondendo a $56 \%$ da media do híbrido CS11. Como esperado, as medias de produção em Rondonopolis, mostraram-se inferiores a Ponta Grossa com valores de $65 \mathrm{~g} / \mathrm{pl}$ para a popul açăo 1 e $53 \mathrm{~g} / \mathrm{pl}$ para a popul ação 2 . Considerando-se a media dos locais, obtiveram-se produçzes medias ao redor de $100 \mathrm{~g} / \mathrm{pl}$ para os dois conjuntos de progenies, comparados a $180 \mathrm{~g} / \mathrm{pl}$ para o hibrido C511 e 170 g/pl para as popul açốes não endógamas (Tabela 11 ).

Para os caracteres altura de planta e altura de espiga, as medias das progenies endogamicas foram semelhantes as apresentadas pela testemunha C511. Para altura de planta, as populaçbes 1 e 2 apresentaram, respectivamente, medias iguais a $230 \mathrm{~cm}$ e $224 \mathrm{~cm}$, em Ponta Grossa, e $202 \mathrm{~cm}$ e $190 \mathrm{~cm} / \mathrm{pl}$ em Rondonopolis, correspondendo a cerca de 96\% da al tura de planta do hibrido Cani (Tabela 11). Para altura de espiga, as medias foram de $140 \mathrm{~cm}$ e $133 \mathrm{~cm}$ em Ponta Grossa, e $108 \mathrm{~cm}$ e $100 \mathrm{~cm}$ em Rondonopolis, nas populaçós 1 e 2, respectivamente. Calculada a media dos dois locais, os percentuais relativos a média da testemunha foram de $104 \%$ para a população 1 e $99 \%$ para a popul ação 2.

A depressão media por endogamia variou em função da população, do ambiente de avaliação, e sobretudo, da natureza do carater em estudo (Tabela 12). o caráter mais 
influenciado pelo efeito da endogamia foi produção de grãos, com valores medios da ordem de $-37 \%$ e $-44 \%$ em Ponta Grossa, e $-42 \%$ e $-46 \%$, em Rondonspolis, nas populaçชes 1 e 2 , respectivamente.

A depressão media por endogamia mostrou-se semel hante para os caracteres altura de planta e altura de espiga. Para altura de planta foram obtidas depressoes iguais a $-7,2 \%$ e -8,9\% em Ponta Grossa, e $-8,9 \%$ e $-7,0 \%$ em Rondonopolis, para as populaçBes 1 e2, respectivamente. Para altura de espiga obtiveram-se depressbes da ordem de $-7,5 \%$ em ponta grossa, nas duas populaçoes, sendo que em Rondonópolis as depressoes medias foram mais elevadas, com valores de $-10,3 \%$ para a população 1 e $-8,5 \%$ para a população 2 .

Os valores medios de depressão por endogamia para $1 \%$ de acrescimo no nível de endogamia populacional tambem foram semel hantes para as duas populaçßes em questão, apresentando estimativas medias variando de 1,30 g/pla 1,40 g/pl para produça de grãos, 0,37 cm para altura de planta e 0,22 cm para al tura de espiga (Tabela 12 ).

Como esperado, a contribuiça dos locos homozigotos $(\mu+2)$ mostrou-se mais acentuada que a dos locos heterozigotos (d) para os caracteres altura de planta e a tura de espiga, ocorrendo o inverso para produção de graos. Os valores de $(\mu+a)$ eda relaçao $(\mu+$ a)/d encontrados para a populaçăo 1, foram superiores aos obtidos para 
a populaçăo 2, nos dois locais de avaliaçăo, para produção de grãos (Tabela 12). Para os demais caracteres, entretanto, as duas populaç̧es apresentaram performances similares.

\subsubsection{Distribuiçóes Observadas}

As distribuiçōes observadas das progenies $S_{1}$, referentes a média do carater, juntamente con seus desvios percentuais em relação a populaçåo não endogama (DE) são apresentadas na forma de histogramas nas figuras 2 a 7 .

A produça das progenies $S_{1}$, em Ponta Grossa, oscilou na faixa de 83 a 225 g/pl, para a população 1 e 85 a 202 g/pl para a populaçăo 2 , a que correspondeu respectivamente a desvios percentuais de $(-0,1$ a $-63,0 \%)$ e $(-14,5$ a -64,8\%) comparados as populaçöes não endogamas (S.) (Figura 2).

No $10 c a 12$, Rondonopolis, a produça variou entre 37 e 116 g/pl, para a população 1 , e 25 a 85 g/pl para a população 2. A faixa de depressão por endogamia foi de $-2,8$ a $-68 \%$ para a população 1 , e -10 a $-74 \%$ para a popula̧̧ă 2, confirmando a maior sensibilidade das progenies endogamicas ao efeito adverso de chuvas na coltieita (Figura 5 ). Para altura de planta, os valores obtidos em Ponta Grossa variaram de 180 a $280 \mathrm{~cm}$, para ambas as populaçôes. Quando comparadas à media das respectivas populaçóses nå endogamas ( $S_{0}$ ), OS desvios percentuais (DE) situaram-se 
entre os 1 imites de -28 a $+13 \%$, indicando a presença de progenies $S_{1}$ com alturas mais elevadas que a media da população $S_{0}$ (Figura 3 ). Tendencias semelhantes para a depressăo, em relação a media da população tambem foram determinadas em Rondonopolis, com valores variando de -27 a $+14 \%$, para a população 1 , e -27 a $+18 \%$ para a população 2 . Em termos absolutos as distribuiçóes de altura de planta situaram-se entre os limites de 150 e $250 \mathrm{~cm}$ para ambas as populaçós, havendo tendencias de menores valores na população 2 (Figura 6 ).

Os valores encontrados para o carater altura de espiga variaram de 95 a $175 \mathrm{~cm}$, em Ponta Grossa, e 75 a $145 \mathrm{~cm}$ em Rondonopolis, para ambas populaçชes, com tendências de valores mais elevados para a populacá 1 . Os desvios percentuais relativos a media da populaçáo $S_{0}$ foram semeIhantes para os dois locais de avaliaģăo oscilando de - 37 a $+18 \%$ (Tabela 12 e figuras 4 e 7 ).

\subsubsection{Anallses Agrupadas por Local}

Os resultados das analises referentes aos tres caracteres avaliados, em ambas populaçoes, encontram-se condensados na Tabela 13 , juntamente com seus respectivos coeficientes de variação experimental (CVe\%) e Indices de variação experimental $(\theta)$.

Para o carater produção de grãos, foram encontradas diferencas altamente significativas entre 
progenies $S_{1}$, com valores de $F$ variando de 2,84 a 4,12 (Tabela 13). As magnitudes de CVe (\%) foram da ordem de $15 \%$, em Ponta Grossa e $20 \%$ em Rondonopolis. Os valores encontrados para $\theta$ situaram-se em torno de 1,00, em Ponta Grossa, e 0,80 , em Rondonopolis, indicando menor influencia ambiental neste local. Em ambos os locais, as estimativas de $\theta$ para a popul ação 1 mostraram-se superiores a população 2 (Tabela 13$).$

Para o carater altura de planta (Tabela 13) foram obtidos os coeficientes de variação ambiental lcve (\%), de menor magnitude, oscilando em torno de $5 \%$, em ambas as populaçôes, com valor máximo em Rondonópolis, para a população 2 (CVe $=6,0 \%$ ). Os Indices $\theta$ variaram de 1,30 a 1,60, confirmando a menor influencia ambiental sobre este caráter, quando comparado a produção de grãos.

Para altura de espiga, os experimentos conduzidos no local 2, Rondonópolis, mostraram maior intluência ambienta 1 (CVe $\cong 9,0 \% ; \theta=1,0)$, comparado-5e ao $10 c a 1$, Ponta Grossa, (CVe $\cong 6,5 \%, \theta=1,3$ ). As estimativas para as duas populaçoes, dentro do mesmo local, foram similares.

\subsubsection{Analises Conjuntas}

Os resul tados relativos as análises conjuntas dos dois locais, Ponta Grossa e Rondonopolis, estão condensados na Tabela 14. Foram detectadas diferenças al tamente 
significativas para o efeito de progenies, nos tres caracteres avaliados.

Como esperado, o efeito de locais mostrou-se bastante pronunciado nas duas populaç̧es, para produção de grăos $(F \cong 200 * *)$, altura de planta $(F=50 * *)$ e altura de espiga $(F \cong 80 * *)$.

\subsubsection{Estimativas de variancia e coeficientes} de herdabil 1 dade

As estimativas de variancias geneticas e ambientais, bem como das herdabilidades ao nivel de medias de progenies, estão apresentados nas Tabelas 15,16 e 17 para os tres caracteres em estudo.

Para produção de grãos (g/pl), a populaçăo 1 , ESALQ PB-2 (C3) apresentou magnitudes de variancia entre progenies ( $\alpha_{p}^{2}$ ) superiores a populaçao 2, ESALQ PB-3 (Ca), tanto em ponta Grossa $\left(\hat{\sigma}_{P_{1}}^{2}=464,7 ; \hat{\sigma}_{P_{2}}^{2}=341,0\right)$ quanto em Rondonopolis $\left(\hat{\alpha}_{p_{1}}=111,4, \hat{\sigma}_{p_{2}}=71,3\right) \cdot$ os erros associados a tais estimativas, $s\left(\hat{\sigma}_{p_{1}}^{2} e s_{P_{2}}^{2} \hat{\sigma}^{2}\right.$, corresponderam a $13,4 \%$ e 14,5\% do valor de $\hat{\alpha}^{2}$, em Ponta Grossa, e $15,2 \%$ e $15,9 \%$, em Rondonopolis, indicando boa precisão das estimativas (Tabela 15).

As estimativas de variancias aditivas intrapopulacionais $\left(\alpha_{A_{1}}^{2}\right.$ e $\left.\alpha_{A_{2}}^{2}\right)$ e dos coeficientes de herdabilidade ao nivel de medias de progenies, $h^{2}, \bar{x}$, foram função das 
hipoteses assumidas para a relação $\sigma_{D}^{2} / \sigma_{A}^{2}$. Em geral, os valores de $\hat{\sigma}_{A}^{2}$ e $h^{2}, \bar{x}$, determinados em ponta Grossa foram superiores aos de Rondonópolis.

$$
\text { Considerando-se } H_{1}: \sigma_{D}^{2} / \alpha_{A}^{2}=1 \text { para produção }
$$
$(\mathrm{g} / \mathrm{p} 1)^{2}$, obtiveram-se as estimativas: $\hat{\sigma}_{A_{1}}^{2}=371$ e $\hat{\alpha}_{A_{2}}^{2}=$ 272 , para ponta Grossa, $e \hat{\sigma}_{A_{1}}^{2}=89$ e $\hat{\sigma}_{A_{2}}=57$, para Rondonópolis. Os coeficientes de herdabilidade foram da ordem de 60 e 50\% para Ponta Grossa e Rondonopolis (Tabela 17).

Assumindo-se as hipoteses $H_{2}: \alpha_{D}^{2} / \alpha_{A}^{2}=1 / 2, a s$ estimativas de variáncia aditiva $c_{A_{1}}^{2} e \sigma_{A_{2}}^{2}$ bem como dos coeficientes de herdabilidade ao nivel de médias tiveram maiores magnitudes, tanto em Ponta Grossa $\left\{\hat{\sigma}_{A_{1}^{2}}=413,1 ; \hat{\sigma}_{A_{2}}=\right.$ 303,$\left.1 ; h^{2}\left(\bar{x}_{1}\right)=67 \%, h^{2}\left(\bar{x}_{2}\right)=63 \%\right)$ quanto em fondonopolis $\left.\hat{\sigma}_{A_{1}}^{2}=99,0 ; \sigma_{A_{2}}^{2}=63,4, \mathrm{~h}_{\left(\bar{x}_{1}^{2}\right.}^{2}=60 \% ; \mathrm{h}_{\left(\bar{x}_{2}\right)}^{2}=57 \%\right)$.

Com relação ao carater altura de planta, as estimativas de $\alpha_{A}^{2}$ ná diferiram sensivelmente entre as duas popul aços (Tabela 16), havendo contudo tendencias de valores mais elevados para a populaçao 2 . As magnitudes de $\hat{\sigma}_{A_{1}}^{2} e \hat{\sigma}_{A_{2}}$ foram da ordem de $200 \mathrm{~cm}^{2}$, em ambos locais. 0 erro associado a tais estimativas foi sempre inferior a $15 \%$ de seu valor, o quociente entre a variancia ambiental dentro das parcelas ( $\sigma_{e d}^{2}$ ) e variancia ambiental entre parcelas ( $\sigma_{\theta}^{2}$ ) variou de 1,70 a 5,44, com media igual a 3,3 . us valores de $h^{2}(\bar{x})$ foram da ordem de $80 \%$, para ambas as populaçóes, nos dois locais de avaliaça o (Tabela 16). 
Para o carater altura de espiga, do mesmo modo que para produção de grăos, as estimativas de variancia aditiva $\left(\mathrm{cm}^{2}\right)$ mostraram-se influenciadas pelo efeito de locais (Tabela 17) obtendo-se: $\left(\hat{\sigma}_{A_{1}}=148,0 \mathrm{~cm}^{2}, \hat{\sigma}_{A_{2}}=176,8\right)$ e $\left.\hat{\sigma}_{A_{1}}^{2}=93,2 ; \hat{\sigma}_{A_{2}}^{2}=75,5\right)$ para Ponta Grossa e Rondonopolis, respectivamente. 0 valor do $5\left(\hat{\sigma}_{A}^{2}\right.$, correspondeu, em media, a $13 \%$ do valor da estimativa. A relaça o o $\sigma^{2} o_{0}^{2}$ oscilou de 1,45 a 3,70 com media 1 gua 1 a 2,56 .

Os coeficientes de herdabilidade ao nlvel de medias, para altura de espiga, foram semelhantes para as duas populaçßes, sendo da ordem de 80\%, en Ponta Grossa, e $70 \%$, em Rondonópolis (Tabela 17 ).

Na Tabela 18 encontram-se condensadas as estimativas dos parametros derivados da análise conjunta. Considerado o efeito de locais como fixo, as estimativas de variáncia aditiva encontram-se livre da interação com $10 \mathrm{cais}$.

Para produção de grăos $(g / p 1)^{2}$, as estimativas de o apresentam di erencas significativas entre as populaçBes 1 e 2 . Consid rando-se $\sigma_{0}^{2} / \sigma_{A}^{2}=1$, determinou-se: $\hat{\sigma}_{\hat{A}_{1}}^{2}=190,0$ e $\hat{\sigma}_{\hat{A}_{2}}^{2}=116,6$; assumindo-se $\sigma_{\mathrm{D}}^{2} / \sigma_{\mathrm{A}}^{2}=1 / 2$, obtevese: $\hat{\sigma}_{A_{1}}^{2}=211,1$ e $\hat{o}_{A_{2}}^{2}=19,5$. os erros associados as estimativas foram da ordem de 12 e $15 \%$, para as populaç̧es 1 e 2 , respectivamente. 
As magnitudes da variancia da interação entre progenies e locals $\left(\alpha_{\mathrm{pl}}^{2}\right)$ foram semelhantes entre as duas populaç̧es, onde: $\left.\hat{\sigma}_{(p l),}^{2}=63,4(g / p)\right)^{2}$ e $\hat{\sigma}_{(p l)}^{2}=64,1$ (g/pl $)^{2}$, equivalendo a 27 e $44 \%$ do valor de $\hat{\sigma}_{p 1}^{2}$ e $\hat{\sigma}_{p z}^{2}$, respectivamente (Tabela 18 ). Os coeficientes de herdabilidades ao nivel de medias de progenies mostraram-se superiores aos calculados individualmente por local, com valores em torno de $60 \%\left(H_{1}=\sigma_{D}^{2} / \sigma_{A}^{2}=1\right)$ e $70 \%\left(H_{2}=\sigma_{D}^{2} / \sigma_{A}^{2}=1 / 2\right)$.

Com respei to ao carater al tura de planta, as estimativas de $\alpha_{A}^{2}, e \sigma_{A_{2}}^{2}$, obtidas da ana lise conjunta foram de $231,5 \mathrm{~cm}^{2}$ e $243,2 \mathrm{~cm}^{2}$, respectivamente, superando os valores de $\alpha_{A}^{2}$ derivados das analises individuais, inflacionadas pela interacão com o ambiente (Tabela 18). Para este carater, a magnitude de $\hat{o}_{p l}^{2}$ foi baixa, sendo que $\left(\hat{a}_{p l}^{2}\right)=$ $8,07(\mathrm{~cm})^{2} \mathrm{e}\left(\hat{\sigma}_{\mathrm{pl}}^{2}\right)_{2}=9,78(\mathrm{~cm})^{2}$. Tais valores mostraram-se duas a tres vezes menores que os erros associados as estimativas de $\alpha_{A}^{2}$, onde: $5\left(\hat{\sigma}_{A}^{2}\right)=24,9(\mathrm{~cm})^{2}$ e $s\left(\hat{\sigma}_{A}^{2},\right)_{2}$ $24,8(\mathrm{~cm})^{2}$. os valores de $h^{2}(\bar{x})$ foram da ordem de $88 \%, 2$ em ambas popul açßes.

Para o carater altura de espiga, as estimativas de $\sigma_{A_{1}}^{2}$ obtidas da analise conjunta $\hat{\sigma}_{A_{1}}^{2}=131,0$ $\mathrm{cm}^{2}, \hat{\alpha}_{2}^{2}=104,7 \mathrm{~cm}^{2}$, mostraram-se intermediarias as estimativas derivadas das análises individuais. Os valores de $s\left(\sigma_{A}^{2}\right.$ ) corresponderam a $15 \% \hat{\sigma}_{A_{1}^{2}}^{2} 12 \% \hat{\sigma}_{A_{2}^{2}}$ (Tabela 18 ) A magnitude de $\alpha_{p l}^{2}$ foi pequena $\left.\hat{\sigma}_{(p l)}^{2}=5,8 \mathrm{~cm}^{2}, \hat{\sigma}_{(p l)}^{2}=9,0 \mathrm{~cm}^{2}\right)$ quando comparada variancia expressa entre progenies $\left(\sigma_{p}^{2},{ }^{2}\right.$ 


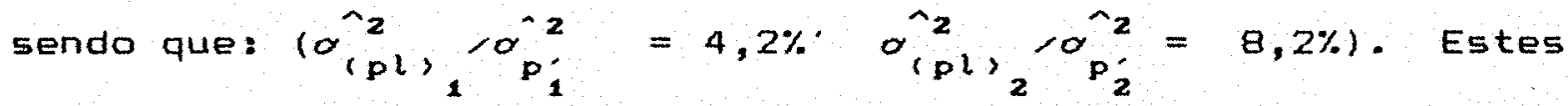
valores, contudo, foram superiores aos obtidos para o carater altura de planta, onde $\left(\sigma_{p l}^{2} / o_{p}^{2}, \cong 3,5 \%(\operatorname{Tabe} 1 a 18)\right.$. Ds coeficientes de herdabilidade para altura de espiga foram semeltiantes aos obtidos para altura de planta, com valores da ordem de $84 \%$ para as duas popu1 aç̧es.

4.1.6. Progressos esperados com a seleçăo

A Tabela 19 reúne estimativas de progressos esperados com a seleção, para o caráter produção de grăos. Săo apresentados os gantios diretos no próprio local de seleção e gantio medio com a seleção baseada na media dos $10 \mathrm{cais}$.

As estimativas de progresso com a seleção variaram de 7,8 a $11,5 \%$ da produção da populaçăo não endogamas (S ), em ambas populaģos, nos dois locais de ava1 iação. A populaçăo 1, entre as duas avaliadas, apresentou os maiores valores de progresso com a seleção. Os gantios mais elevados foram obtidos com esta população, en ponta Grossa, onde $G s=10,3 \%\left(H_{1}=\sigma_{D}^{2} / \sigma_{A}^{2}=1\right)$ e Gs $=11,5 \%\left(H_{2}\right)$ $\left.\sigma_{D}^{2} / \sigma_{A}^{2}=1 / 2\right)$. o gantio medio com a seleção praticada na media dos locais, para a populaçá 1, mostrou-se intermediário aos gantios diretos no proprio local de seleção. 
Para a população 2 , os maiores gantos percentuais foram determinados em Rondonópolis, com valores de 8,6 e $9,6 \%$, assumindo-se $\sigma_{D}^{2} / \alpha_{A}^{2}=1,0 e \alpha_{D}^{2} / \alpha_{A}^{2}=0,5$ respectivamente. Os progressos medios obtidos com a seleçăo praticada na media dos locais foram inferiores aos determinados diretamente no proprio local de seleça.

4.2. Resultados dos "Testcrosses" Reciprocos

\subsubsection{Valores Medias e Amplitudes dos Valores Observados}

As medias referentes ao conjunto de "testcrosses" 12 (ESALQ PB-2 (C2) $q$ × ESALQ PB-3 (C2) e "testcrosses" 21 (ESALQ PB-3 (C2) Q × ESALQ PB-2.(C2) sao apresEntados na Tabela 20 para os caracteres produção de grãos, altura de planta e altura de espiga e estão representados respectivamente por $T(12)$ e $T(21)$.

A produção media dos "testcrosses" foi de 141 g/pl para T(12) e $1549 / p^{\prime}$ para $T(21)$, correspondendo a cerca de $97 \%$ da produção da testemuntia C511. A media de $20 \%$ dos "testcrosses" mais produtivos $\left(\bar{Y}_{s}\right)$ superou em torno de $10 \%$ a produça do híbrido C511 com produçoes de 161 g/pl para $T(12)$ e 173 g/pl para $T(21)$. 
Para altura de planta os dois conjuntos de "testcrosses" apresentaram medias similares $\left(\bar{Y}_{(12)}=240 \mathrm{~cm}\right.$; $\left.\bar{\gamma}_{(21)}=246 \mathrm{~cm}\right)$, superando ao redor de $2 \%$ a media do hibrido C511. Este percentual foi acrescido quando comparada a media de $20 \%$ dos "testcrosses" mais produtivos ( $\bar{Y}_{s}$ ), com valores de 8,6 e $2,6 \%$ para $T(12)$ e T(21), respectivamente. Apesar desta tendencia, valores de alturas de planta semelhantes a media da testemunha podem ser detectadas entre os "testcrosses" mais produtivos Apendices A1 e A2). Considerando-se a interpopulaçăo (21) 5 entre 18 progenies superiores ( $\bar{Y}_{\mathrm{s}}$ ) apresentaram porte inferior ao hibrido C511.

Assim como para altura de planta, as medias de altura de espiga mostraram-se semel hantes entre os dois grupos de "testcrosses", com valores da ordem de $143 \mathrm{~cm}$, para $T(12)$, e $146 \mathrm{~cm}$ para $T(21)$, excedendo respectivamente, em 7,0 e $5,2 \%$ a media da testemuntia. A. altura de espiga do conjunto de "testcrosses" mais produtivos $\left(\bar{Y}_{5}\right)$ superou em 14,1 e $7,1 \%$ a media do hibrido c511, para $T(12)$ e $T(21)$, respectivamente, indicando maiores aumentos percentuais do que para altura de planta. Apesar desta tendencia, pode-se detectar entre os $20 \%$ "testcrosses" mais produtivos, tratamentos com altura de espiga e posiçao relativa da espiga na planta semelhantes a testemuntia (Apéndices A1 e A2). 


\subsubsection{Análises de Variáncia}

As Tabelas 21 e 22 apresentam os resultados obtidos das analises referentes aos experimentos 2.1 e 2.2 , contendo "testcrosses" (12) e (21), respectivamente. Em ambos os casos, apenas os efeitos de "testcrosses" e entre "testcrosses" pertencentes a grupo I (GI) mostraram diferenças altamente significativas nos tres caracteres em avaliaçå.

Considerando-se o experimento 2.1 , as magnitudes de QM para GI foram da ordem de 706,5 (g/pl $)^{2}$ para produçáo de gráos, $354,0 \mathrm{~cm}^{2}$ para al tura de planta e 223,1 $\mathrm{cm}^{2}$ para altura de espiga. Comparado a estes valores, estimativas dos componentes (QM dgII), estimado com apenas 7 graus de liberdade, acham-se discordantes, analisando-se suas esperanças de quadrados medios, com valores de 96,7 $(g / p 1)^{2}$, para produçao de grãos, $383,9 \mathrm{~cm}^{2}$ para altura de planta e $290,2 \mathrm{~cm}^{2}$ para altura de espiga. Com relaçao ao efeito de pares de progenies aparentadas (GII), as estimativas de aM para altura de planta $\left(\mathrm{cm}^{2}\right.$, e altura de espiga $\left(\mathrm{cm}^{2}\right)$ foram $408,04 \mathrm{~ns}$ e $338,99 \mathrm{~ns}$, respectivamente. Para produção $(g / p 1)^{2}$ o valor de $582,0 * *$ mostrou-se inferior ao apresentado para GI, ao contrário do esperado (Tabela 21 ). Quanto ao nI vel de significancia dos QM, note-se que em GII, o valor de $F$ influenciado pela magnitude de $Q M$ dGII (Tabela 21 ). 
Com respeito ao experimento 2.2 , envolvendo "testcrosses" (21), o efeito de progenies pertencentes ao grupo I (GI) apresentou magnitudes de QM da ordem de $643,2 * *$ para produçåo de grăos $(g / p 1)^{2}, 388,4$ para altura de planta $\left(\mathrm{cm}^{2}\right)$ e $251,5 * *$ para altura de espiga $(\mathrm{cm})^{2}$. os efeitos devidos a variação entre progenies dentro de grupos aparentados (dGI e dGIII) nao se mostraram significativos para os tres caracteres em questão. Com relação ao efeito GII, as magnitudes de QM foram de $1035,0 *$ para produçă $(g / p l a n t a s)^{2}, 536,6 *$ para altura de planta (cm) e 385,1 ns para altura de espiga (cm $)^{2}$. Comparadas as estimativas de aM GI, estes valores se mostraram coerentes com o esperado.

Os coeficientes de variação experimental, bem como os erros padróes da media, tiveram estimativas semeIhantes no experimento 2.1 (Tabelas 21 e 22 ). Obtiveram-se, na media, valores baixos de CVe para altura de planta (@ $6, \%)$ e para altura de espiga $(\cong 8, \%)$, e valores médios para produção de grãos ( $\cong 11 \%$ ). Os erros padróes da media, comparados a media experimental, foram da ordem de $4,0 \%$ para altura de planta, $5,70 \%$ para altura de espiga e 6,5\% para produçao de gráos (Tabelas 21 e 22 ), refletindo bons niveis de precisáo experimental em ambos os experimentos. 


\subsection{Estimativas}

A Tabela 23 reúne estimativas de variancia ditiva ao nivel interpopulacional $\hat{\sigma}_{\mathbf{A}_{12}^{2}}, \hat{\sigma}_{\mathbf{A}_{2}}$, estimativas de variancia genetica entre progenies, expressas no modelo hierarquico $\left(\hat{\sigma}_{p I}^{2}, \hat{\sigma}_{d p I X}, \hat{\sigma}_{p I I}^{2}\right)$, bem como da variancia do erro experimental $\left(\hat{\sigma}^{2}\right)$ para cada carater. Os valores de $\hat{o}_{\mathrm{pI}}^{2}$, $\hat{\sigma}_{d p I I}^{2}, \hat{\sigma}_{d p I I}^{2}, \hat{\sigma}_{p I I}^{2}$ foran derivados à partir de $\hat{\sigma}_{A}^{2}$ e $\hat{\sigma}_{A 2}^{2}$ (Tabelas 18 e 19).

Para produção de grãos, a magritude das estimativas de $\hat{\sigma}_{A}^{2} E \hat{\sigma}^{2}$ foi da ordem de $300(g / p l)^{2}$, onde: $\hat{\sigma}_{A_{12}^{2}}=292,7 e_{A_{21}}^{12} \hat{\sigma}^{21}=316,2$. o erros associados a $\hat{\sigma}_{A_{12}} e \hat{\sigma}_{A_{21}}$, correspondem a cerca de $30 \%$ de seu valor $\left[5 \hat{0}_{A_{12}}=91,7\right.$; $\left.5\left\{\hat{\sigma}_{A_{21}^{2}}^{2}=94,2\right\}\right\}$. Para as variancias geneticas expressas entre progenies, determinou-se: $\hat{\gamma}_{\mathrm{pI}}^{2}=109, \theta ; \hat{\sigma}_{\mathrm{dpII}}^{2}=36,6 ; \hat{\sigma}_{\mathrm{pII}}^{2}=$ $73,2)$ em $T(12)$ e $\left\{\hat{\sigma}_{\mathrm{pI}}^{2}=118,6 ; \hat{\sigma}_{\mathrm{dpII}}^{2}=39,5 ; \hat{\sigma}_{\mathrm{pII}}^{2}=79,1\right\} \mathrm{em}$ $T(21)$

Com relacão aos caracteres altura de planta $(\mathrm{cm} / \mathrm{pl})$ e altura de espiga $(\mathrm{cm} / \mathrm{pl})$, determinaram-se tendencias de maior variabilidade genetica entre "testcrosses" (21), quando comparados a populaçáo reciproca. Para altura de planta (cmipl) obteve-se: $\hat{\alpha}_{A_{12}^{2}}=211,0$ e $\hat{\sigma}_{A_{21}^{2}}=267,9$, com erros equivalentes a 25 e $21 \%$ de seus valores, respectivamente. As estimativas de variancia genetica entre pro\left. genties foram: ${\hat{\sigma_{F}^{2}}}_{\mathrm{F}}^{2}=79,1 ; \hat{\sigma}_{\mathrm{dFII}}^{2}=26,4 ; \hat{\sigma}_{\mathrm{pII}}^{2}=52,8\right), \mathrm{em}$ $\left.T(12), e \hat{\sigma}_{p I}^{2}=100,5 ; \hat{\sigma}_{d p I I}^{2}=33,5 ; \hat{\sigma}_{p I}^{2}=67,0\right)$ em $T(21)$. 
Para altura de espiga (cm), obteve-se: $\hat{\sigma}_{A_{12}}^{2}=124,1$ e $\hat{\alpha}^{\hat{A}_{21}}=162,9$ com erros da ordem de 28,8 e $23,8 \%$ de suas estimativas, respectivamente. Os valores de $\hat{\alpha}_{p I}^{2}, \hat{\alpha}_{d p I I}^{2}$ e $\hat{\alpha}_{p I I}^{2}$ foram, respectivamente: $(46,5 ; 15,5 ; 31,0)$ $c m^{2}$ para $T(12), e(61,7 ; 20,3 ; 40,7) \mathrm{cm}^{2}$, para $T(21)$.

Com relaça a estimativa da variancia residual $\left(\hat{a}^{2}\right)$, obteve-se: $299,1\left(g^{\prime p l}\right)^{2}$, para produça de grăos, $189,0 \mathrm{~cm}^{2}$ para altura de planta $\mathrm{e} 134,3 \mathrm{~cm}^{2}$ para altura de espiga, coom erros associados a estas estimativas iguais a $10 \%, 10 \%$ e $14 \%$ de seu valor, respectivamente (Tabela 23 ).

\subsection{Progressos Esperados com a Seleç̃o de Hibridos}

As estimativas de progresso com a seleça de hibridos simples ( (12) $_{(2)}$ ), hibridos triplos (HT ${ }_{12}$ e HT ${ }_{21}$ e

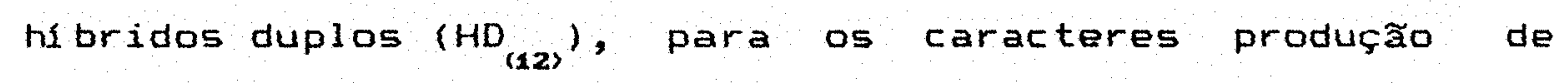
graos, altura de planta e altura de espiga, está apresentados nas Tabelas 24 e 25 supondo-se diferentes niveis de endogamia nas lintiagens.

Como esperado, para um mesmo nivel de endogamia dos parentais, as estimativas de progresso com a seleção sequiram a sequencia: Gs HS>GS HT > Gs HD. Dentro de um mesmo tipo de hibrido, maiores valores de Gs são esperados aumentando-se o ni vel de endogamia das lintagens. obtiveram-se, para os tres caracteres, estimativas de progressos semelhantes entre $H T_{12}$ e $H T_{21}$. 
Considerando-se o carater produção de grãos, as maiores estimativas de Gs são esperadas quando assumido o maior nivel de dominancia para o carater (h, $\sigma_{0}^{2}{ }_{(12)}^{2} \sigma_{(12)}^{2}$ 1), Tabela 24. Supondo-se esta hipotese, obtiveram-se como limites de Gs para hibridos de linhagens os valores de 40,3 Q/pl $(27,2 \%)$ a $17,0 \mathrm{~g} / \mathrm{pl}(11,5 \%)$ referentes, respectivamen-

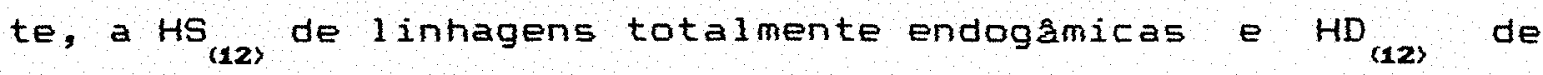
progenies $S_{2}$. Quando comparadas a testemuntia, C511, esperaSe produçós superiores em $24 \%$ para $H_{\text {(12) }}$ (So) e $8,8 \%$ para $H D_{(12)}\left(S_{2}\right)(T a b e 1 a 24)$.

o progresso esperado com a seleção de hibridos triplos (HT, eHT, $_{21}$ oscilou entre $23 \mathrm{~g} / \mathrm{pl}$ (16\%) a $30 \mathrm{~g} / \mathrm{pl}(20 \%)$, para progenies $S_{2}$ e lintagens totalmente endogamicas, respectivamente, refletindo uma superioridade de 13 a $18 \%$, sobre o het ido C511.

Apesar do crescente aumento na produção estimada dos hibridos, com o aumento na endogamia dos parentais, observa-se pela Tabela 26 que incrementos significativos foram obtidos ate a gerasá s s. Acrescimos na geraçao $S 00$ (F = 1 ) quando comparados a $S_{3}$ foram inferiores a $3,0 \%$ para todos os tipos de hibridos.

Com respeito aos caracteres altura de planta e altura de espiga, o progresso foi calculado visando-se a a redugão nos valores medios destes caracteres nos híbridos selecionados. Comparados a producão de grãos, ambos os caracteres apresentaram maiores amplitudes de variaçáo. 
Para altura de planta estimaram-se reduçôs variando de $13,4 \mathrm{~cm}(5,5 \%)$ para $H D_{(12)}\left(S_{2}\right)$ a 27,1 en $(11,1 \%)$, para $H S_{\text {(12) }} S_{\text {low }}$ correspondendo a $96,2 \%$ e $90,5 \%$ da m edia do padrão C511 (Tabela 25). As estimativas de Gs para HT 12 e $H_{21}$ oscilaram de $17,5 \mathrm{~cm}(7,2 \%)$ a $22,3 \mathrm{~cm}(9,2 \%)$, considerando-se 1 inhagens $\mathrm{S}_{2}$ e $\mathrm{S}_{\mathrm{O}^{3}}$ respectivamente.

Para o carater altura de espiga, os extremos estimados de Gs foram de $10 \mathrm{~cm}(6,9 \%)$ e $20,6 \mathrm{~cm}(14,2 \%)$, para $H D_{(12)}\left(S_{2}\right)$ e HS $(12)\left(S_{\infty}\right)$ respectivamente. As reduçoes esperadas com a seleçao de HT 12 e HT 21 variaram de $13 \mathrm{~cm}(9,1 \%)$ a $17 \mathrm{~cm}(11,8 \%)$ comparado ao híbrido intervarietal, correspondendo a $96 \%$ e $94 \%$ da media obtida para a testemuntia C511 (Tabela 25).

4. 2.5. Distribui ção Esperada de Hi bridos e "Testcrosses"

As distribuiçoses esperadas de "testcrosses" $\left(S_{2}\right), H S_{(12)} T_{12}$ e HD ${ }_{(12)}$, obtidos de linhagens totalmente endogamicas, săo apresentadas para os caracteres produção de grãos (Figura 8 e Figura 9 ), altura de planta (Figura 10) e altura de espiga (Figura 11 ).

$$
\text { Assumida } H_{1}=\left(\sigma_{D}^{2},\left(\alpha_{A 2}^{2}, A_{(12}\right)=1\right. \text {, as produços }
$$
maximas esperadas sao de $193 \mathrm{~g} / \mathrm{pl}, 202 \mathrm{~g} / \mathrm{pl}, 214 \mathrm{~g} / \mathrm{pl}$ e 228 g/pl para "testcrosses" $S_{2}, H D_{12}, H T_{12}, H S_{12}$, , supe- 
rando, respectivamente em $27 \%, 33 \%, 41 \%$ e $50 \%$ a produtividade da testemuntia c511.

Para altura de planta (cm), as estimativas encontram-se entre os limites: (206 e 280 ) para "tescrosses" $\left(S_{2}\right),(201$ e 285$)$ para HD (12) (194 e 292) para HT, e (18) e 299) para HS (12), equivalendo, neste caso, a 78 e $125 \%$ da al tura media do hibrido Csi1.

Com relação a al tura de espiga, (cm), estimaram-se valores de 115 a 175 para "tescrosses" (S, 112 a 178 para $H D_{(12)}, 106$ a 186 para $H T_{12}$ e 101 a 189 para HS $_{\text {(12) }}$ correspondendo, neste caso, a 74 e $139 \%$ da media de al tura de espiga da testemuntia Csil. 


\section{DISCUSSÃO}

\subsection{Progenies $S_{1}$}

\subsubsection{Valores Medios e Distribuiç̧es Observadas}

A analise do melhoramento "per se" de lintagens endogámicas, produzidas em programas de seleção recorrente, e um dos pontos importantes a ser considerado na integração de tais programas com o mel horamento para produção de hótidos. Consideraçoes de natureza teorica ( HALLAUER, 1980, HALLALER \& MIRANDA FILHO, 1988), e resu1tados praticos (HALLAUER et ali1, 1988) tem revelado que a seleção recorrente com progénies endogámicas apresenta-se como eficiente metodologia promotora de ganhos geneticos nas lintagens, reduzindo sua depressão por endogamia.

Os valores de depressão media por endogamia determinados para as duas populaçoes em estudo, ESALQ PB-2 (C) e ESALQ PB-3 (C3) encontram-se proximos a média obtida por LIMA et alis (1984), avaliando 32 populaçoes brasileiras. Entretanto, comparadas a ciclos anteriores de seleção, avaliados por MARQUES (1988), as populaç̧es em estudo 
revelam reduçăo na depressão media por endogamia para produફăo de grăos (Tabela 27).

No trabal ho de MARQUES (1988), progenies $\mathrm{s}_{1}$ das populaçßes ESALQ PB-2 e ESALQ PB-3 apresentaram acentuada carga genetica, mesmo após un ciclo de seleçao recorrente com progenies endogamicas. Segundo o autor, as populaçBes deveriam apresentar muitos locos dominantes em heterozigose e a carga genetica presente na populaçăo năo deveria ter sido suficientemente eliminada com apenas um ciclo de seleçăo. o autor observou, entretanto, tendencia de acrescimos no valor medio das fami lias endogamicas com o decorrer dos tres ciclos de seleção com endogamia. A utilização de progenies $S_{2}$ no terceiro ciclo de seleção pode ter contribul do para a reduça significativa da carga genética populacional, refletindo em aumento de vigor nas progenies do quarto ciclo de seleção, avaliadas no preșente estudo.

As progenies 5 mais vigorosas da populaçao ESALQ PB-2 (Ca) apresentaram produçסes similares a sua população năo endógama, sendo que, para a população ESALQ PB-3 (Ca), as melhores progenies se mostraram inferiores em apenas $13 \%$ (Figura 2 e Figura 5 ). Tais produçBes encontram-se relativamente superiores as obtidas por MARQUES (1988) avaliando o segundo ciclo de seleção en ESALQ PB-2 e ESALQ PB-3, onde as melhores progenies $S_{1}$ produziram em media $18 \%$ abaixo das populaçoes não endogamas (Tabela 27 . Estes resultados poderiam ser esperados, haja visto a eliminaça de 


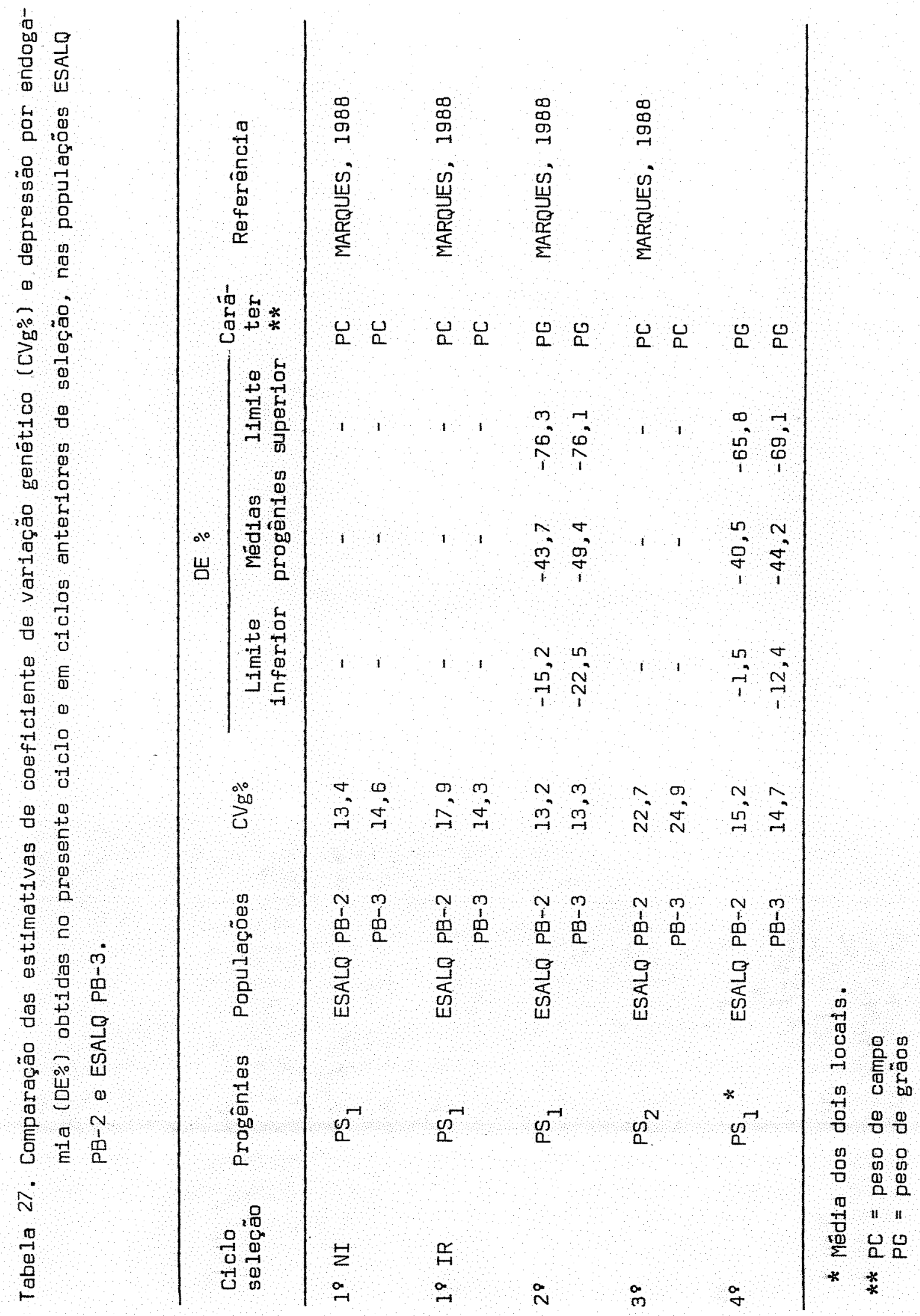


alelos letais e/ou deleterios, associada ao aumento na fre quência de alelos favoráveis na populaçăo via seleçă com progenies endogámicas (HALLAUER, 1980). Deve-se salientar que os valores de depressao por endogamia apresentados nos histogramas (Figuras 2 a 7 ) referem-se ao desvio percentual das progenies $S_{1}$ en relaçăo a media da população $S_{0}$ e nåo a valor da planta $S_{0}$ da qual a progenie foi extralda.

Um aspecto interessante observado para o carater produçăo de grăos foi a maior depressão media por endogamia detectada no local 2, Rondonopolis, em ambas populaçoes (Tabela 12). Comparado a Ponta Grossa, Rondonopolis se caracteriza por apresentar solos menos féteis, temperaturas diurnas e noturnas mais elevadas, sendo tambem afetada por chuvas na colheita. Espera-se, assim, que os maiores valores de depressá por endogamia detectados em Rondonopois se devam a dois fatores: maior potencial de resposta a condiços favoraveis das populaçós $S_{0}$ do que de suas progenies 5 , em Ponta Grossa; maior sensibilidade a condiçoes de estresse ambiental das progenies endogamicas, em Rondonopolis. Nos dois locais, entretanto, ESALQ PB-3 (C3) mostrou-se mais senslvel ao efeito da endogamia do que ESALQ PB-2 (Ca), para produça de grãos (Tabe la 12 ).

Respostas diferenciadas de depressao media por endogamia, em função do ambiente de avaliaçăo tem sido reportadas na literatura, principalmente para caracteres de baixa herdabilidade. LIMA et ali i (1984) determinaram que a 
interação entre os efeitos de endogamia e locais foi altamente significativa para o caráter produção de grãos, apresentando ausencia de significancia para altura de planta e altura de espiga.

No presente estudo, o efeito da endogamia sobre a media dos caracteres altura de planta e altura de espiga mostrou-se aproximadamente constante, para as duas populaçres e os dois locais de avaliação (Tabela 12), variando de $7 \%$ a $9 \%$ para altura de planta e de $7 \%$ a $10 \%$ para altura de espiga. Estes valores encontram-se abai $\times$ o das medias observadas en populaçoes brasileiras, conforme apresentado por LIMA et alii (1984), onde as depressaes medias de 32 populaçóes foram de $14 \%$ para altura de planta e $15,4 \%$ para al tura de espiga.

Ds decrescimos medios da ordem de $0,35 \mathrm{~cm}$ para altura de planta e $0,20 \mathrm{~cm}$ para altura de espiga, decorrentes do acrescimo de $1 \%$ na endogamia populacional, aproximam-se dos 1 imites inferiores de depressão por endogamia reportados por HALLAUER \& MIRANDA FILHO (1988), referente a diversas populaç̧es norte-americanas. Para produção de grãos, entretanta, as reduç̧es da ordem de $1,35 \mathrm{~g} / \mathrm{pl}$, determinadas no presente estudo (Tabela 12), encontram-se acima da media de 1,20 g/pl apresentado pelos mesmos autores.

As diferengas nos valores de depressão por endogamia percentual (DE\%), quando comparados os tres caracteres (Tabela 12), são explicados pela natureza diversa 
de cada carater; os maiores valores de DE (\%) obtidos para produção de grăos, do que para altura de planta e altura de espiga, se devem ao elevado grau de dominancia que possui este carater (HALLAUER \& MIRANDA FILHO, 1988).

Sabe-se que a perda de vigor resultante do aumento da endogamia funça do dois fatores: redução da heterozigosidade en locos que apresentem dominancia genica (FALCONER, 1960), exposição de alelos recessivos desfavoraveis presentes na condição heterozigótica no conjunto genico da popUlaçăo (JENKINS, 1936, STEBBINS, 1957). Maiores depressbes, assim, devem ser esperadas: em caracteres controlados por maior número de fatores dominantes, em populaçós com elevada frequencia de heterozigotos em locos com dominancia genica, e en populaçós que apresentem acentuada carga genetica (FALCONER, 1960 ).

Alem da reduzida depressão media por endogamia, aspectos interessantes são detectados para os caracteres altura de planta e altura de espiga, analisando-se as distribuiçós observadas das progenies $S_{1}$ (Figuras $3,4,6$ e 7) e os limites inferiores de depressao para ambas populaçaes (Tabela 12). As progenies S, com maior media superaram em $13 \%$ e $17 \%$ os valores de altura de planta e altura de espiga das populaç̧es nao endógamas, obtendo-se assim valores positivos do desvio percentual de cada progenie em relação a media da população não endógama ( $\left.S_{1}-\bar{S}_{0}\right) / \bar{S}_{0}$, f Tabela 12 e Figuras $3,4,6$ e 7 ). Tais 
tendencias, observadas nas duas populaç̧es, apresentaram-se da mesma magnitude para os dois locais de avaliação.

A presença de valores positivos para o desvio $\left(S_{1}-\bar{S}_{0}\right) / \bar{S}_{0}$ nas progenies mais vigorosas pode ser explicada pela associação de dois fatores: valores superiores a media populacional, para algumas plantas $S_{0}$ das quais se extrafram as progenies; segregação de plantas não endogamas heterozigotas ( $\left.S_{0}\right)$, resultando em progenies $S_{1}$ que concentrem fatores dominantes positivos para a expressão do carater. Esta segunda hipotese e mais viável de ser aplicada em caracteres com baixo grau de dominancia, como altura de planta e altura de espiga, por exemplo, quando avaliados um número muito restrito de plantas $S_{1}$ por planta $S_{0}$ original. De fato, considerando-se um carater sem dominancia em uma população com ausencia total de gens letais elou deleterios, a media esperada em progenes $S_{1}$ e igual à media populacional (S, e, sob uma distribuif̧a tebrica simetrica, $50 \%$ das progenies $S_{1}$ seriam superiores a media populacional.

As estimativas da contribuifăo dos homozigotos $(\mu+a)$, dos locos heterozigotos (d) e da relaçao $(\mu+a) / d$, apresentados na Tabela 12 confirmam a natureza predominantemente aditiva dos caracteres altura de planta e a tura de espiga, e contribuição não aditiva maior para o carater produção de grãos. Para este caráter, as estimativas obtidas de d foram de 3 a 10 vezes superiores aos valores encontrados de $(\mu+a)$ (Tabela 12). Os valores medios da 
relação $(\mu+a) / d$, iguais a 0,25 para ESALQ PB-2 (Ca) e 0,19 para ESALQ PB-3 (C3) foram inferiores a estimativa de 0,28 obtida por LIMA et alii $(1984)$, como media de 32 populaçzes brasileiras; para Ponta Grossa, entretanto, obtiveram-se valores iguais a 0,35 e 0,29 para ESALQ PB-2 e ESALQ PB-3, respectivamente.

Para o componente $(\mu+$ a) as estimativas de $36(g / p 1)$ e $29(g / p 1)$, encontrados para ESALQ PB-2 e ESALQ PB, respectivamente, superam o valor medio de 22,4 (g/p1) ou 1,12 t/ha, reportado por LIMA et ali1., 1984. Resultados recentes de NASS (1992), demonstraram valores medios de $(\mu+a)$ iguais a 6,5 g g/pl, e de ( $\mu$ + a)/d inferiores a 0,10 , em duas populaçoes semi-exoticas de milho, confirmando seu baixo grau de mel horamento.

Comparando-se os caracteres altura de planta e altura de espiga, as estimativas de ( $\mu,+$ a), fornecidas pela Tabela 12, superaram os valores medios obtidos por LIMA et a 11 i (1984) e NASS (1992). As maiores diferengas, entretanto, foram obtidas para a relaçăo $(\mu+$ a $) / d$ com as presentes estimativas superando em cerca de $90 \%$ as medias encontradas por LIMA et ali i (1984).

Considerando-se que os valores de $(\mu+$ a) estimam a comportamento médio de linhagens totalmente endogamicas (GARDNER, 1965), espera-se que, nas populaçBes em estudo, obtentiam-se linhagens com bom vigor, com elevados valores de altura de planta e produtividade. Não devem, 
entretanto, ser observados acrescimos no porte das populaçós não endógamas, devido a pequena influencia de locos heterozigotos, $(\mu+a) / d$, sobre a media do carater.

Os elevados valores de $(\mu+a)$ encontrados em ambas as populaçóes, associada a reduzida depressão por endogamia no presente ciclo de seleçăo, demonstram a eficiencia do metodo de seleção recorrente com progenies : endogâmicas em promover a obtenção de linhagens menos depressivas, confirmando supasiçoes teoricas (HALLAUER \& MIRANDA FILHO, 1988 ) e resultados de natureza pratica descritos na 1 iteratura (GENTER \& ALEXANDER, 1966, BURTON et a 1 il, 1971, WEST et a1ii, 1980, ODHIAMBO \& COMPTON, 1989, entre outros). Conforme ja discutido, a obtenção de linhagens vigorosas é de fundamental importancia em programas de melhoramento pois permite que a exploração da heterose não seja restringida pela inviabilidade de produção da semente hrorida.

\subsubsection{Parametros Genetico-Estatisticos}

Os resultados obtidos nas análises agrupadas por local revelam a presença de significativa variabilidade genstica entre progênies $S_{1}$ para as duas populaçós e para os trés caracteres avaliados (Tabelas 15,16 e 17). As diferenças al tamente significativas detectadas entre ambientes, pelas analises conjuntas (Tabela 14 ) corroboram as expecta- 
tivas iniciais de que Ponta Grossa e Rondonopolis deveriam ser tratados como ambientes contrastantes.

Como esperado, dentre os caracteres avaliados, produção de grăos foi o que se apresentou mais sensivel aos efeitos ambientais. Considerando que os valores medios de produçao obtidos em Ponta Grossa foram cerca de duas vezes superiores aos de Rondonópolis (Tabela 11), diferengas da ordem de quatro vezes deveriam ser esperadas para a magnitude da variancia entre progenies $\left(\sigma_{p}^{2}\right)$, conforme modelo multiplicativoapresentado por CHAVES (1982), para a relação entre a media e a variáncia. os resultados apresentados na Tabela 18 confirmam estas expectativas.

A influencia da media sobre a magnitude da variabilidade genetica torna relativamente dificil a comparação direta das estimativas de variancia obtidas sob diferentes condiços ambientais, mostrando-se mais adequada a utilização do coeficiente de variação genetica (CVg\%) para fins comparativos, quando avaliado a mesmo tipo de progenie. Desta forma, as estimativas de CVg\% obtidas para peso de grãos para as duas popul açÖEs ESALQ PB-2 (Cs) e ESALQ PB-3 (C9), em ambos os locais, mostram-se levemente superiores as estimativas determinadas por MARQUES (1988) nos dois primeiros ciclos de selecão con progenies $S_{1}$ (Tabela 27 ), demonstrando a manutenção da variabilidade genetica com o decorrer dos ciclos de seleção. 
o risco de reduçao na variabilidade durante programas de seleção recorrente deve-se fundamentalmente ao reduzido tamantio efetivo mantido en alquns programas, aumentando sua probabilidade de fixação alelica (HALLAUER, 1984). Para as populaçós ESALQ PB-2 e ESALQ PB-3 tem-se mantido tamantios efetivos da ordem de 30 a 50 durante os ciclos de seleção, superando o limite minimo de $N e=30$, proposto por BAKER \& CURNOW (1969) E RAWL INGS (1970).

As estimativas de variancia aditiva, $\alpha^{2}$, e do coeficiente de herdabilidade ao nivel de medias, h $\frac{2}{x}$ (Tabelas 15, 16, 17) foram obtidas formulando-se hipoteses para a relaçå $\sigma_{A}^{2} / \sigma_{D}^{2}$, variando para cada carater en função dos resultados descritos na literatura (HALLAUER \& MIRANDA FI-, LHO, 1989 ). Considerando-se iqualdade de frequencia alelica nas duas populaçaes $(p=q=0,5)$, a variabilidade genetica entre progenies endogamicas restringe-se a seu componente aditivo $\left(\sigma_{A}^{2}\right)$ e dominante $\left(\sigma_{D}^{2}\right)$, sendo que os componente $D_{1}$ e $D_{2}$, definidos por COCKERHAM (1983) igualam-se a zero. Esta condiça especl fica de frequencias genicas, entretanto, limita-se a geraçao $F_{2}$ de um cruzamento. Segundo COCKERHAM (1983) a variancia genetica entre progenies $S_{1} e$ expressa como:

$$
\sigma_{g}^{2}=\sigma_{A}^{2}+\frac{1}{4} \sigma_{D}^{2}+D_{1}+\frac{1}{\theta} D_{2}
$$


Resultados recentes da literatura tem demonstrado que as estimativas de $\mathrm{D}_{1}$ e $\mathrm{D}_{2}$ não devem ser desprezadas (COORS, 1988; NASS, 1992), sugerindo que boa parte do insucesso obtido em alguns programas de seleção com progénies endogámicas se deva a elevada e negativa magnitude do componente $D_{1}$.

Apesar de não considerados os componentes $D_{1}$ e $D_{2}$, as estimativas de variancia genetica aditiva obtidas nos locais individualmente (Tabela 15,16 e 17) e nas análises conjuntas (Tabela 18 ) fornecem uma idéla do nivel de variabilidade genetica exploravel na seleção e presente em ambas populaçós. os resultados da Tabela 15 , indicando maior variabilidade genetica na populaçă ESALQ PB-2 do que em ESALQ PB-3, para produção de grãos, não concordam com aqueles obtidos em MARQUES (1988) em ciclos anteriores de seleção, nas mesmas populaçBes. No presente estudo, entretanto, a estimativa de variancia aditiva para a população ESALQ PB-2 SUPETOU em $40 \%$ a obtida para ESALQ PB-3, refletindo assim em maiores coeficientes de herdabilidade ao ni vel de medias para a primeira popul ação.

Para altura de planta e altura de espiga, entretanto, as similares magnitudes de variancia aditiva $\left(\sigma_{A}^{2}\right)$ e variáncia fenotipica $\left(\sigma_{f e}^{2}\right)$, determinadas nas duas populaçós refletiram em semelhantes estimativas de coeficiente de herdabilidade ao nivel de medias (Tabelas 16,17 e 18). 
As estimativas de progresso esperado com a seleça, situadas ao redor de $9 \%$ e $11 \%$, para as hipoteses $\sigma_{D}^{2} / \sigma_{A}^{2}=1$ e $\sigma_{D}^{2} / \sigma_{A}^{2}=0,5$, respectivamente, apresentam-se bastante elevadas, superando significativamente os valores de $2 \%$ a $4 \%$ normalmente observados a cada ciclo de seleção recorrente (PATERNIANI \& MIRANDA FILHO, 1987). RESU1tadOS discrepantes entre as estimativas esperadas e os progressos observados tem sido reportados na literatura para o mel horamento das populaçzes "per se", em programas de seleção recorrente com progenies endogamicas (HORNER et alii, 1973; VALOIS, 1982, TANNER \& SMITH, 1987, entre outros). AO eventual insucesso da seleça recorrente com progenies endogamicas atribuem-se tres fatores: o aumento na probabilidade de fixação genica dado ao baixo tamantio efetivo; a posslvel presença de ação genica sobredominante em alguns locos, e a magnitude e sinal do componente $D_{1}$ (HALLAUER, 1984, HALLAUER \& MIRANDA FILHO, 1988, HALLAUER Et a11i, 1988, SOUZA JR, , 19891.

Apesar da pequena probabilidade de fixaçăo genica gerada por reduzido tamantio efetivo nas populaçoes em estudo, conforme já discutido, a determinação da estimativa de D, faz-se necessaria para uma predicá mais segura da performance destas populaçás após o quarto ciclo de seleção recorrente com progenies endogamicas. 
5. 2. Analise dos "Testcrosses" Reciprocos

\section{2. 1. Valores Médios e Distribuiçăo Observadas}

Conforme apresentado na Tabela 20 a media dos conjuntos de "testcrosses" (12) e (21) derivadas das populaşos ESALQ PB-2 (C2) E ESALQ PB-3 (C2) mostram-se similares para os tres caracteres avaliados. Este valor poderia ser esperado, haja visto a pequena influencia do efeito maternal e(ou) herança extracromossômica controlando os caracteres produçăo de grãos, altura de planta e altura de espiga (HALLAUER \& MIRANDA FILHO, 1988).

Considerando que a amostragem dos "testcrosses" foi realizada de maneira aleatória, espera-se que a performance media de todos os cruzamentos avaliados represente a media do hibrido interpopulacional ESALQ PB-2 (C2) $\times$ ESALQ PB-3 (C2) e consequentemente dos hibridos simples, triplos e duplos derivados de ambas as populaçós (COCKERHAM, 1961). Os valores similares de produção obtidos para o hibrido interpopulacional ESALQ PB-2 (C2) $\times$ ESALQ $\mathrm{PB}-3$ ( $\mathrm{C} 2$ ) a a testemunta, o híbrido Csi1 (Tabela 20 ) demonstram o potencial das popul açós ESALQ PB-2 (C2) e ESALQ PB-3 (C2) para utilização em programas de obtenção de hibridos e(ou) de seleção recorrente reciproca.

SEgundo SWANTARADON \& EBERHART (1974), duas popul açoes poderiam ser importantes fontes de desenvolvimento de novos hibridos quando a cruzamento entre elas 
apresentar pelo menos $90 \%$ da produçăo dos melhores híbridos comerciais. Os autores afirmam que a produça esperada do melhor hibrido entre duas populaçós deve superar de 18 a $25 \%$ o valor obtido para o cruzamento interpopulacional.

Uma analise de $20 \%$ dos "testerosses" mais produtivos revelou um comportamento medio superando em cerca de $10 \%$ a media do hlbrido C511 (Tabela 20), sendo que o "testcross" mais produtivo excedeu em $22 \%$ a produçăo da testemunha (Apendice 2). Apesar da tendencia de aumento dos valores de altura de planta e altura de espiga dos genstipos superiores quando comparada a media de todos os "testcrosses" (Tabela 20), e possivel se detectar materiais com porte reduzido mesmo dentro do conjunto dos $20 \%$ superiores (Apendices 1 e 2). Espera-se, assim, que a seleçao das linhagens parentais, conduza a obtençă de híbridos simples, triplos e duplos de alta produtividade sem, contudo, implicar em restriçbes quanto ao porte da planta.

Ao lado da performance da combinação interpopulacional, a presença de heterose no cruzamento e uma importante informaça indicativa do potencial de duas populaçoes para o desenvolvimento de hi bridos (MIRANDA FILHO \& VIEGAS, 1987). Conforme apresentado por FALCONER (1960) a magnitude da heterose em relação a media dos pais e função da divergencia genetica entre os pais e do nivel de dominancia do carater, de modo que:

$$
n=\sum_{i}\left(P_{i}-r\right)^{2}, d
$$


onde: $\underline{f} f$ a heterose em relação à media dos parentais; e $10 c 0$; d e o efeito de dominancia genica em cada $10<0$.

Apesar do presente estudo năo fornecer estimativas da magnitude da heterose do cruzamento ESALQ PB-2 (C2) $\times$ ESALQ PB-3 (C2), evidências indiretas da presença de heterose em relação ao pal superior sã observadas, haja visto a similar media de produça do híbrido interpopulacional e do hibrido comercial C511 (Tabela 20), ao lado da superior produçăo obtida por esta testemuntia quando comparada a população ESALQ PB-2 (C3) e ESALQ PB-3 (C3) no Ciclo sequinte de seleção (Tabela 11 ).

Alem da performance média e da presença de heterose no cruzamento interpopulacional, as magnitudes das variancias geneticas a ele associadas tambem devem ser analisadas. nem sempre do melhor hibrido interpopulacional derivarão os melhores hibridos simples, triplos e duplos, sendo a performance destes função conjunta da média do hibrido interpopulaciona 1 e da magnitude dos componentes da varianeia entre nibridos (MIRANDA Fo \& VIEGAS, 1987; VENCOUSKY et a 1ii, 1987; SOUZA Jr., 1989). As estimativas dos componentes $o_{12}^{2}, \alpha_{21}^{2} e_{D_{112}}^{2}$ para a interpopul açá en estudo, bem como suas implicaçóes em um programa de híbridos serão discutidas no item 5.2 .5 . 
5.2. 2. Partição da variabilidade genética

A avaliação de "testcrosses" de progenies $\mathrm{S}_{2}$ ou $S_{3}$ obtidas no metodo genealogico, tem sido uma metodologia amplamente utilizada para avaliação da capacidade de combinaçăo en programas de desenvolvimento de linhagens de milho. A estimação dos componentes de variancia envolvidos neste tipo de progenie devem, entretanto, considerar a estrutura de famlias, intrinseca ao metodo genealogico.

Os esquemas de analise de variancia aqui Utilizados basearam-se no modelo original de COCKERHAM (1963) para estimaça dos componentes de variaça genetica entre individuos aparentados e nao aparentados, em avançadas geraçBes de autofecundação. As adaptaç̧es apresentadas nas Tabelas 8 e 9 permitem assim, que se estime a variancia aditiva ao nivel interpopulacional, considerando-se os diferentes graus de parentesco entre as progenies "testcross". Para outros estudos, a utilizaçăo direta deste esquema, ben como dos conteúdos de variancia genetica entre progenies, 56 pode ser extrapolada quando avaliados ltestcrosses" obtidos de progenies $S_{2}$. Conforme apresentado no item 3.2 .3 , a variabilidade entre "testcrosses" pode ser assim representada: 
$o_{p x}^{2}$ : variancia genetica entre "testcrosses" pertencentes ao grupo dos nao aparentados, onde $\sigma_{p I}^{2}=3 / 8 \sigma_{A}^{2}$

$\sigma_{\text {pap }}^{2}$ : variancia genetica entre grupos "testcrosses" aparentados, onde $\sigma_{\text {Pap }}^{2}=1 / 4 \sigma_{A}^{2}$

$\sigma_{d p}^{2}$ : variancia genetica entre "testcrosses" aparentados, derivados da mesma planta $S_{0}$, onde $o_{d p}^{2}=1 / 8$ $\alpha^{2}$

A utilizaçå de todas estas estimativas para se determinar $\hat{o}_{A}^{2}$ em un sistema matricial, depende da propria estimativa de cada quadrado medio, a qual pode apresentar-se distorcida em funça de baixo numero de graus de liberdade da referida fonte de variação rKEMPTHORNE, 1957). Apesar do metodo dos quadrados minimos ponderados conduzir a uma homogeneizaça dos erros associados a as quadrados medios (OBILANA, 1977), o fator de ponderação de cada quadrado medio é influenciado pela propria estimativa do quadrado medio. Sendo assim, estimativas distoreidas promoverăo tambem uma ponderaçå distorcida de cada quadrado medio

Do ponto de vista pratico, deve-se assim evitar a utilização de estimativas de quadrados medios com baixos graus de liberdade. Desta forma, foram rejeitados os componentes entre grupos de tres "testcrosses" aparentados $\sigma_{\text {prrx }}^{2}$. assim como os quadrados medios entre "testcrosses" 
aparentados $\left(\alpha_{d p}^{2}\right)$, devido ao efeito da seleçăo praticada por ocasião de sua obtenção.

\subsection{Estimativas de Parametros Genetico- Estatisticos}

As significativas estimativas de quadrado medio para os dois conjuntos de "testcrosses" (12) e (21), bem como entre "testcrosses" pertencentes ao grupo I (Figura 1) indicam a presença de variabilidade genetica interpopulacional para os tres caracteres avaliados (Tabelas 21 e 22).

Entretanto, a baixa significancia das estimativas de quadrado medio entre grupos de "testcrosses" aparentados (QM gix $e$ QM girx pode ser explicada por dois fatores: pequena amostragem de "testcrosses" pertencentes a estes grupos; e a menor variabilidade genetica presente dentro de grupos de aparentados, uma vez que $\sigma_{d p}^{2}=1 / 8$ $\alpha^{2}$

As estimativas de variancia aditiva interpopulacionass, $\hat{\sigma}_{A_{12}}^{2} e_{A_{21}}^{\hat{\sigma}_{2}}$, de magnitude da ordem de 300 (g/p1) (Tabela 23), superaram os valores apresentados por VENCOUSKY et alil (1988) para medias de sete interpopulaşes brasileiras, mostrando-se inferiores as estimativas de PELLICCANO (1990) para peso de espigas em BR106 x BR105. Entretanto, quando comparados os coeficientes de variação aditivo ( $V_{A}$ ), onde elimina-se o efeito da media sobre a variancia, 
as estimativas interpopulacionais para ESALQ PB-2 (C2) $\times$ ESALQ PB-3 (Cz) mostram-se similares aos valores médios obtidos pelos autores acima, com estimativas da ordem de 0,11

os valores aproximados de $\hat{\sigma}_{A_{12}}$ e $\hat{o}_{A_{21}^{2}}$, obtidos quandoutilizadas as populaçóes 2 e 1 como testadoras, respectivamente, refletem o grau de melhoramento similar em que se encontram as duas populaçós. Pela teoria de testadores (RAWLINGS \& THOMPSON, 1962; ALLISON \& CURNOW, $1966)$ espera-se que testadores menos produtivos, ou com menor frequencia de alelos favoraveis em locos com domináncia gênica discriminem melhor as progênies da população reciproca aumentando a variabilidade entre seus "testcrosses", definida como sendo:

$$
\begin{aligned}
& \sigma^{2}= \frac{1}{2} p(1-p)(1+F)[a+(1-2 r) . d]^{2} \\
& \text { (HALLAUER \& MIRANDA FILHO, 1988) }
\end{aligned}
$$

onde $p$ e r referem-se a frequencia de alelos favoraveis na populacăo base e no testador, respectivamente.

Em geral, resultados de literatura tem revelado grandes diferenças de magnitude nas estimativas de $a^{2}{ }_{12}$ $\sigma_{A_{21}}^{2}$ em outros pares de populaçoes (MIRANDA FILHO \& PATERNIANI, 1983; SOUZA Jr, 1983; MARTINS, 1986), o que pode apresentar-se como fator limitante para uma maior exploração 
da variancia genetica en programas de hibridos triplos (SOUZA Jr., 1987).

Com relaçåo ao carater altura de planta, a estimativa de variancia aditiva interpopulacional $\left(\sigma_{A}^{2},{ }_{12}\right)$ da ordem de $240 \mathrm{~cm}^{2}$ aproxima-se do valor encontrado por SQUZA Jr. (1983) para ESALQ PB-1 × BR 105, superando em carca de tres vezes a estimativa obtida por PELLICANO (1990) para a interpopulaçá BR105 x BR106. Para altura de espiga entretanto, o valor de $\hat{\sigma}_{A, 12)}^{2}$ mostrou-se superior as estimativas encontradas por SOUZAJr. (1983) como por PELLICANO $(1990)$.

As elevadas magnitudes de variancia aditiva para os tres caracteres avaliados, demonstram a possibilidade de progresso com a seleção de hibridos derivados diretamente destas populaçoes, bem como do mel horamento da performance do hifbido interpopulacional, em programas de seleção recorrente reciproca.

\subsection{Selesão Recorrente Reciproca}

Conforme abordado no item 2.1, , os métodos de seleça recorrente reclproca apresentam-se como a mel hor opção, dentre os metodos de seleção recorrente, para a integraçao com programas de obtençao de híbridos, haja visto que a seleção e efetuada diretamente sobre a performance do hibrido interpopulacional. 
MIRANDA FILHO (1982) sugeriL que a viabilidade da utilizaçåo da seleçao recorrente reclproca para o melhoramento da heterose do cruzamento interpopulacional seja medida pelo Indice 6, sendo que:

$$
\sigma=\left(\sigma_{A_{12}}^{2}+\sigma_{A_{21}}^{2}\right) /\left(\sigma_{A_{1} A_{2}}+\sigma_{A_{2} A_{1}}\right)
$$

onde $\sigma_{A_{1} A_{2}} \sigma_{A_{2} A_{1}}$ são definidos como covariancias geneticas aditivas entre individuos da populaça 1 e 2 , respectivamente, com individuos do hl brido interpopulacional entre elas. Desta forma estimativas de 0 maiores que 1,0 indicam que o progresso esperado no hibrido interpopulacional deve superar a estimativa de progresso obtido nas populaçoes "per se", promovendo gantos de heterose no cruzamento. Os resultados apresentados no trabalio de MIRANDA FILHO (1982) demonstram valores de. $\varnothing=1$ para a condição de ausencia de dominancia, aumentando gradativamente com a elevação do grau medio de domináncia (d/a). Esta tendencia foi observada em todas as supostas distribuiçoes teoricas de frequencias alelicas (tomadas como distribuição Beta) assumida para as duas populaç̧̃es.

Apesar do presente estudo nã fornecer estimativas dos componentes $\sigma_{A_{1} A_{2}} \sigma_{A_{2} A_{1}}$ e do Indice 0 , espera-se, pelas conclusBes de MIRANDA FILHO (1982), que a substituiçao do atual esquema de seleçao recorrente com progenies endogamicas por metodos interpopulacionals 
mostre-se vantajosa para o melhoramento da produtividade do hibrido interpopulacional.

Apos o esquema original de seleç̃o recorrente reciproca proposto comsTOCK et alii (1949), várias metodologias tem sido propostas na literatura (HALLAUER \& EBERHART, 1970; PATERNIANI \& VENCQVSKY, 1977; 1978; SOUZA Jr., 1987), sendo que uma revisão contendo descrição detal hada de cada metodo pode ser encontrada em PELLICAND (1990).

Estudos comparativos entre metodos (JONES et alii, 1971, SOUZA Jr,, 1983, SOUZA Jr., 1987), baseados na sua eficiencia teórica, tem revelado que a seleção com progenies de irmãos germanos, SRRIG (HALLAUER \& EBERHART, $1970)$ deve proporcionar maiores progressos que o metodo original de COMSTOCK et alii (1949), sendo, contudo, menos eficiente que a seleção baseada em progenies de meios-irmãos de plantas prolificas, SRRMI-2 (PATERNIANI \& VENCOVSKY, 1978) quando esta foi conduzida em un ciclo por ano. Dentre os métodos descritos de meios-irmáos produzidos alternadamente com plantas $S_{0} e S_{1}$ (SOUZA Jr,, 1987) mostra-se como o de maior potencial, podendo tambem ser conduzido um ciclo por ano. Apesar de avaliar progenies de meios-irmãos, assim como SRRMI-2, maior variabilidade genetica explorada com a seleção, dada a recombinação de plantas $S_{1}$ ao inves de $S_{0}$, na primeira fase e a obtenção de progénies de meios irmãos de plantas $S_{1}$ a a inves de $S_{0}$, na segunda fase de avalia६ัฐ. 
Para o presente estudo, os resultados dos "testcrosses" reciprocos das progenies $S_{2}$ podem ser utilizados para se efetuar um primeirociclo de seleço interpopulacional nas populaçชes ESALQ PB-2 e ESALQ PB-3.

Segundo as estimativas de progresso esperado com a seleção, a simples recombineção das progênies $S_{2}$, parentais dos "testcrosses" superiores deve promover acréscimos da ordem de $10 \%$ sobre a média de produção do atual hibrido interpopulacional, superando deste modo em $7,4 \%$ a media da testemuntia C511, para estas condiç̧es de avaliação. Deve-se ressaltar que as estimativas de Gs, obtidas fixando-se como 33 o nümero de progenies selecionadas $(\mathrm{Ne}=$ 25), encontram-se, entretanto, superestimadas, dada a existencia de grupos de "testcrosses" aparentados. Nestas condiçós, o coeficiente de $\hat{\sigma}_{A_{12}}$ e $\hat{o}_{A_{21}}$ explorado na seleça E inferior a $(3 / 8)$, valor utilizado no preșente calculo.

A manutenção deste esquema de seleção recorrente interpopulacional, avaliando-se "testcrosses" de progenies $S_{2}$ e recombinando-se tais progenies ve-se limitada, entretanto por dois fatores: maior número de anos necessarios para se completar un ciclo de seleção, reduzindo o Gs/ano; utilização de progenes $S_{2}$ para recombinaçăo, reduzindo o tamantio efetivo populacional, para um mesmo número de progenies recombinadas. Reduçôes no numero de anos por ciclo de seleção poderiam ser efetuadas caso fossem extrai das progenies de meios-irmás interpopulacionais de plantas 
$S_{1}$, as quais equivalem geneticamente a "testcrosses" de progenies $S_{2}$. Neste esquema, cada ciclo seria completado em dois anos (Apendice 3), necessitando-se, contudo, da ocorrência de prolificidade, para que na mesma planta fossem produzidas uma progenie $S_{2}$ e uma progenie de meios-irmås interpopulacional. Comparado a outras metodologias, este tipo de selecão mostrou boa eficiencia, superando a metodologia proposta por HALLAUER \& EBERHART (1970) e mostrando-se intermediaria entre as metodologias propostas por PATERNIANI \& VENCOUSKY (1978) e SOUZA Jr. (1987) (Tabela 28). Para tais comparaçãos foram utilizadas as mesmas estimativas de $\sigma_{A_{12}}^{2}, \alpha_{21}^{2}$, empregadas por SouzA Jr. (1987) para as interpopulaçBes A (BR $105 \times$ ESALQ PB-1) e B (ESALQ PB-A $\times$ ESALQ PB-5), bem como demais suposiçBes formuladas pelo autor.

$$
\text { Percebe-se pela Tabela 28, que apesar das }
$$
limitaçoes compostas pela necessidade de prolificidade em plantas $S_{1}$ e da condução de duas geraçoes por ano, a utilização deste tipo de seleção interpopulacional pode se mostrar interessante para integracão com programas de histidos, principalmente quando nestes programas, a capacidade de combinaça das linhagens seja avaliada atraves de "testcrosses" de progenies $S_{2}$. Neste caso, a mesma avaliação realizada para capacidade de combinação também seria utilizada para fins de selecão recorrente reciproca, aumentando a eficiencia do programa como um todo. 


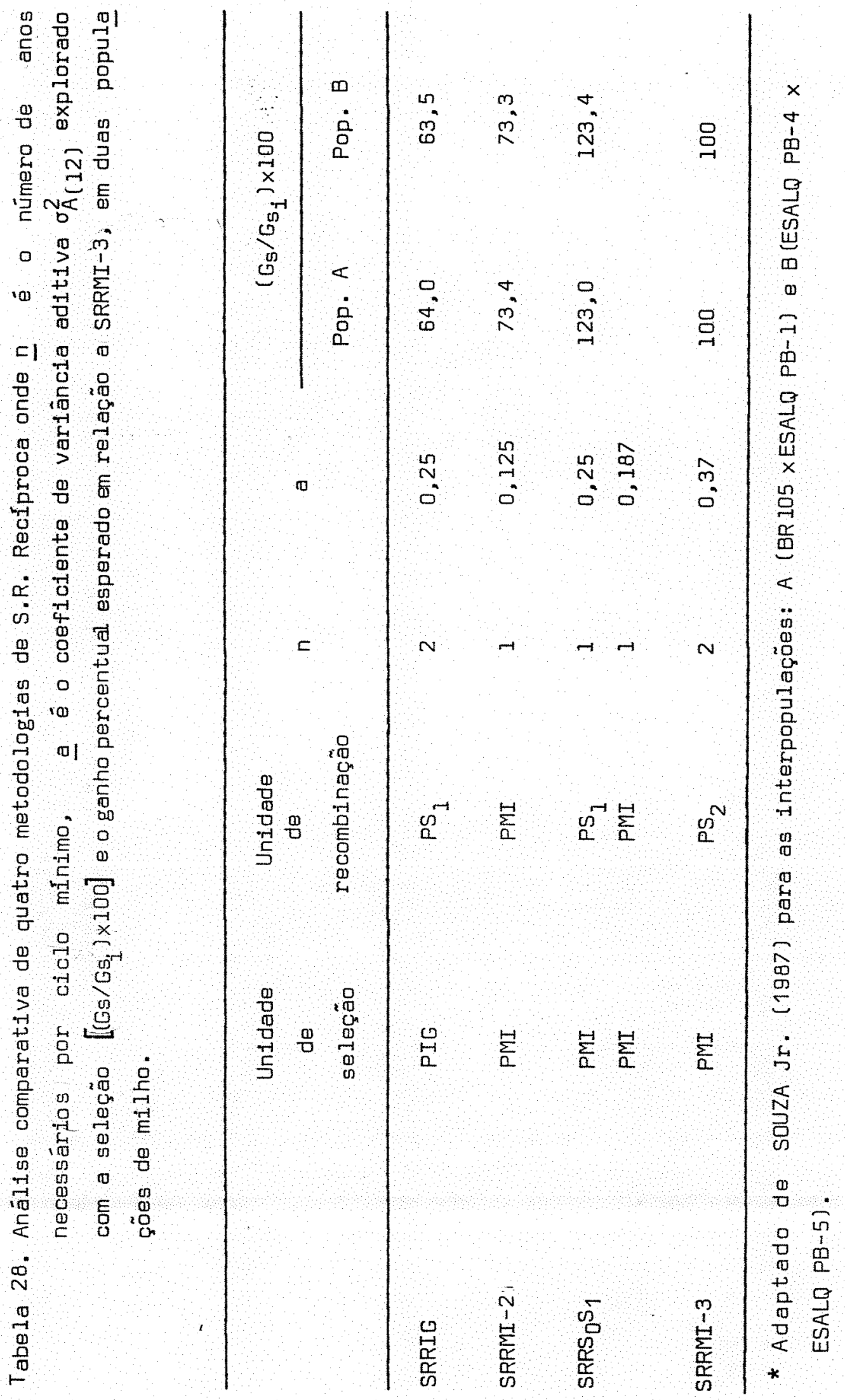


A recombinação de progennies $S_{2}$, apesar de reduzir o tamanho efetivo em $1 / 4$ quando comparado a progenies $S_{1}$, contribui para a eliminaça de alelos letais e deleterios na população, acentuando as reduçoses na depressão por endogamia das linhagens extraldas.

\subsection{Seleção de Híbridos}

Ao contrario dos metodos de seleção recorrente, a seleção de híbridos visa a identificaçăo e fixação das combinaçoes superiores, reproduzidas atraves de suas linhagens parentais. Explora-se desta forma todos os tipos de efeitos genicos (aditivos e não aditivos) esperando-se maiores progressos com a seleção em caracteres com al to grau de dominancia. Isto pode ser verificado pela Tabela 26 , onde maiores prog essos foram estimados quando assumida a hipo-

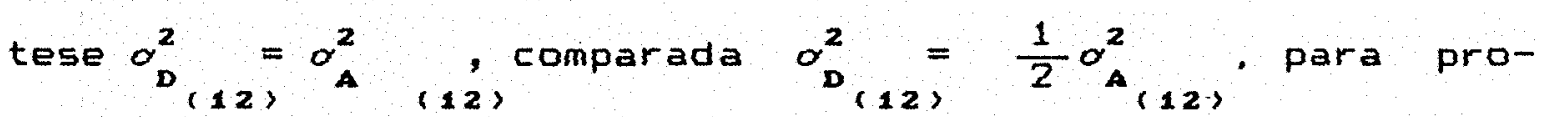
dução de grås.

o bom potencial das populaçoes ESALQ PB-2 e ESALQ PB-3 para a obtença de híbridos, verificado anteriormente por GERALDI \& MIRANDA FILHO (1986), foi confirmado neste estudo atraves das elevadas estimativas de progresso esperado com a seleção, nos diversos tipos de hibridos, resultando em estimativas de produçao que superam de 5 a $25 \%$ a media do testemuntia comercial c511. Como esperado, progressos superiores foram detectados para a 
seleção de híbridos simples, sucedendo-se a híbridos triplos e duplos, para um mesmo nivel de endogamia dos parentais. A diferença entre a produção estimada dos híbridos simples e hibridos duplos aumenta, entretanto, a medida que as Intragens parentais se tornam mais endogamicas (Tabela 24 ). As estimativas de progresso com a seleção nos caracteres altura de planta e altura de espiga, indicam o máximo ganho que se deve esperar nestes caracteres, quando selecionados hibridos simples, triplos e duplos. Espera-se, entretanto, acrescimos indiretos inferiores aos limites de 11 e $14 \%$ para altura de planta e altura de espiga rTabela 25), quando praticada seleção para produção de grãos. Resul tados da literatura revelam que apesar de positiva, a correlação entre estes caracteres nă e absoluta, possuindo valores médios da ordem de 0,26 (HALLAUER \& MIRANDA FILHO, 1988).

Para o caráter produção de grãos, resultados interessantes foram obtidos para a seleção entre híbridos triplos, encontrando-se valores similares de GS para HT, $\mathrm{HT}_{21}$, produzidos quando o hiforido simples parental foi derivado das populaçoes 1 e 2, respectivamente. Este tipo de resposta e esperada quando as estimativas de variancia aditiva interpopulacionais associadas as populaçóes 1 e 2 $\left(\hat{\sigma}_{A_{12}}\right.$ e $\hat{o}_{A_{21}}$, respectivamente) apresentarem-se aproximadas. Em casos onde as magnitudes de $\hat{\alpha}_{A_{12}}^{2}$ e $\hat{\sigma}_{A_{21}}^{2}$ forem diferentes, maiores progressos devem ser esperados quando o hibrido 
simples parental derivar da população a qual estiver associada a menor das duas estimativas, de tal modo que:

$$
\begin{aligned}
& G 5 H T_{12}>G 5 H T_{21} \text { se } \sigma_{A_{12}}^{2}<\sigma_{A_{21}}^{2} e \\
& \text { Gs } H T_{12}<G 5 H T_{21} \text { se } \sigma_{A_{12}}^{2}>\sigma_{A_{21}}^{2} \text { (SOUZA Jr., 1988) }
\end{aligned}
$$

Do ponto de vista pratico, a similar resposta entre $H T_{12}$ HT $_{21}$, no atual estudo, apresenta-se como um ponto positivo, não limitando o sentido dos cruzamentos entre as duas populaçaes. O hibrido simples parental (femea) pode, deste modo, derivar tanto de uma como de outra população, sem comprometimento da variabilidade genetica expressa entre os hibridos.

A influencia do nivel de endogamia das lintias parentais sobre a produçăo media de quatro. tipos de híbridos pode ser visualizada comparando-se os progressos esperados em cada caso. Apesar do aumento na endogamia dos parentais resultar em maiores estimativas de gantos com a seleção (Tabela 24), observa-se que esta relaçao não e linear, apresentando pequenos acrescimos apos a terceira autofecundação (Tabela 26$)$.

A utilização de híbridos comerciais derivados de linhagens com endogamia intermediaria $\left(S_{1}\right.$ e $S_{2}$ ) tem sido sugerida por alguns autores como op̧̧a para reduzir os efeitos negativos da depressão por endogamia em milho 
(WELLHAUSEN, 1954; LOEFFEL, 1964, 1971). Pela Tabe1a 24 percebe-se que o potencial produtivo de híbridos simples de Iinhagens $S_{2}$ assemelha-se ao de hiforidos triplos de lintagens totalmente endogámicas, sendo que, no presente estudo, - seleção de $10 \%$ das mel hores combinaçbes deve superar de $15 \%$ a $18 \%$ a media da testemuntia c511.

A seleção de hi bridos simples de plantas não endógamas (progenies de irmáos germanos) tem sido proposta por alguns autores IMIRANDA FILHO, 1979, MIRANDA FILHO Et alii, 1986), dada a simplicidade de sua obtenção e à sua correspondencia genetica com hibridos duplos de linhagens totalmente homozigotas (MIRANDA FILHO \& VIEGAS, 1987 ). Para as populaçóses em avaliação, este tipo de híbrido também apresenta um bom potencial, sendo que a media de produçå dos $10 \%$ selecionados deve superar de 10 a $12 \%$ a performance do habrido C511.

Quanto a seleção de hibridos simples, as produçóes estimadas dos genotipos selecionados superam de 10 a $25 \%$ a media do hibrido C511, para linhagens totalmente endogamicas (Tabela 24). A seleção e utilização comercial deste tipo de hlorido ná pode ser descartada, haja visto a reduzida depressão por endogamia encontrada nas progenies $S_{1}$ superiores de ESALQ PB-3 (C3) E ESALQ PB-3 (Ca) (Figuras $2=51$

A utilização de hibridos simples modificados tem sido proposta por diversos autores como op̧̧̃o a 
esquema tradicional de hibridos simples (MIRANDA FILHO \& VIEGAS, 1987: HALLAUER et a $1 i i, 1988$ ), promovendo progressos superiores a selecão de hloridos simples de linhagens parcialmente endogamicas, para igual ni vel de endogamia das linhagens parentais (SOUZA Jr., 1988). Para hibridos de linhagens modificadas com coeficiente de endogamia (F) igual a 3/4, espera-se progressos iguais a hloridos simples entre $S_{3}(F=7 / 8)$. Nesta condiça, os meltores hloridos modificados devem superar de 18 a $21 \%$ a testemuntia C511, aproximando-se da performance de hibridos simples de lintiagens homozigotas.

Apesar de alta produtividade esperada com a seleç̃o dos hibridos extraldos diretamente das populaşes avaliadas, espera-se o estabelecimento de platos, apos sucessivas amostragens de linhagens das mesmas populaçoes. Consideraçoes teoricas (COMSTOCK, 1964), bem como resultados praticos (HALLAUER, 1984 ) demonstraram a eficiencia da integraçăo do mel horamento de hi bridos a seleçăo recorrente em promover progressos contínuos nos híbridos extraldos de duas populaçoes.

Conforme apresentado neste estudo e corroborando os resultados de MARQUES (1988), a condução de trés ciclos de seleção recorrente com progenies endogamicas em sucessão a un ciclo de seleça massal foi eficiente em melhorar tanto a performance "per se" bem como das linhagens derivadas das populaçBes ESALQ PB-2 e ESALQ PB-3. 
Entretanto, apos a fase de adaptação e melhoramento individual de cada população, a substituição deste esquema por metodos interpopulacionais deve maximizar os gantos sobre a capacidade combinatoria, promovendo progressos continuos na performance do híbrido interpopulacional, integrando-se perfeitamente a um programa pratico de obtenção de híbridos. 


\section{CONCLUSÕES}

a) As popul açZes ESALQ PB-2 (C3) e ESALQ PB-3

(C3) constituem-se fontes promissoras, tanto para sua utilização "per se", como para extração de linhagens de al to vigor, evidenciando o efeito positivo de tres ciclos de seleça recorrente com progenies endogamicas.

b) A população ESALQ PB-2 (C3) apresentou, para o carater produçăo de grãos, maior sensibilidade a depressão por endogamia do que ESALQ PB-3 (C3), em ambos os locais de avaliação. Esta tendencia não foi observada para altura de planta e altura de espiga.

c) Dentre os dois locais de avaliaçă, Rondonópolis caracterizou-se por apresentar menores valores de produçá, de altura de planta e de altura de espiga, tanto nas populaçós não endogamicas (s, como nas progenies $S_{1}$. A influencia de estresses ambientais foi, entretanto, superior nas progenies $S_{1}$, acarretando maiores estimativas dos desvios $\left(S_{1}-\bar{S}_{0}\right) / \bar{S}_{0}$ em Rondonspolis do que Ponta Grossa. 
d) 0 esquema de partição da variância genetica entre "testcrosses" de progenies $\mathrm{S}_{2}$, adotado neste trabaliho, mostrou-se adequado e passlvel de utilizaçã em programas de extração de lintiagens conduzidos pelo metodo genealogico, onde diferentes graus de parentesco estão presentes entre as progenies.

e) As magnitudes obtidas para as estimativas dos componentes aditivos interpopulacionais $\left(\alpha_{A}^{2} e_{12} \alpha_{A}^{2}\right)_{21}$ associada a boa performance do híbrido interpopulacional, sugerem a viabilidade de uso das duas populações em programas de seleção recorrente reciproca. Assumidos valores hipoteticos para a variancia dominante $\left\{\sigma_{D_{12}}\right.$, , espera-se que da interpopulação ESALQ PB-2 × ESALQ PB-3 sejam obtidos hibridos de linhagens de alta produtividadee de porte semelhante a testemuntia comercial c511.

f) A seleço entre nibridos triplos e hibridos triplos modificados, no presente estudo, mostra-se pouco alterada en função do sentido do cruzamento, apresentando potencial similar tanto quando de ESALQ PB-2 quanto de ESALQ PB-3 foram derivados os parentais femeas (tiloridos simples) na sintese do hibrido final. 


\section{REFERẼNCIAS BIBLIOGRÁFICAS}

AJUDARTE NETO, F. Avaliação de progenies de irmãos germanos interpopulacionais obtidas de compostos de miltio lzea mays L.). Piracicaba, 1978. 93p. (Mestrado - Escola Superior de Agricultura "Luiz de Queiroz"/USP).

ALLISON, J.C.S. \& CURNOW, R.W. On the choice of tester parent for the breeding of synthetic varieties of maize ( $Z$ ea mays L.). Crop Science, Madison, 6: 541-4, 1966.

BAKER, L.H. \& CURNOW, R.N. Choice of population size and use of variation between replicate populations in plant breeding selection programs. Crop Science, Madison, 9 : $555,1969$.

BOJANOWSKI, J. Recurrent selection for smut resistance in corn. Züchter, Ber1in, 37: $151-55,1967$.

BURTON, 3.W. : PENNY, L.H.; HALLAUER, A.R.; EBERHART, S.A. Evaluation of synthetic populations developed from a maize variety (BSK) by two methods of recurrent selection. Crop Science, Madison, 11: 361-5, 1971.

CARLONE, M.R. \& RUSSELL, W.A. EValuation of S2 maize lines reproduced for several generation by randon mating within 1ines. I. Comparisons between the original and maintained S2 1ines. Crop Science, Madison, 28: 921-5, 1988.

CARLONE, M.R. \& RUSSELL, W.A. Evaluation of $S_{2}$ maize 1 ines reproduced for several generations by randon mating within lines. II. Comparisons for testcross performance of original and advanced $S_{2}$ and $S_{\text {a }}$ lines. Crop Science, Madison, 29: 899-904, 1989. 
CHAVES, L.J. Um modelo não linear aplicadao ao estudo das interaçás de genótipos com ambientes. Piracicaba, 1982. 102p. Mestrado - Escola Superior de Agricultura "Luiz de Queiraz"/USP).

CHAVES, L.J. \& MIRANDA FILHO, J.B. Plot size for progenY selection in maize (zea mays L.). Theoretical and Applied Genetics, Berlim, 84: $963-70,1992$.

COCKERHAM, C.C. Estimation of genetic variances. In: HANSON, W.D. \& ROBINSON, H.F., ed. Statistical Genetics and Plant Breeding, NAS-NRC n? $982,1963 ., 0.93$.

COCKERHAM, C.C. Covariances of relatives from self fertilization. Crop Science, Madison, 23, 1177-80, 1983.

COCKERHAM, C.C. \& WEIR, B.S. Covariances of relatives stemming from a population undergoing mixed self and random mating. Biometrics, wastington, 40: 157-64, 1984.

COCHERHAM, C.C. \& MATZINGER, D.F. Selection response based on selfed progenies. Crop Science, Madison, 25: 483-8, 1985.

COCHRAN, W.G. \& COX, G.M. Experimental designs. 2.ed. NeW Yok, John Wiley \& Sons, 1957. 611p.

COMSTOCK, R.E. Selection procedures in corn improvement. In: HYBRID CORN INDUSTRY RESEARCH CONFERENCE, 19, Chicago, 1964. Proceedings. Chicago, American Seed Trade Association, 1964. P.12-23.

COMSTOCK, R.E. \& ROBINSON, H.F. The components of genetic variance in populations. Biometrics, Raleigh, 4: 254-6, 1948 . 
COMSTOCK, R.E.; ROBINSON, H.F.; HARVEY, P.H. A breeding procedure designed to make maximum use of both general and specific combining ability. Agronomy Journal, Madison, 41 : $360-7,1949$.

COMSTOCK, R.E. \& ROBINSON, H.F. Estimation of average dominance of genes. In: GOWEN, J.W., ed. Heterosis. Ames, Iowa State University Press, 1952. p.494-516.

COORS, J.G. Response to four cycles of combined half-sib and $S_{1}$ family selection in maize. Crop Science, Madison, $28: 891-6,1988$.

DANTAS, A.C.V.L. Cruzamento dialelico parcial circulante - para avaliação de linhagens de milho (lea mays L.) e predif̧ão de hlbridos . Piracicaba, 1988. 153p. lDoutorado - Escola Superior de Agricultura "Luiz de Queiroz"/USPI.

DANTAS, J.L.L. Cruzamentos dialelicos parciais para avaliação de híbridos intermediarios entre duas populaçbes de miltio (Zea mays L.). Piracicaba, 1992. $216 p$. (Doutorado - Escola Superior de Agricultura "Luiz de Queiroz"/USP).

DAVIS, R.L. Report of the plant breeder. Puerto Rico Anual Report Agricultural Experimental Station, 1927. p. 14-15.

EBERHART, S.A. Factors affecting efficiences of breeding methods. African Salls, Bangui, 15, 669-80, 1970. 
EMPIG, L.T.; GARDNER, C.O.; COMPTON, W.A. Theoretical gains for different population improvement procedures. Bulletin of the Nebraska Agricultural Experimental Station, Lincon1, MP26, 1972.

FALCONER, D.S. Introduction to quantitative genetics. New York, Ronald Press, 1960. 365p.

FERNANDES, J.S.C. Progressos esperados em linhagens de milho (Zea mays L.) via seleção recorrente e interpopulacional. Piracicaba, 1990. 235p. (Doutorado Escola Superior de Agricultura "Luiz de Queiroz"/USP).

FYFE, J.L. \& GILBERT, N, Partial diallel crasses. Biometrics, Raleigh, $19: 278-86,1963$.

GARDNER, C.0. Teoria de genetica estadistica aplicable a las medias de variedades, sus cruces y poblaciones afines. Fitotecnia Latinoamericana, San Jose, 2 : 11-22, 1965.

GARDNER, C.O. \& EBERHART, S.A. Analysis and interpretation of the variety cross diallel and related populations. Biometrics, Raleigh, $22: 439-52,1966$.

GENTER, C.F. Comparison of $S_{1}$ and testcross evaluation after two cycles of recurrent selection in maize. Crop Science, Madison, 13: $524-7,1973$.

GENTER, C.F. \& ALEXANDER, M.W. Comparative, performance of S1 progenies and test-crosses of corn. Crop Science, Madison, $2: 516-9,1962$. 
GENTER, C.F. \& ALEXANDER, M.W. Development and selection of productive $S_{1}$ inbred 1 ines of corn (Zea mays L.). Crop Science, Madison, $6: 429-31,1966$.

GERALDI, I.O.; SOUZA JUNIOR, C.L.; MIRANDA FILHO, J.B. obtenf̧ão avaliaçă de híbridos $S_{0} \times S_{0}$ entre duas variedades de milho. In: REUNIAO ANUAL DA SBPC, 38. , Curitiba, 1986. Resumos. P.912.

GERALDI, I.Q. \& MIRANDA FILHO, J.B. Adapted models for the analysis of combining ability of varieties in partial diallel crosses. Revista Brasileira de Genetica, Ribeirão Preto, 11 : $419-30,1988$.

GONGALVES, P. de S. Esquema circulante de cruzamento para avaliação de lintiagens de milho (Zea mays L.) ao nivel interpopulacional. Piracicaba, 1987. 140p. (Doutorado - Escola Superior de Agricultura "Luiz de Queiroz"/USP).

GQOD, R.L. \& HALLAUER, A.R. Inbreeding depression in maize by selfing and full-sibbing. Crop Science, Madison, 17: $935-40,1977$.

GOODRICH, C.L.; STUBER, R.E.; COMPTON, W.A. Average gene frequency estimates in two open-pollinated cultivars of corn. Crop Science, Madison, 15: 746-9, 1975.

GRIFFING, J.B. Concept of general and specific combining ability in relation to diallel crosses. Australian Journal of Biological Science, Melbourne, 9: 463-93, 1956. 
HALLAUER, A.R. Development of single-cross hybrids from two-eared maize populations. Crop Science, Madison, 7 : $192-5,1967$.

HALLAUER, A.R. Zygote selection for the development of single cross hybrid in maize. Adr. Front. Plant Sei., 25 : $75-81,1970$.

HALLAUER, A.R. Hybrid development and population improvement in maize by reciprocal full-sib selective. Egyptian Journal Genetics and Cytology, Giza, $2: 84-101$, 1973.

HALLAUER, A.R. Relation of quantitative genetics to applied maize breeding. Revista Brasileira de Genetica, Ribeirãofreto, $3: 207-33,1980$.

HALLAUER, A.R. Compendium of recurrent selection methods and their application. Critical Review in Plant Sciences, $3(1): 1-33,1984 a$.

HALLAUER, A.R. Recipracal full-sib selection in maize. Crop Science, Madison, 24: $755-9,1984 b$.

HALLAUER, A.R. Methods used in developing maize inbred 1ines. Maydica, Bergamo, 35:1-16, 1990.

HALLAUER, A.R. \& EBERHART, S.A. Reciprocal ful1-5ib selection. Crop Science, Madison, 10: 315-6, 1970.

HALLAUER, A.R. \& SEARS, J.H. Changes in quantitative traits associated with inbreeding in a synthetic variety of maize. Crop Science, madison, 13: 327-30, 1973. 
HALLAUER, A.R. \& MIRANDA FILHO, J.B. Quantitative genetics in maize breeding. 2.ed. Ames, Jowa state University Press, 1988.

HALLAUER, A.R.; RUSSELL, W.A.; LAMKEY, K.R. Corn Breeding. In: SPRAGUE, G.F.\& DUDLEY, J.W., ed, Corn and Corn Improvement. Madison, 1988. P.469-554.

HELMS, T.C. Evaluation of three recurrent selection methods in corn (Zea mays L.). Ames, 1986. (Ph.D. - Iowa state Universityl.

HOEGEMEYER, T.C. \& HALLAUER, A.R. SElection among and within full-sib families to develop single crosses of maize. Crop Science, Madison, 16: 76-81, 1976.

HORNER, E.S. Effects of selection for $S_{2}$ progeny versus testcross performance in corn. ANNUAL CORN SORGHUM INDUSTRY RESEARCH CONFERENCE, 40. ChICagO, 1985. Proceedings. Washington, American Seed Trade Association, 1985. p.142-50.

HORNER, E.,S.; LUNDY, H.W.; LUTRICK, M.C.; CHAPMAN, W.H. Comparison of three methods of recurrent selection in maize. Crop Sciene, Madison, 13: 485-89, 1978.

HORNER, E.S.; MAGLOIRE, E.; MORERA, J.A. COMparison of selection for $S_{2}$ progeny vs. testcross performance for population improvement in maize. Crop Science, Madison, $29: 868-74,1989$.

HULL, H.F. Recurrent selection and specific combining ability in corn. Journal American Society of Agronomy, Wastington, 37 : $137-45,1945$. 
JENKINS, M.T. The effect of inbreeding and of selection within inbred lines of maize upon the hybrids made after sucessive generations of selfing. Towa State Journal Science, Ames, 9:429-50, 1935 .

JENKINS, M.T. Corn Improvement. Wastington, USDA, 1936. p.455-522 (Yearbook of Agriculture).

JENKINS, M.T. Methods of estimating performance of doublecrosses in corn. Journal of American Society of Agronomy, Wastington, 26: 199-204, 1934.

JONES, D.F. The effects of inbreeding and crossbreeding upon development. Bulletin of the Connecticut Agricultural Experimental Station, Connecticut, 207 : $5-100,1918$.

JONES, D.F. Continued inbreeding in maize. Genetics, Princeton, 24: $462-73,1939$.

JONES, L.P.; COMPTON, W.A.; GARDNER, C.O. COMparison of full and half-sib reciprocal recurrent selection. Theoretical and Applied Genetics, Berlin, 41 ; 36-9, 1971.

KEMPTHORNE, 0. Design and analysis of experiments. New York, Robert Krieger Publishing Company, 1973. 631p.

KEMPTHORNE, O. \& CURNOW, R.N. The partial diallel crosses. Biometrics, Raleigh, 17: 229-50, 1961.

LAMKEY, K.R. \& HALLAUER, A.R. Heritability estimed from recurrent selection in maize. Maydica, Bergamo, 32 : $61-78,1987 a$. 
LAMKEY, K.R. \& SMITH, O.S. Performance and inbreeding depression of populations representing seven eras of maize breeding. Crop Science, Madison, 27: 695-9, 19876.

LIMA, M.; GIMENES-FERNANDES, N.; MIRANDA FILHO, J.B.; PEREIRA, J.C.V.A. Introduction of maize (lea mays L.) germplasm as sources for downy mildew (Peronoselerospora sorghi) resistance. Maydica, Bergamo, 27 : 159-68, 1982.

LIMA, M.; MIRANDA FILHO, J.B.; BOLLER GALLO, P. InbreEdIII depression in brazilian populations of maize (Zea mays L.). Maydica, Bergamo, 29 : $203-15,1984$.

LOEFFEL, F.A. Si crosses compared with crosses of homozYgOUS IINES. ANNUAL HYBRID CORN INDUSTRY - RESEARCH CONFERENCE, 19., ChICago, 1964. Proceedings. Washington, American Seed Trade Association, 1964. p. $-95-104$.

LOEFFEL, F.A. Development and utilization of vigorous parental lines. ANNUAL HYBRID CORN INDUSTRY - RESEARCH CONFERENCE, 26., Chicago, 1971. Proceedings. Wastington, American Seed Trade Association, 1971. p. $-209-17$.

LONNQUIST, J.H. The effect of selecting for combining ability within segregating lines of corn. Agronomy Journal, Madison, 42: $503-8,1950$.

LONNQUIST, 3.H. Metodos de seleccion utiles para majoramiento de poblaciones. Fitotecnia Latino-americana, San Jose, 2 : $1-10,1965$. 
LONNQUIST, J.H., \& WILLIAMS, N.E. Development of maize hybrids through selection among full-sib families. Crop Science, Madison, 7: 368-70, 1967.

MARQUES, J.R.B. Seleça recorrente com endogamia em duas populaçzes de milho (Zea mays L.). Piracicaba, 1988. 145p. (Mestrado - Escola Superior de Agricultura "Luiz de Queiroz"/USP).

MARTINS, C.C. Potencial genetico de linhagens e híbridos de duas populaçoes de milho (zea mays L.) braquítico. Piracicaba, 1986. 143p. (Mestrado - Escola Superior de Agricultura "Luiz de Queiroz"/USP).

MEGHJI, M.R.; DUDLEY, J.W.; LAMBERT, R.J.; SPRAGUE, G.F. Inbreeding depression, inbred and hybrid grain yields and other traits of maize genotypes representing three eras. Crop Science, Madison, 24: $545-9,1984$.

MIRANDA FILHO, J.B. Avaliação de faml lias de meios irmãos do segundo ciclo de seleção da população ESALQ PB-1 de miltio. Relatorio Cientifico do Departamento de Genetica, Piracicaba, (13): 148-58, 1979 .

MIRANDA FILHO, J.B. Avaliação de híbridos cripticos $S_{0} \times S_{0}$ entre duas populaçóes de milho braquítico. Relatório Cientifico do Departamento de Genetica, Piracicaba, (13): $159-71,1979$.

MIRANDA FILHO, J.B. Cruzamentos dialelicos e slntese de compostos de milho (Zea mays L.) com enfase na produtividade e no porte da planta. Piracicaba, 1974. 115p. (Doutorado - Escola Superior de Agricultura "Luiz de Queiroz"/USPI. 
MIRANDA FILHO, J.B. Seleção e métodos de melhoramento. In: REUNIAO DA SOCIEDADE BRASILEIRA DE GENETICA, 14., Jaboticabal, 1981. Anais. Jaboticabal, UNESP, 1981. p. $145-50$.

MIRANDA FILHO, J.B. Mating schemes to predict gain on heterosis in reciprocal recurrent selection. Revista Brasileira de Genética, Ribeirão Preto, 5: 745-60, 1982.

MIRANDA FILHO, J.B. Breeding methodologies for tropical maize. In: BRANDOLINI, A. \& SALAMINI, F., ed, Breeding Strategies for Maize Production Improvement in the Tropical, Firenze, FAO, 1985. P.179-206.

MIRANDA FILHO, J.B. Principios da experimentação e analise estatistica. In: PATERNIANI, E. \& VIEGAS, G.P., ed. Melhoramento e Produção do Milho. Campinas, Fundação Cargil1, 1987. v.1, p.765-95.

MIRANDA FILHO, J.8. \& GERALDI, I.O. Un modelo para ana I Ise de cruzamentos dialelicos parciais. Relatório Tecnico Cientifico do Departamento de Genética, Piracicaba, (14): $50-7,1980$.

MIRANDA FILHO, J.B. \& GERALDI, I.O. An adapted model for the analysis of partial diallel crosses. Revista Brasileira de Genetica, Ribeirão Preto, $7,677-89,1984$.

MIRANDA FILHO, J.B. \& PATERNIANI, E. Intra e interpopulation genetic parameter estimates and implications in selection. Revista Brasileira de Genetica, Ribeirão Preto, 6: 15-27, 1983 . 
MIRANDA FILHO, J.B.; SOUZA Jr., C.L.; GERALDI, I.O. Avaliagăo de híbridos $S_{0} \times S_{0}$ entre duas variedades de milho. In: CONGRESSO NACIONAL DE MILHO E SORGO, 15., Maceis, 1986. Anais. P.195-206.

MIRANDA FILHO, J.B. \& VIEGAS, G.P. Milho hibrido. In: PATERNIANI, E. \& VIEGAS, G.P., ed. Melhoramento e Produção do Milho. Campinas, Fundação Cargi11, 1987. $v .1, p .275-340$.

MOLL, R.H. \& STUBER, C.W. Quantitative genetics - empirical results relevant to plant breeding. Advances in Agronomy, New York, 26: 277-313, 1974.

MORO, J.R. Efeito da al ta intensidade de seleção no mel horamento de milho (lea mays L.l. Piracicaba, 1982. 52p. (Mestrado - Escola Superior de Agricultura "Luiz de Queiroz"/USP).

MOTA, M.G.C. Comportamento de progenies de meios irmãos e $S_{1}$ na variedade de miltio (Zea mays L.) Centralmex. Piracicaba, 1974. 73p. (Mestrado-Escola Superior de Agricultura "Luiz de Queiroz"/USP).

MULAMBA, N.N.; HALLALER, A.R.; SMITH, O.S. Recurrent selection for grain yield in a maize population. Crop Science, Madison, 23 : $536-40,1983$.

NASS, L.L. Variabilidade genetica de populaçoes semiexóticas de milho (zea mays L.). Piracicaba, 1992. 136p. (Doutorado - Escola Superior de Agricultura "Luiz de Queiroz"/USP). 
OBILANA, A.B. Estimation of genetic components of variance in the interpopulation formed by crossing two maize synthetics, BS10 and BS11. Ames, 1978. 151P. (Ph.D. Iowa States University).

OBILANA, A.T.; HALLAUER, A.R.; SMITH, O.S. Estimated genetic variability in a maize interpopulation. Journal of Heredity, Wastington, $70: 127-32,1979$.

ODHIAMBO, M.O. \& COMPTON, W.A. Five cycles of replicated S. reciprocal full-sib index selection in maize. Crop Science, Madison, $29: 314-9,1989$.

PANDEY, S. \& GARDNER, C.0. Recurrent selection for population, variety, and hybrid improvement in tropical maize. Advances in Agronomy, New York, 48: 1-87, 1992.

PATERNIANI, E. Selection among and within half-sib families in a brazilian population of maize (Zea mays L.). Crop Science, Madison, $17: 212-6,1967$.

PATERNIANI, E. Avaliação do metodo de seleção entre e dentro de famlilas de meios-irmas no melhoramento do miltio (zea mays L.). Piracicaba, 1968. 92p. (Catedra Escola Superior de Agricultura "Luiz de Queiroz"JUSPl.

PATERNIANI, E. Fatores que afetam a eficiencia da seleção nas plantas. CONGRESSO LAT INOAMERICANO DE GENETICA, 4., 1980. Acta, $0.37-43$.

PATERNIANI, E. Maize breeding in the tropics. Critical Review in Plant Sciences, $9(2): 125-54,1990$. 
PATERNIANI, E., \& VENCOUSKY, R. Reciprocal recurrent selection in maize (Zea mays L.) based on testcrosses of half-sib families. Maydica, Bergamo, 22: 141-52, 1977 .

PATERNIANI, E. \& VENCOUSKY, R. RECiprocal recurrent selection based on half-sib progenies and prolific plants in maize (zea mays L.). Maydica, Bergamo, 23 : 209-19, 1978.

PATERNIANI, E. \& MIRANDA FILHO, J.B. Melhoramento de POPUlaçBEs. IN: PATERNIANI, E. \& VIEGAS, G.P., ed. Melhoramento e Produçăo do Milho. Campinas, Fundação Cargi11, 1987. V.1, p.217-74.

PELLICANO, I.J. Potencial da interpopulação de milho ( mays L. BR 105 x BR 106 para o meltoramento. Piracicaba, 1990. 139p. (Mestrado - Escola Superior de Agricultura "Luiz de Queiroz"/USP).

PENNY, L.H.; RUSSEL, W.A.; SPRAGUE, G.F., Types of gene action in yield heterosis in maize. Crop Science, Madison, 2 : $341-4,1962$.

PENNY, L.H.; RUSSEL, W.A.: SPRAGUE, G.F. , HALLAUER, A.R. Recurrent selection. In: HANSON, W.D. \& ROBINSON, H.F., ed. Statistical genetics and plant breeding. Wastington, National Academy of Sciences, 1963. p.362-7.

RAWLINGS, J.0. Present states of research on long- and short-term recurrent selection in finite populations Choice of population size. MEETING WORK IN GROUP OF QUANTITATIVE GENETICS, 2., Raleigh, 1970. Proceedings. 
RAWLINGS, J.0. \& THOMPSON, D.L. Performance level as criterion for the choice of maize testers. Crop Science, Madison, 2: 217-20, 1962 .

RESENDE, M.D.V. de. Seleção de genotipos de milho (Iea mays L.) en solos contrastantes. Piracicaba, 1989. 212p. Mestrado - Escola Superior de Agricultura "Luiz de Queiraz"/USP).

ROBINSON, H.F.; COMSTOCK, R.E.; HARVEY, P.H. GENEtic variances in open-pollinated varieties of corn. Genetics, Princeton, 40: 45-60, 1955.

RUSSELL, W.A. Comparative performance of maize hybrids representing different eras of maize breeding. ANNUAL CORN AND SORGHUM RESEARCH CONFERENCE, 29., ChICagO, 1974. Proceedings. Wastington, American Seed Trade Association, 1974. p.81-101.

SATTERTHWAITE, F.E. An aproximate distribution of estimates of variance components. Biometrics Bulletin, $2: 110-4$, 1946.

SHULL, G.H. The composition of a field of maize. American Breeders Association Report, 4: 296-301, 1908 .

SHULL, 6.H. A pure line method of corn breeding. American Breeders Association Report, $5: 51-9,1909$.

SILVA, J.C. Genetic and environmental variances and covariances estimated in the maize (Zea mays L.) variety, Iowa Stiff Stalk Synthetic. Ames, 1974. (Ph.D Iowa State University). 
SMITH, 0.S. Evaluation of recurrent selection in BSSS, BSCB1 and BS13 maize populations. Crop Science, Madison, 23 : 1983 .

SOUZA JUNIOR, C.L. Variabilidade genetica em milho (zea mays L.) e relaçós com a seleção recorrente intra e interpopulacional. Piracicaba, 1983. 151p. (Doutorado - Escola Suerior de Agricultura "Luiz de Queiraz"/USP).

SOUZA JUNIOR, C.L. Reciprocal recurrent selection with half-sib progenies obtained alternately from non-inbred (S.) and inbred (Si) plants in maize (Zea mays L.). Maydica, Bergamo, 32: 19-31, 1987 a.

SOUZA JUNIOR, C.L. Variancias geneticas interpopulacionais e suas relações com a obtenção e seleção de hí bridos. Piracicaba, 1987b. 140p. LLivre Docencia - Escola Superior de Agricultura "Luiz de Queiroz"/USP).

SOUZA JUNIOR, C.L. Componentes da variancia genética e suas implicaços no mel horamento vegetal. Piracicaba, FEALQ, 1989. 134p.

SOUZA JUNIOR, C.L. \& MIRANDA FILHO, J.B. DESENvolvimento de linhagens endogamicas de duas populaçôs com base na capacidade reciproca de combinaçóes. Relatório Cientifico do Departamento de Genetica, Piracicaba, (15): $258-70,1981$.

SOUZA JUNIOR, C.L. \& MIRANDA FILHO, J.B. AlteraçBES na heterose via seleção intra e interpopulacional. Pesquisa Agropecuaria Brasileira, Brasilia, 20: 1197-201, 1985. 
SOUZA JUNIOR, C.L. \& MIRANDA FILHO, J.B. GENEtIC variability in two maize (Zea mays L.) population and its relationships with intra and interpopulation recurrent selection. Revista Brasileira de Genetica, Ribeirão Preto, 12: 271-86, 1989 .

SOUZA JUNIOR, C.L.; MIRANDA FILHO, J.B.; IINSLY, J.R. Potencial genetico de dois compostos de milho (Zea mays L.) para obtenção de híbridos. Relatório Cientifico do Departamento de Genética, Piracicaba, (14): 153-62, 1980.

SPRAGUE, G.F.\& TATUM, L.A. General vs specific combining ability in single crosses of corn. Joumal of American Society of Agronomy, Madison, 34: $923-32,1942$.

SPRAGUE, G.F. Early testing of inbred lines. Journal American Society of Agronomy, Washington, 38: 108-17, 1946.

SPRAGUE, G.F. \& EBERHART, S.A. Corn breeding. In: SPRAGUE, G.F., ed. Corn and Corn Improvement. Madison, ASA, 1977. cap. 6, p.305-62 (Agronomy, 18).

STANGLAND, G.R. \& RUSSELL, W.A. Variability within $S_{2}$ and $S_{\text {, }}$ inbred lines in maize. Maydica, Bergamo, 24: 227-38, 1981.

STEBBINS, G.L. Self-fertilization and population variability in the higher plants. Amererican Waturalist, Lancaster, 91 : $337-54,1957$.

STEEL, R.G.G. \& TORRIE, J.H. Principles and procedures of statistics. New York, MeGraw-Hil1 Book, 1960, 481p. 
STUBER, C.W.; MOLL, R.H.; HANSON, N.D. Genetic variances and interrelationships of $s i x$ traits in a hybrid population of Zea mays L. Crop Science, Madison, 6: $455-8,1966$.

TANNER, A.H. \& SMITH, 0.S. Comparison of hal-sib and $S 1$ recurrent selection in krug Yellow Dent maize population. Crop Science, Madison, 27: 509-13, 1987.

VALOIS, A.C.C. Eficiencia comparativa de quatro métodos de seleção en uma população meltorada de milho (zea mays L). Piracicaba, 1982. 119p. (Doutorado-Escola Superior de Agricultura "Luiz de Queiroz"/USP).

VELLO, N.A. \& VENCOVSKY, R. Variancias associadas às estimativas de variancias geneticas e coeficientes de herdabilidade. Relatorio Cientifico do Departamento de Genetica, Piracicaba, (8): $238-48,1974$.

VENCQUSKY, R. Herança quantitativa. In: PATERNIANI, E. \& VIEGAS, G.P., ed. Melhoramento e Produção do Milho. Campinas, Fundação Cargi11, 1987. v.1, p.137-209.

VENCOUSKY, R.; MIRANDA FILHO, J.B.; SOUZA JUNIOR, C.L. Quantitative genetics and corn breeding in Brazil. In: INTERNAT IONAL CONFERENCE ON QUANTITATIVE GENETICS, 2. Raleigh, 1987. Proceedings. Sunderland, Sinauer Associates, $1988.0 .465-77$.

VENCOVSKY, R. \& BARRIGA, P. Genética biometrica no fitomelhoramento. Ribeiráofreto, Sociedade Brasileira de Genetica, 1992. 496p. 
VIANNA, R.T.; GAMA, E.E.G.; NASPOLINI FILHO, V.; MORO, J.R.; VENCOUSKY, R. Inbreeding depression of several introduced populations of maize (Zea mays L.). Maydica, Bergamo, 27: 151-7, 1982.

WELLHAUSEN, E.J. Modern corn breeding and production in México. Phytopathology, 44: 391-5, 1954.

WEBEL, O.D. \& LONNQUIST, J.H. An evaluation of modified ear-to-row selection in a population of corn lzea mays L.1. Crop Science, Madison, 7: 651-5, 1967.

WEST, D.R.; COMPTON, W.A.; THOMAS, M.A. COMParison of replicated $S_{s}$ per se vs. reciprocal full-sib index selection in corn. I. Indirect response to population densities. Crop Science, Madison, 20: 35-42, 1980. 
TABELAS 


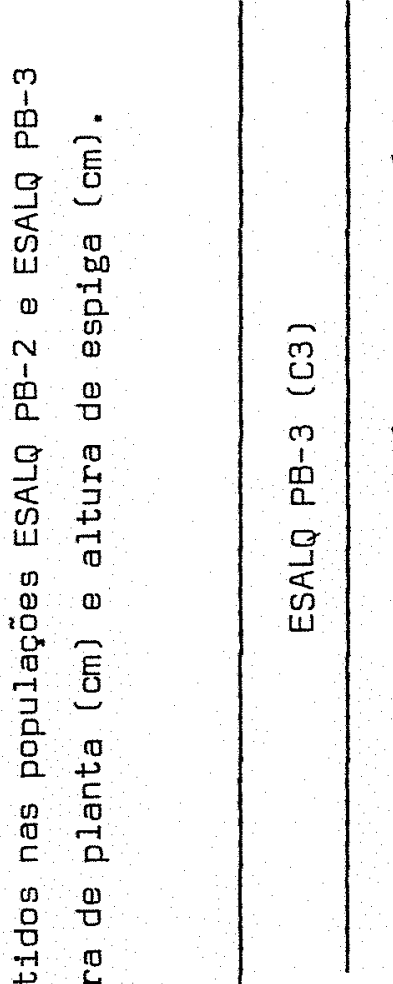

$\sum_{0}^{0}$

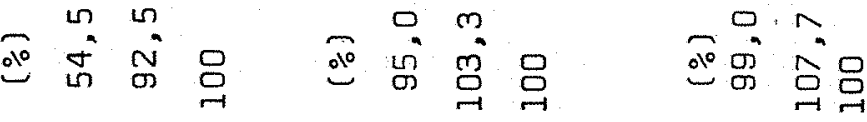

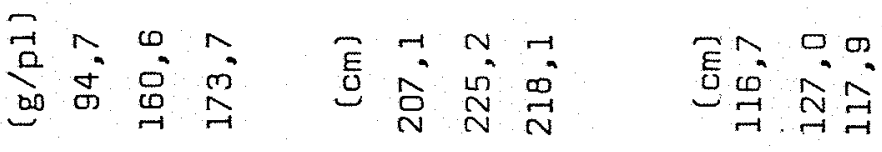

믐

인 吕

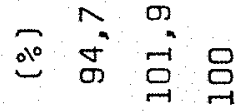

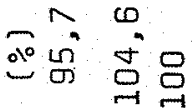

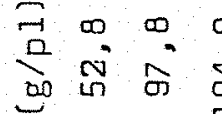

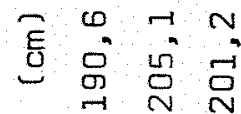

हैं

o $\quad m 0$

i०

i

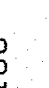

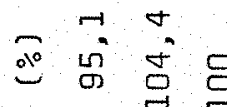

$-0 N$

品

궁

कo

in

$\stackrel{\infty}{\infty}$

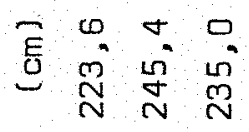

임

010

$\wedge r$

3

D.

गे ने 号

$\underbrace{\infty}_{m} \underbrace{\infty}_{-\rightarrow}$

号 음

战 음

ic

总 을

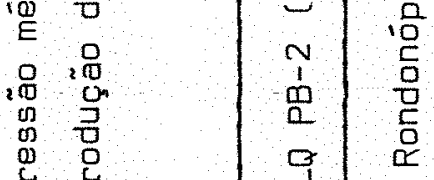

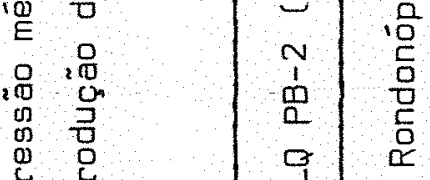

䆑

3
3
1
0
$\frac{1}{2}$
$\frac{1}{4}$
$u$

2 in $~ n$

$\underset{\sim}{\sim}$

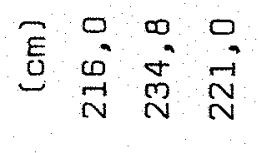

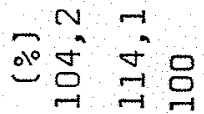

\begin{tabular}{ll|l}
4 & \\
0 & 0 \\
0 & $\frac{1}{4}$ \\
0 & 0
\end{tabular}

(1)

ง.

- 0

总

is o

$\begin{array}{ll}5 & 0 \\ 0 & 0 \\ & \stackrel{0}{0} \\ > & 0\end{array}$

$\overrightarrow{-1}$

品

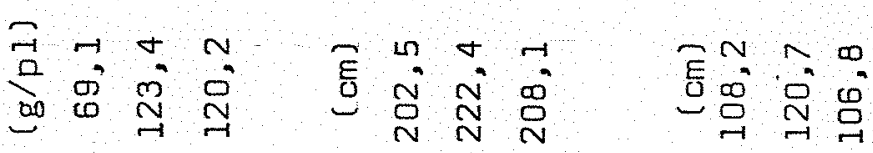

0
0
0
0
0

$-m$

की in का

은 की

윰ำ

吾

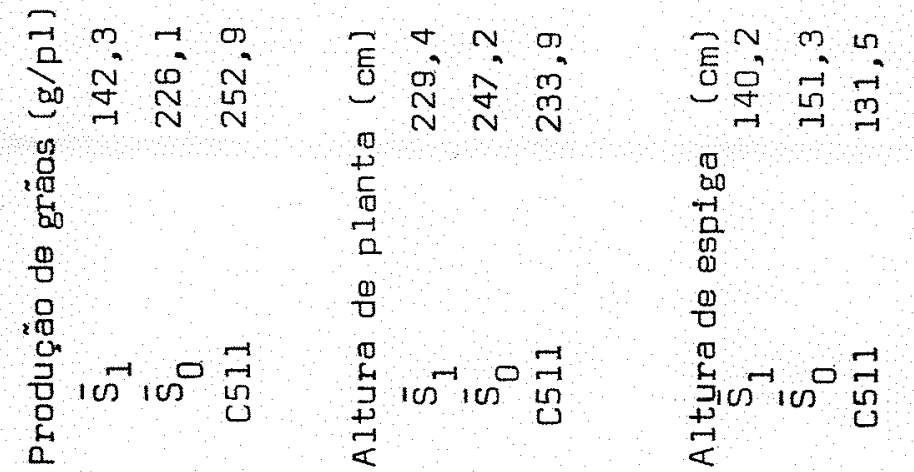




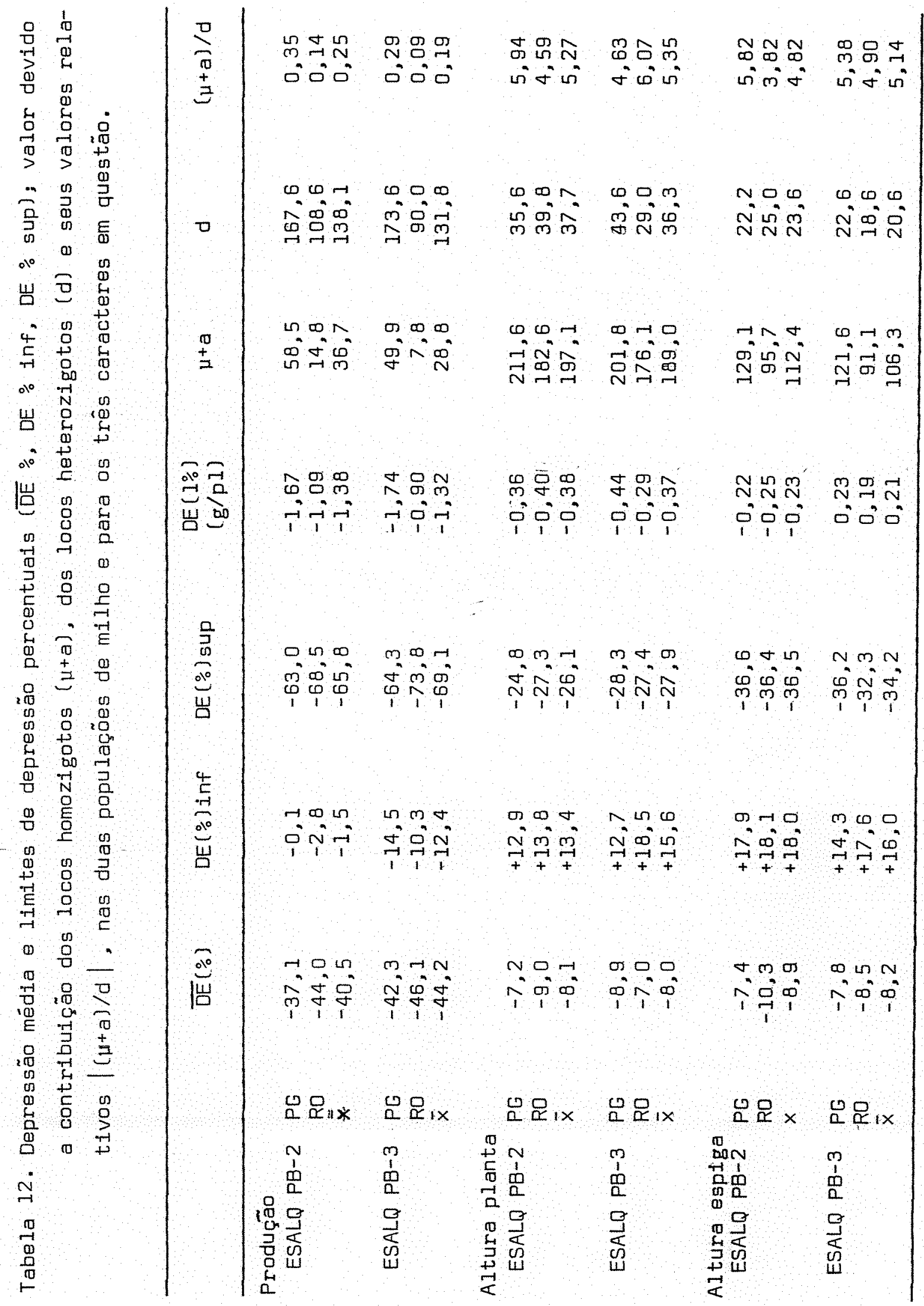




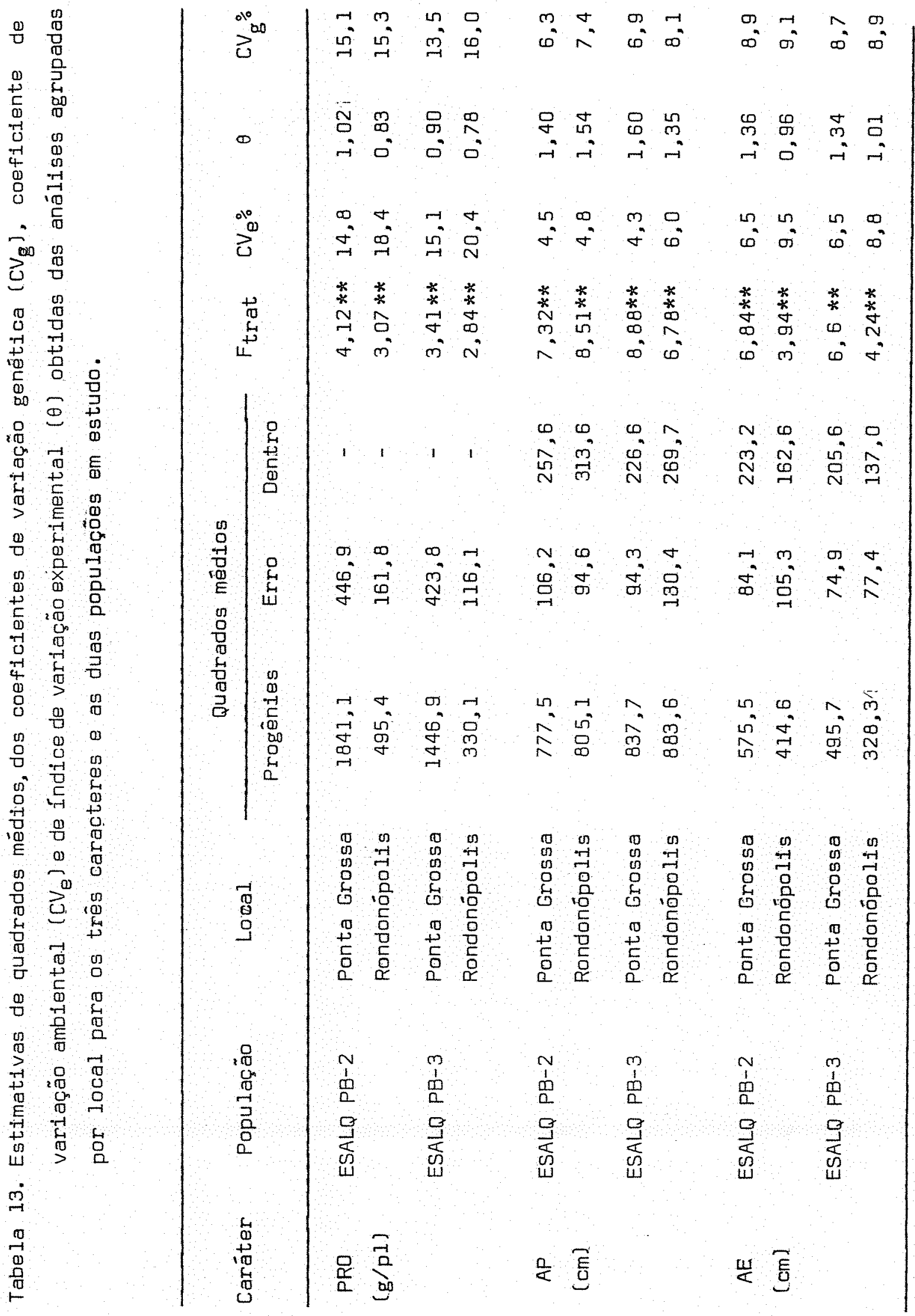




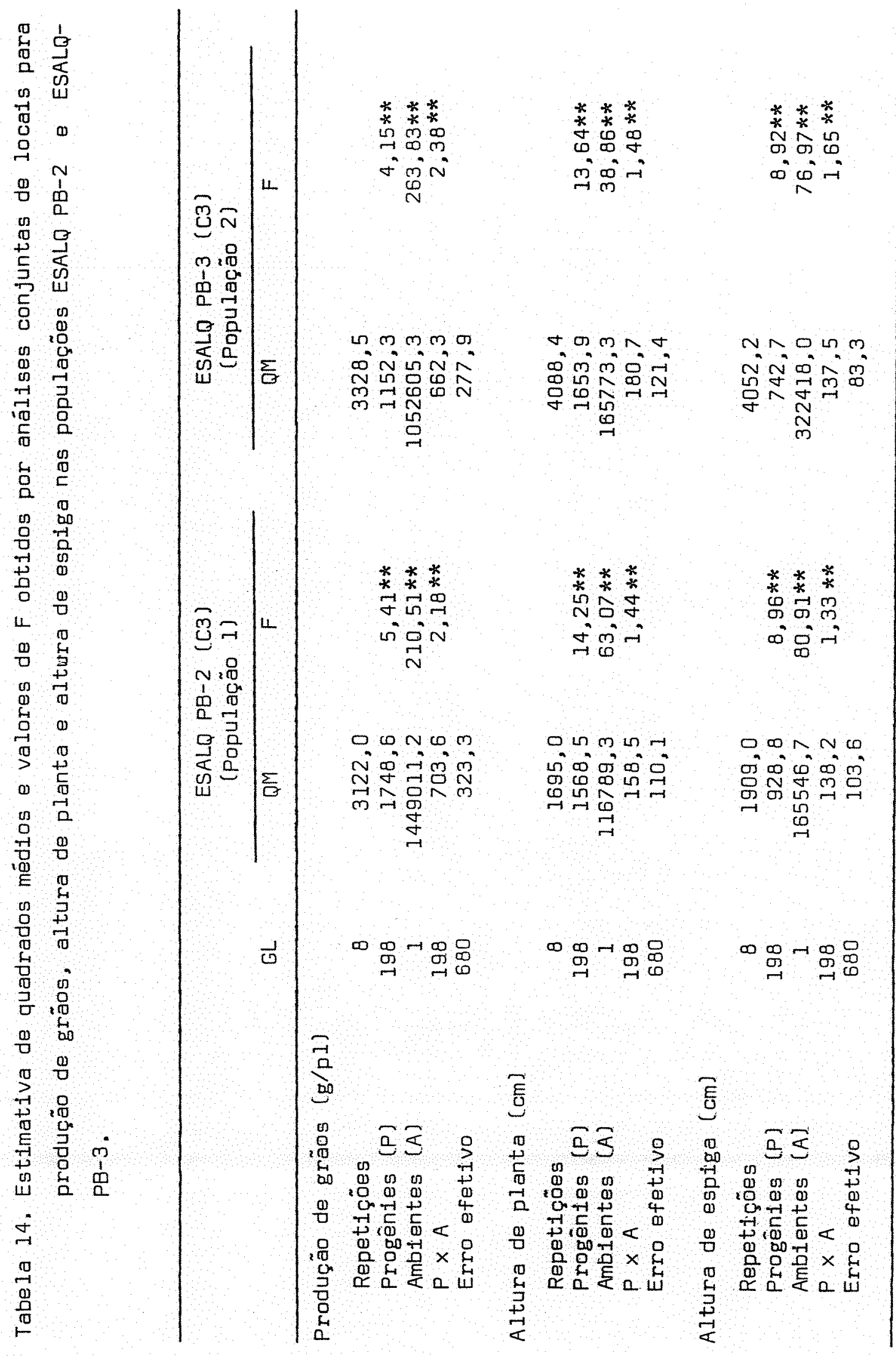




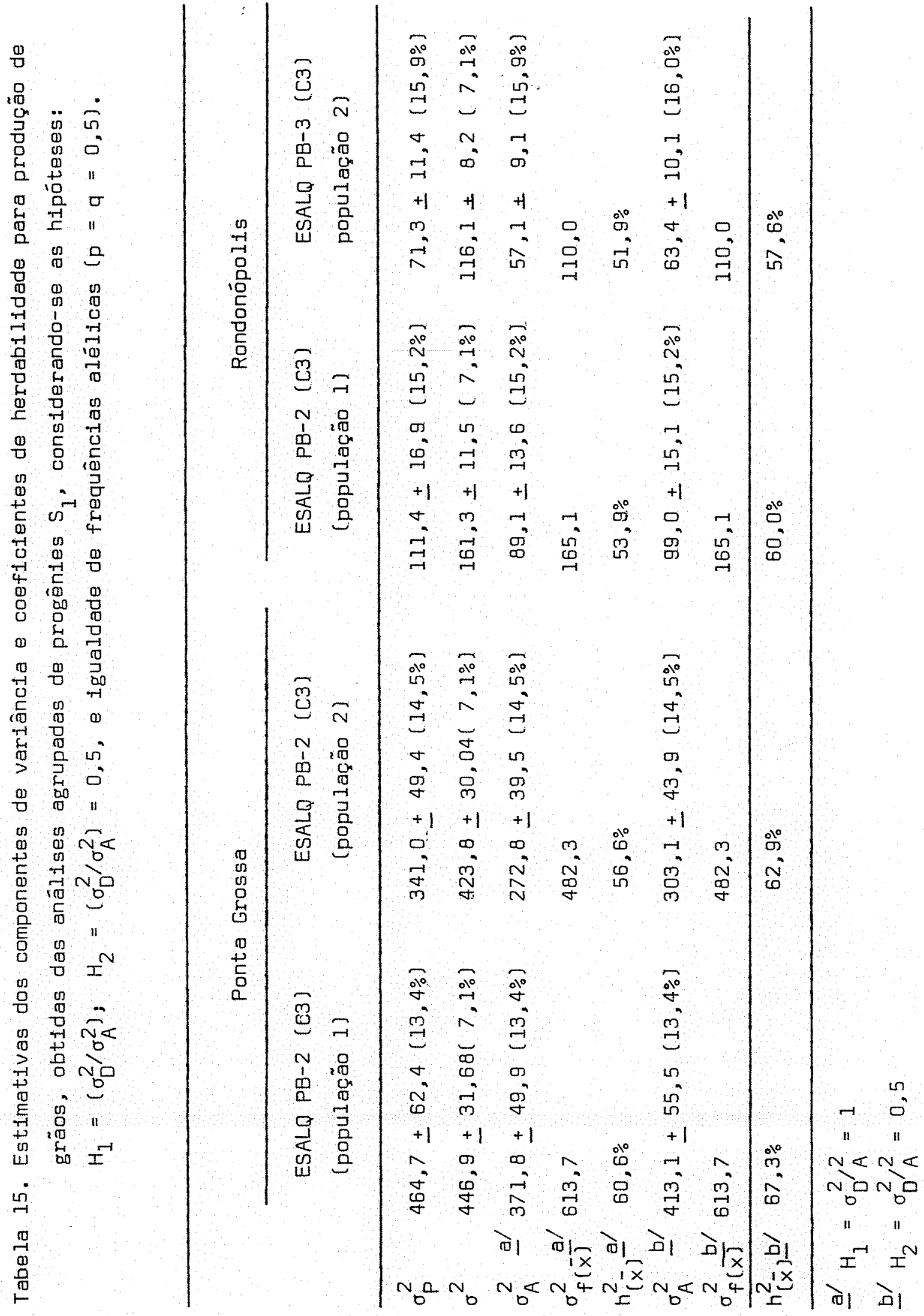



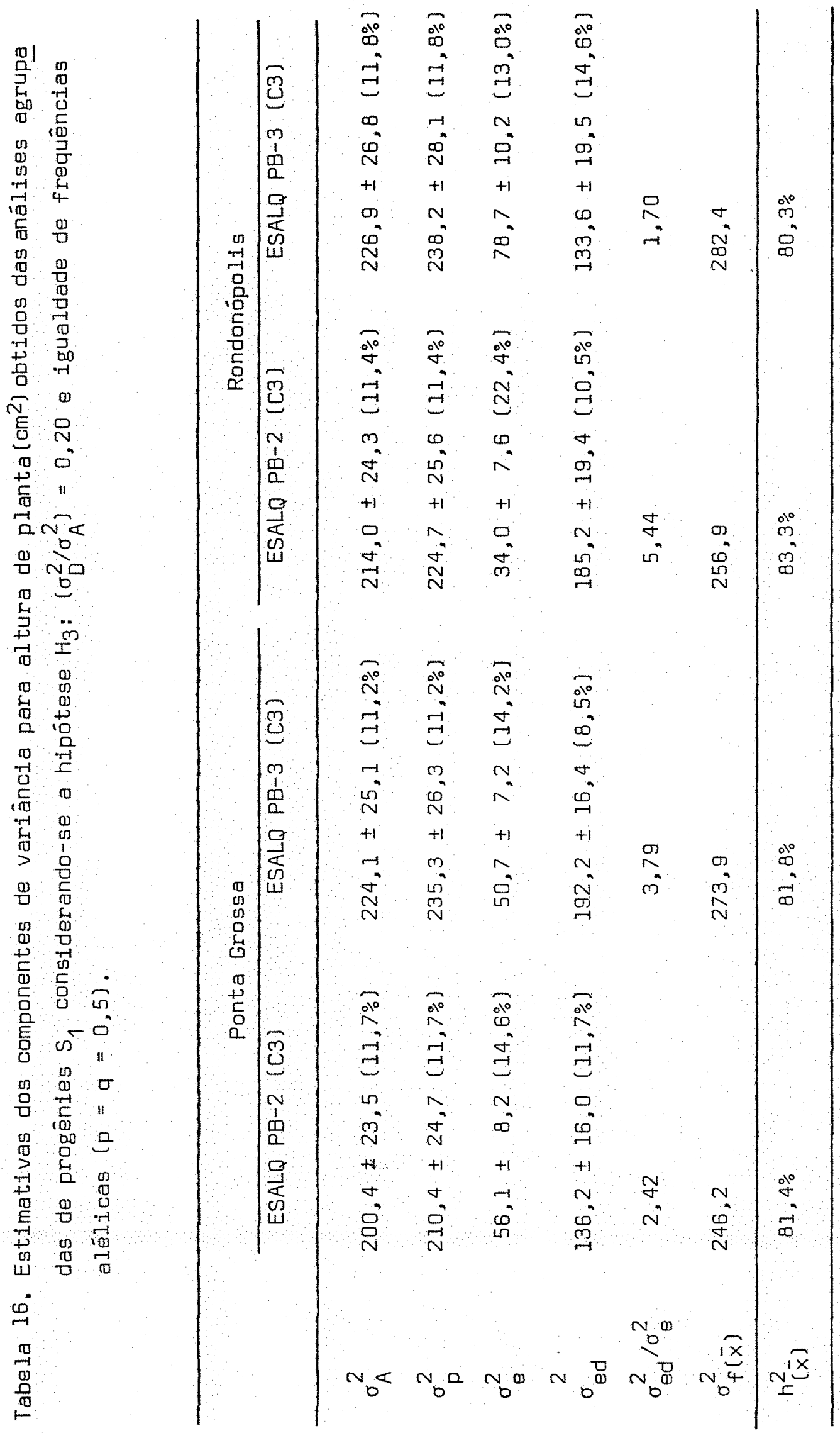


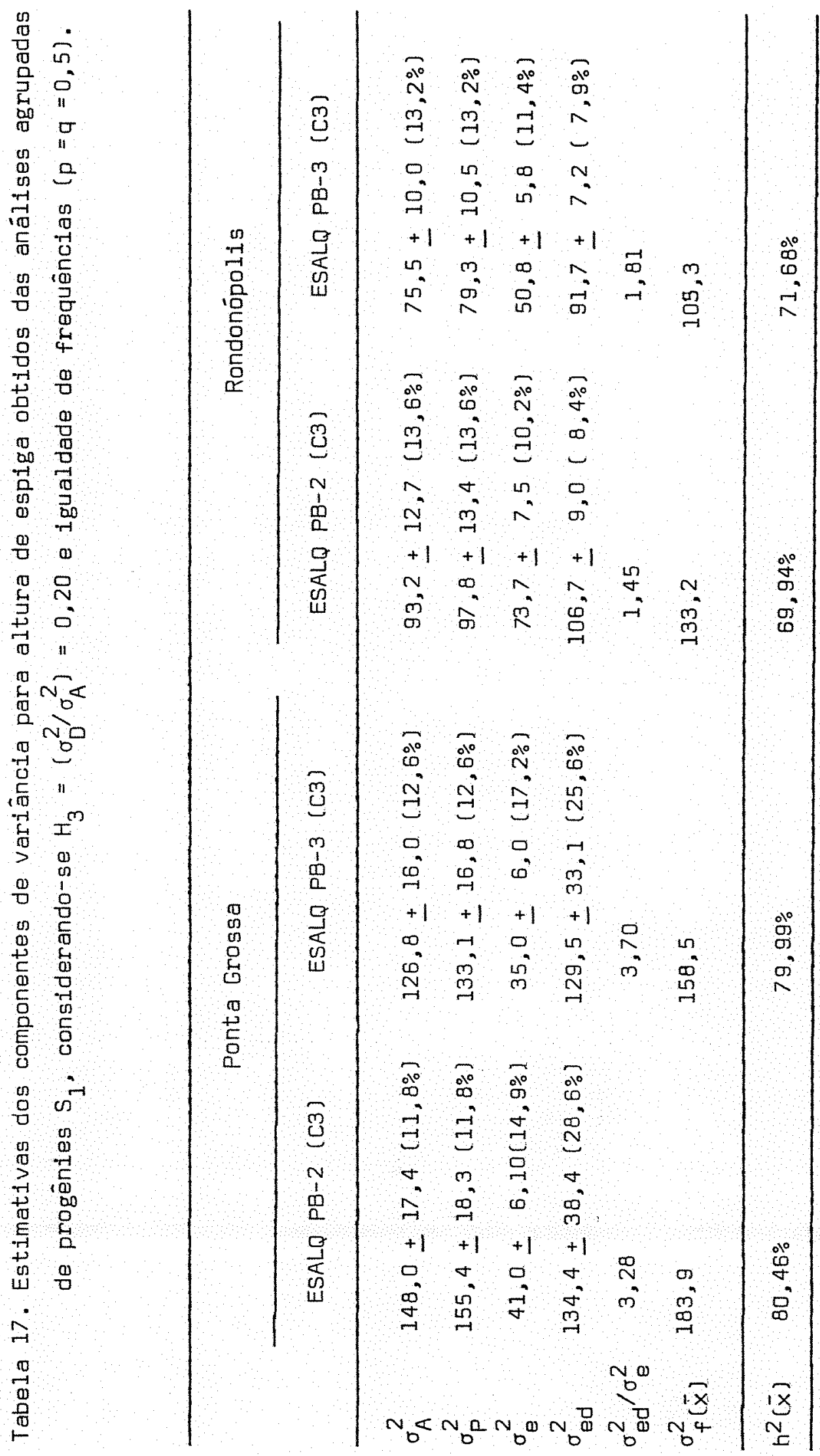



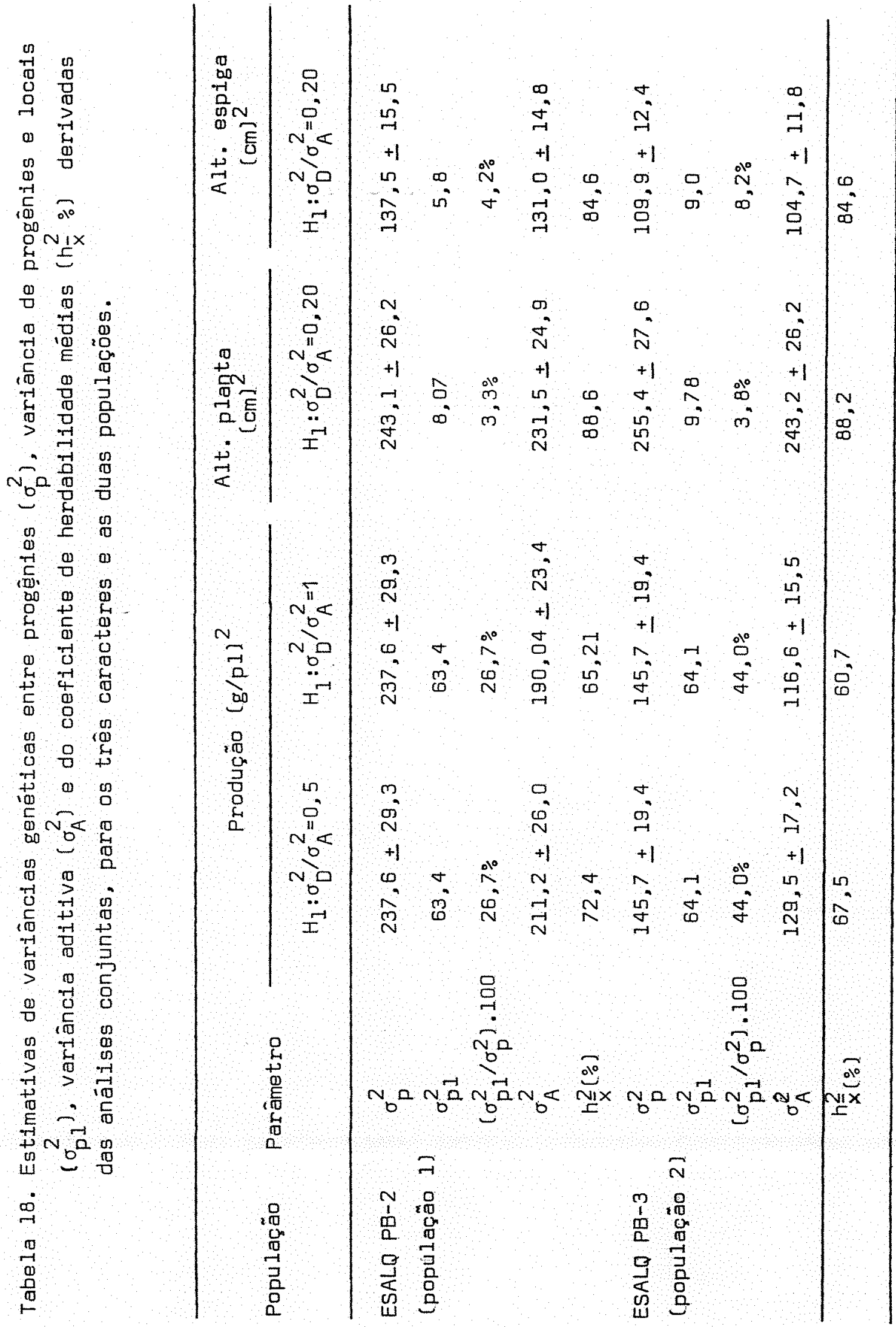


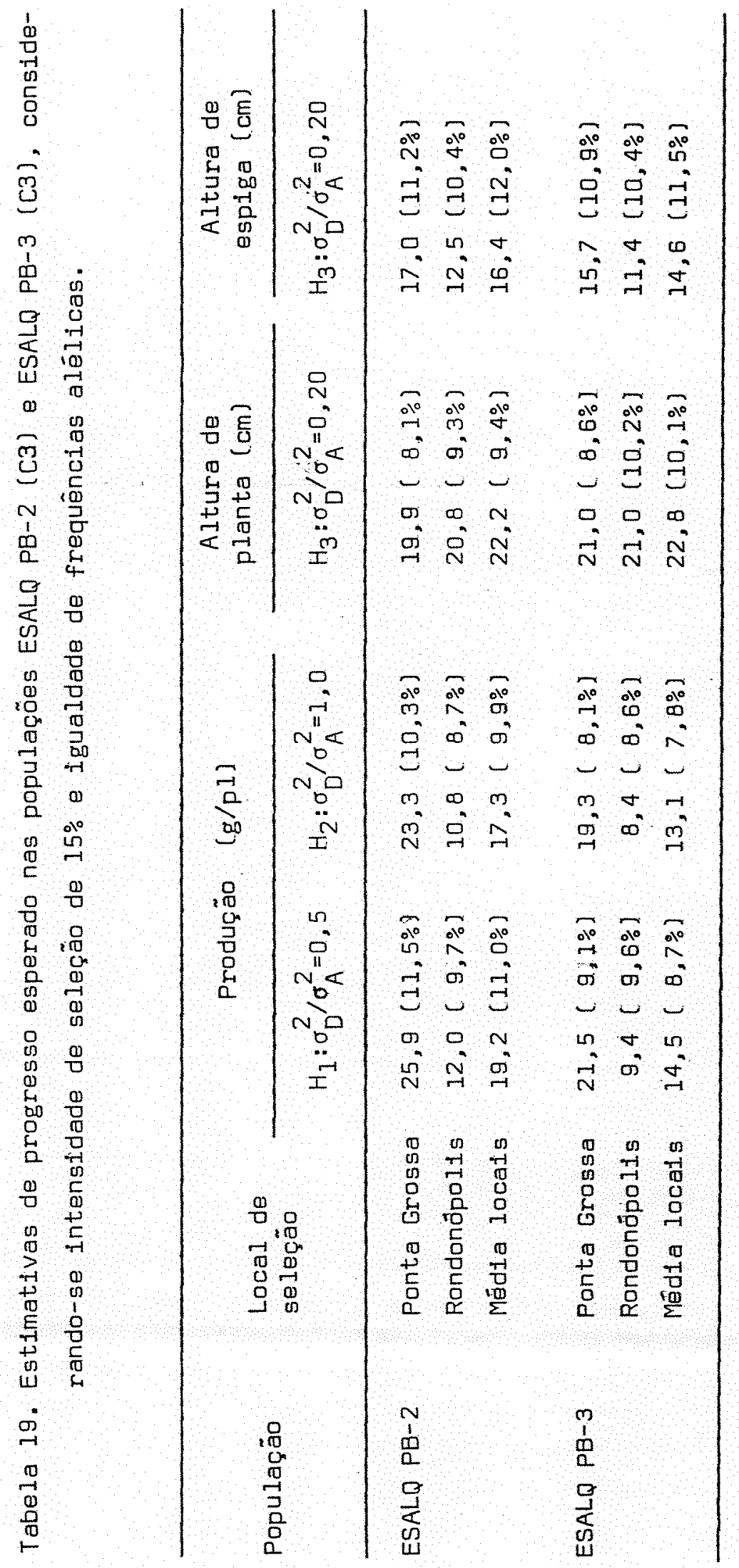




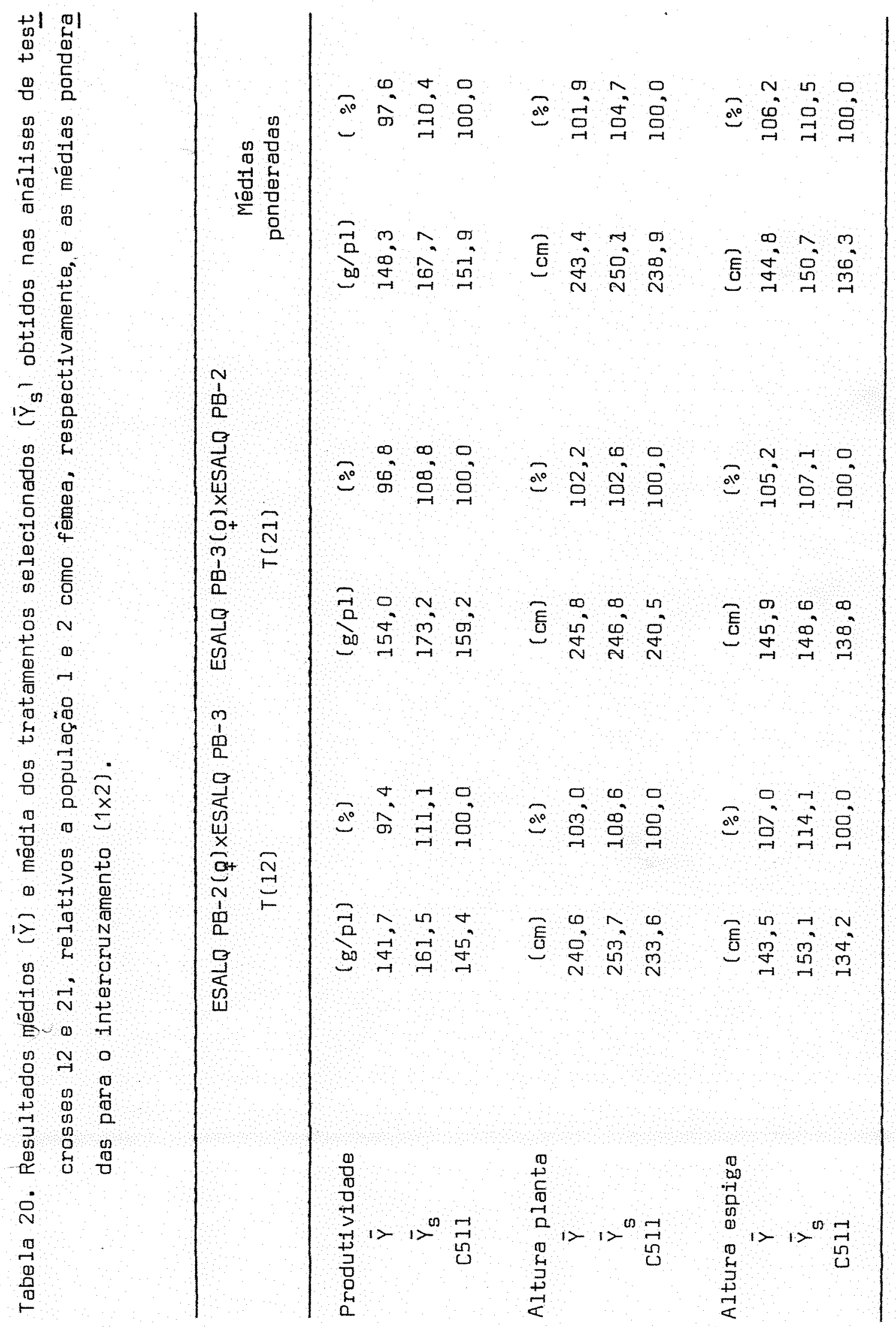




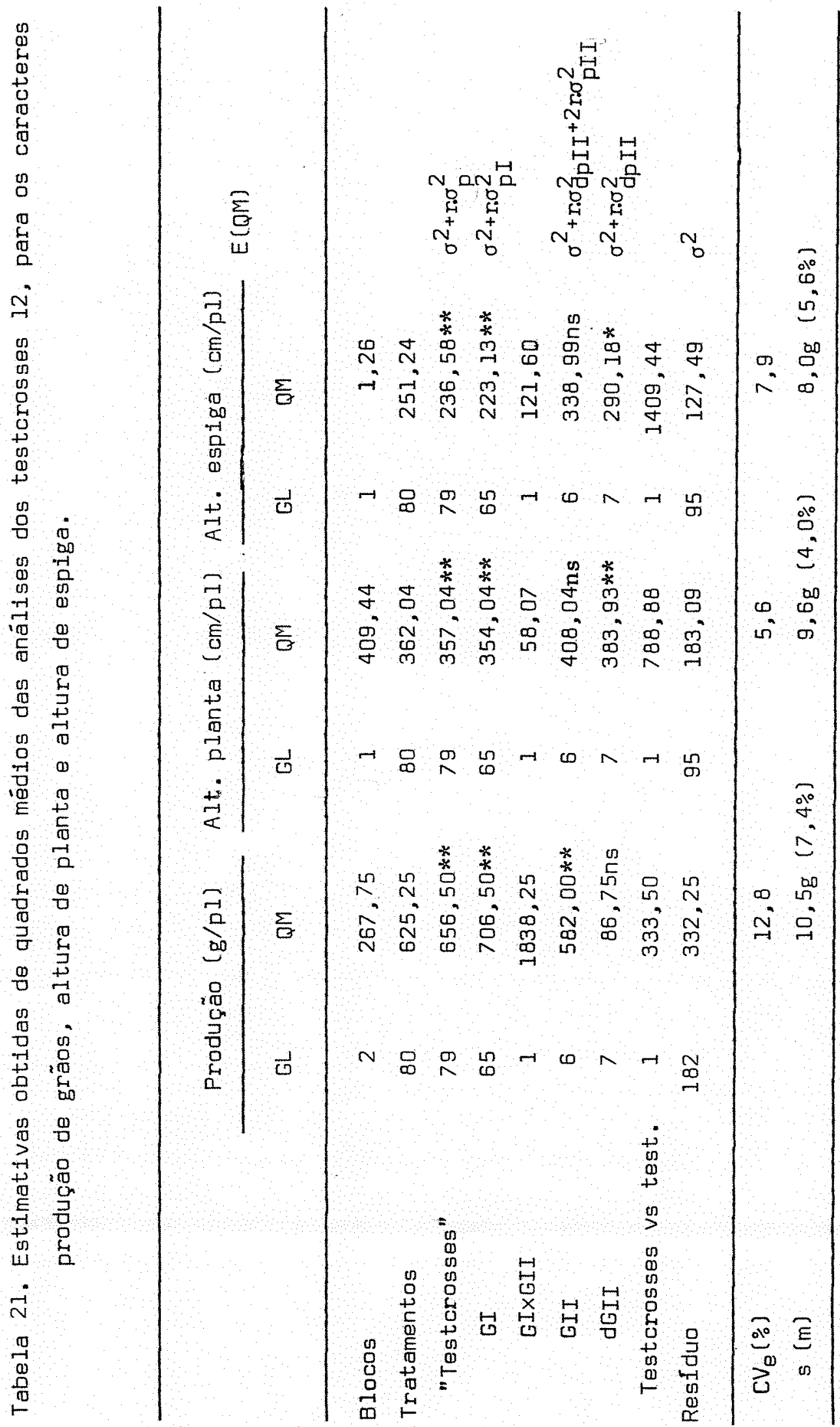




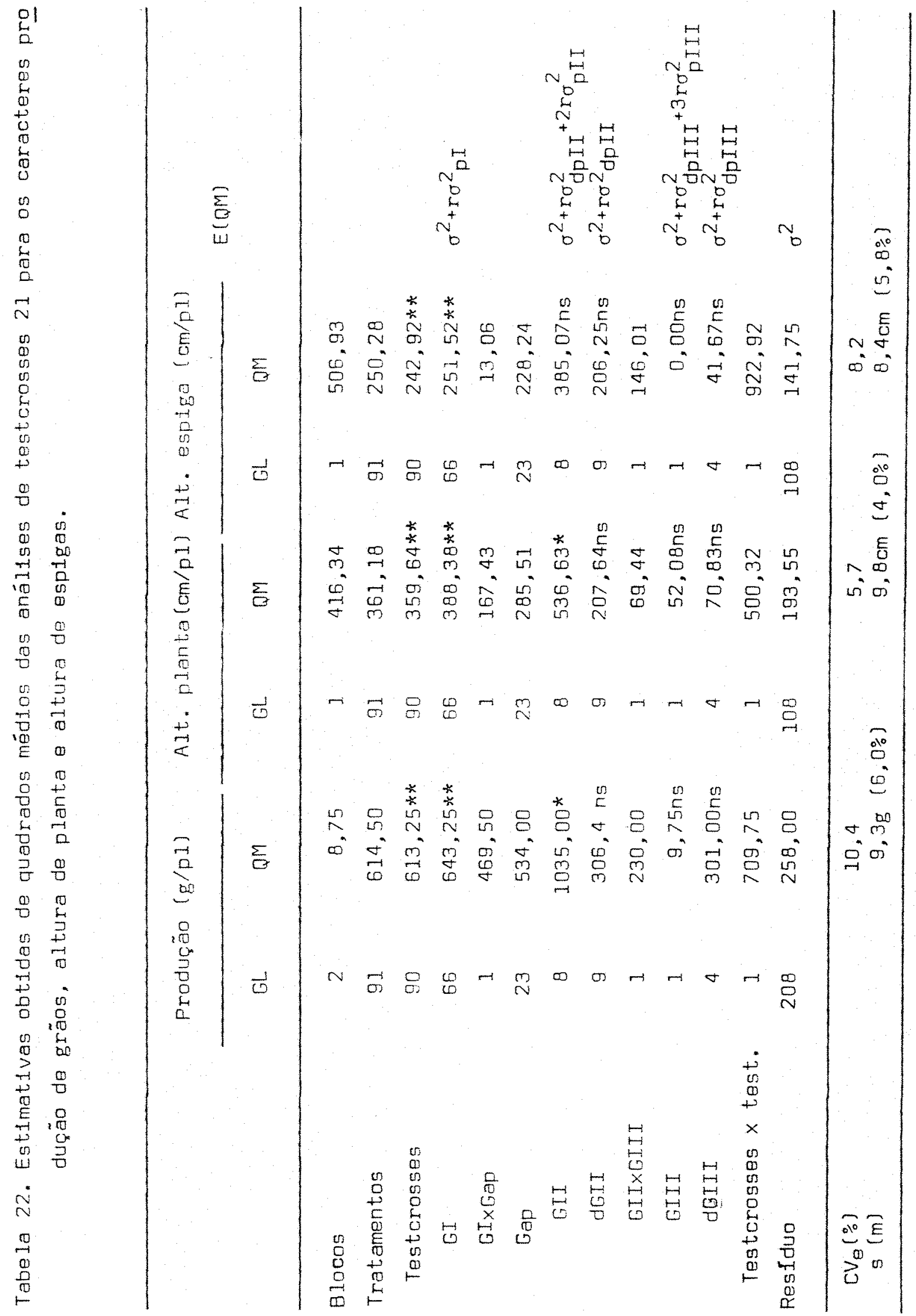




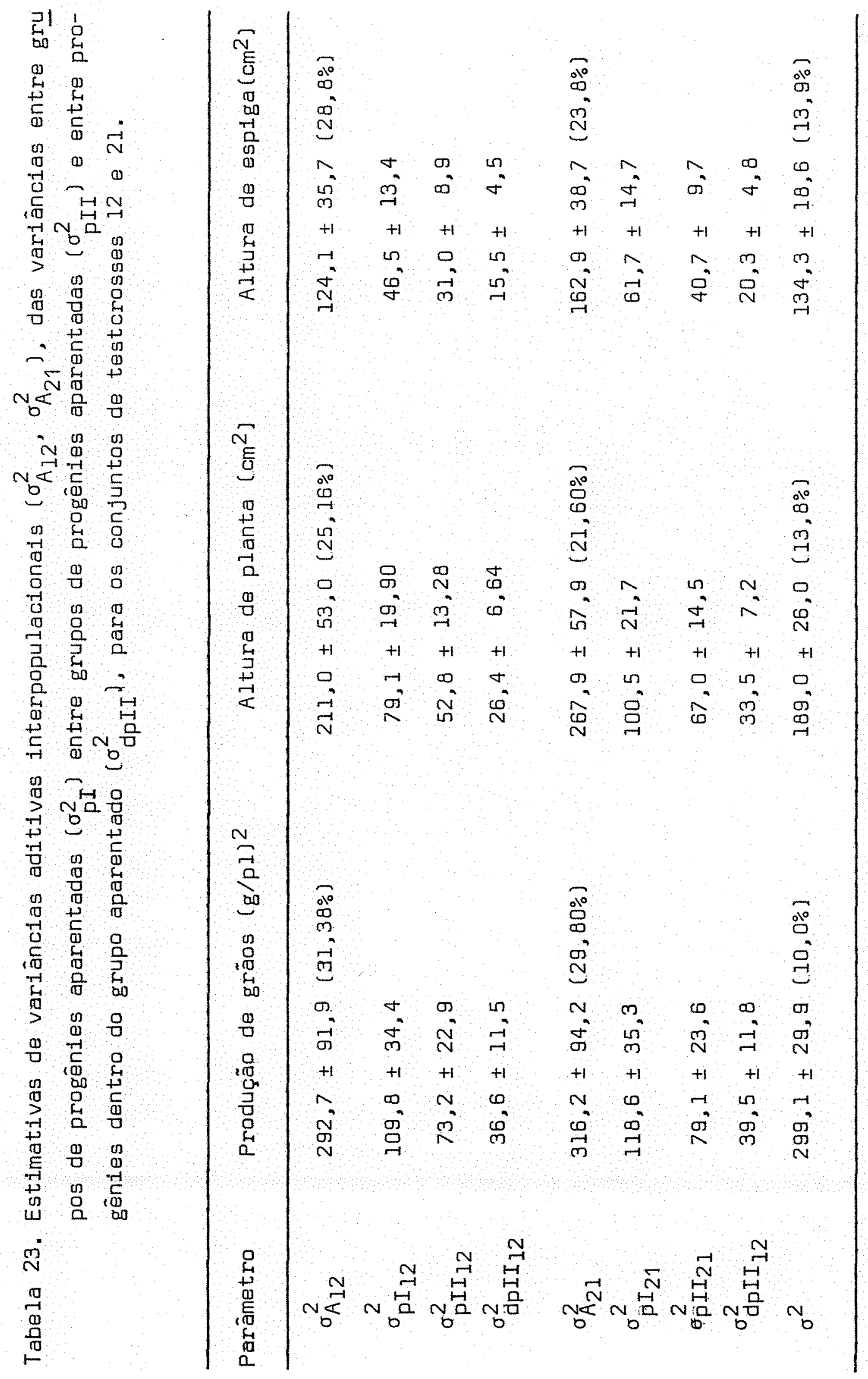




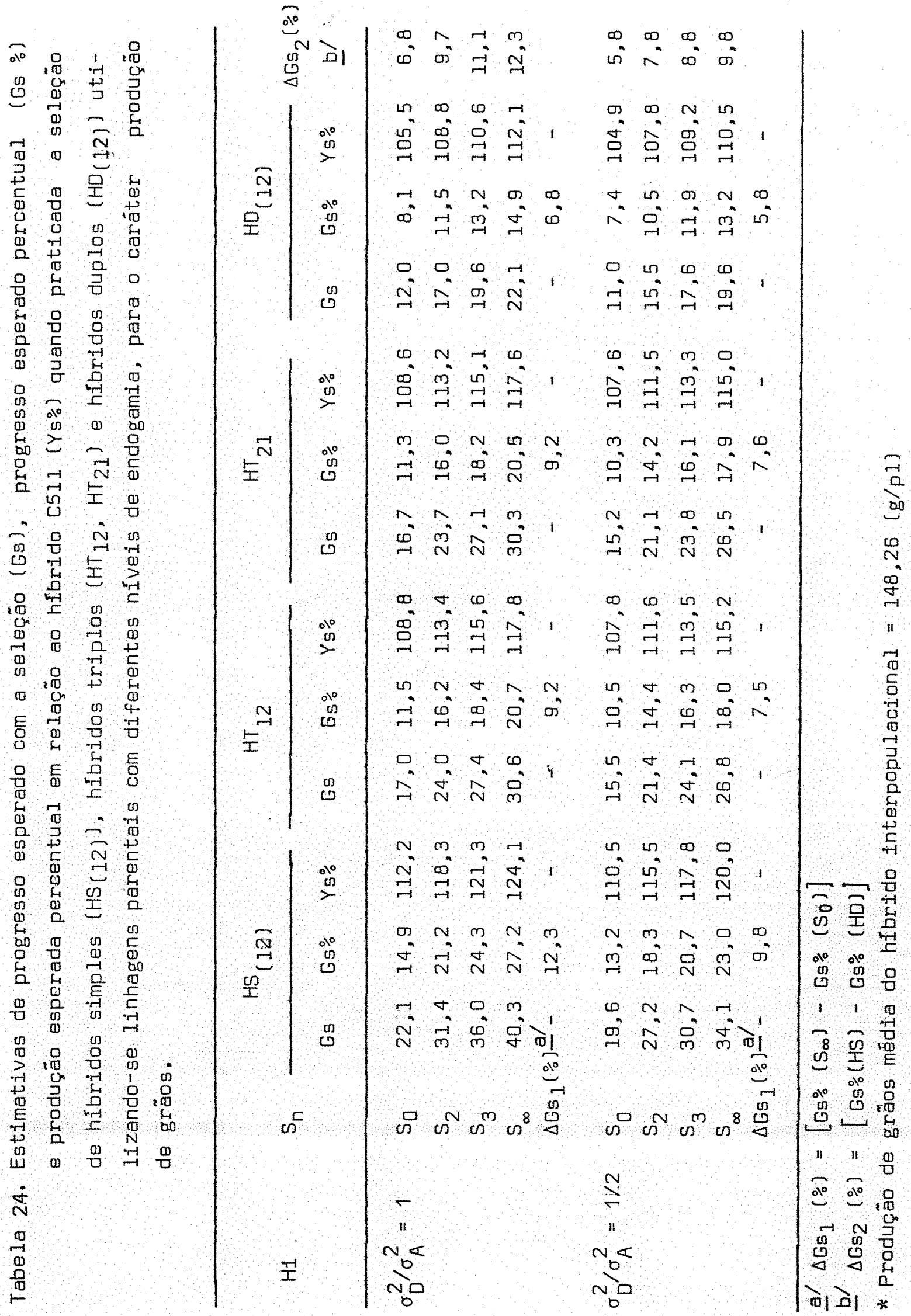




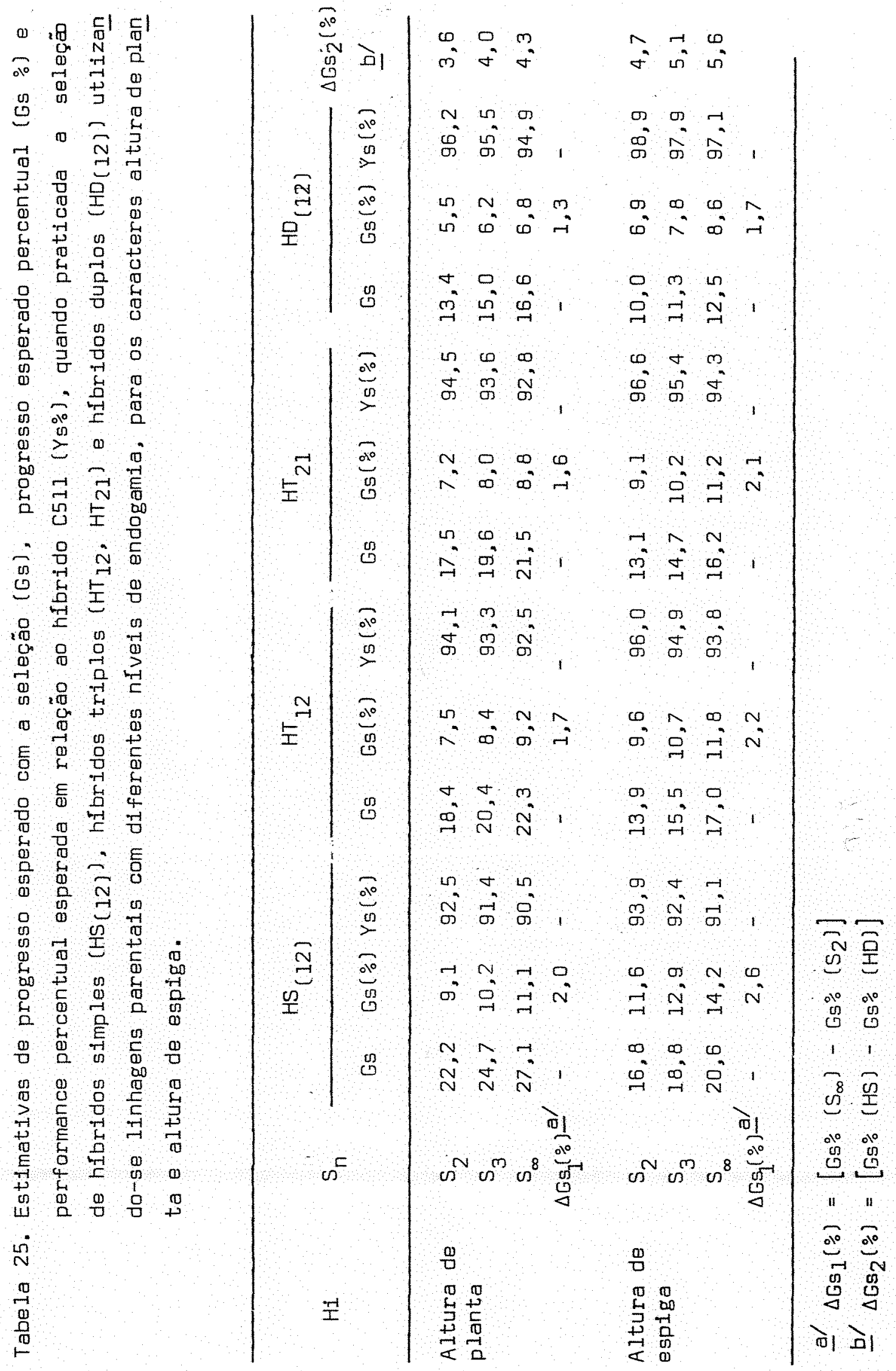




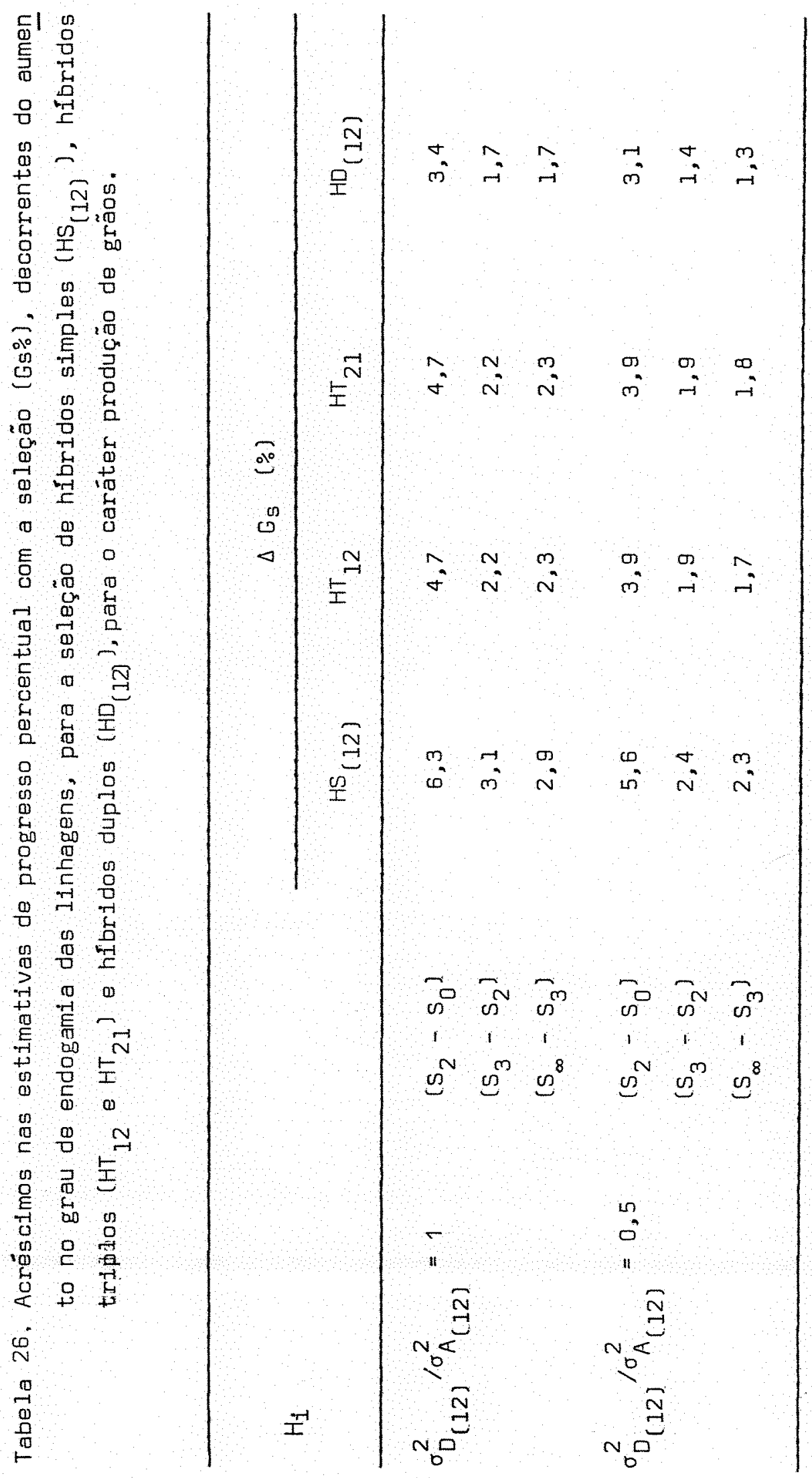


FIGURAS 

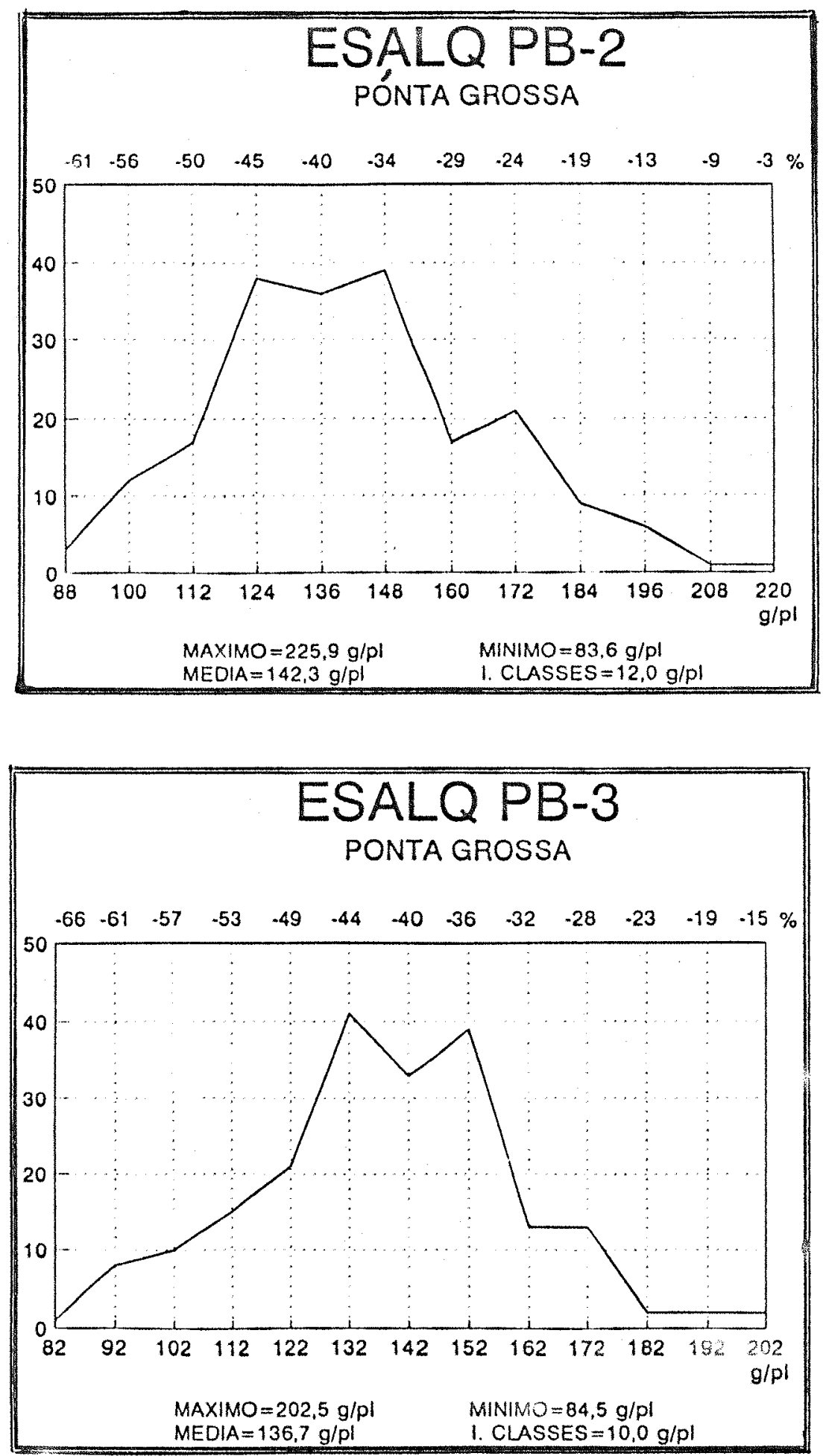

Figura 2. Distribuições observadas das progénies $S_{1}$ e seus desvios parcen tuais em relação as respectivas populações $S_{O}$. para produção de grãos $(g / p l)$ em Ponta Grossa. 

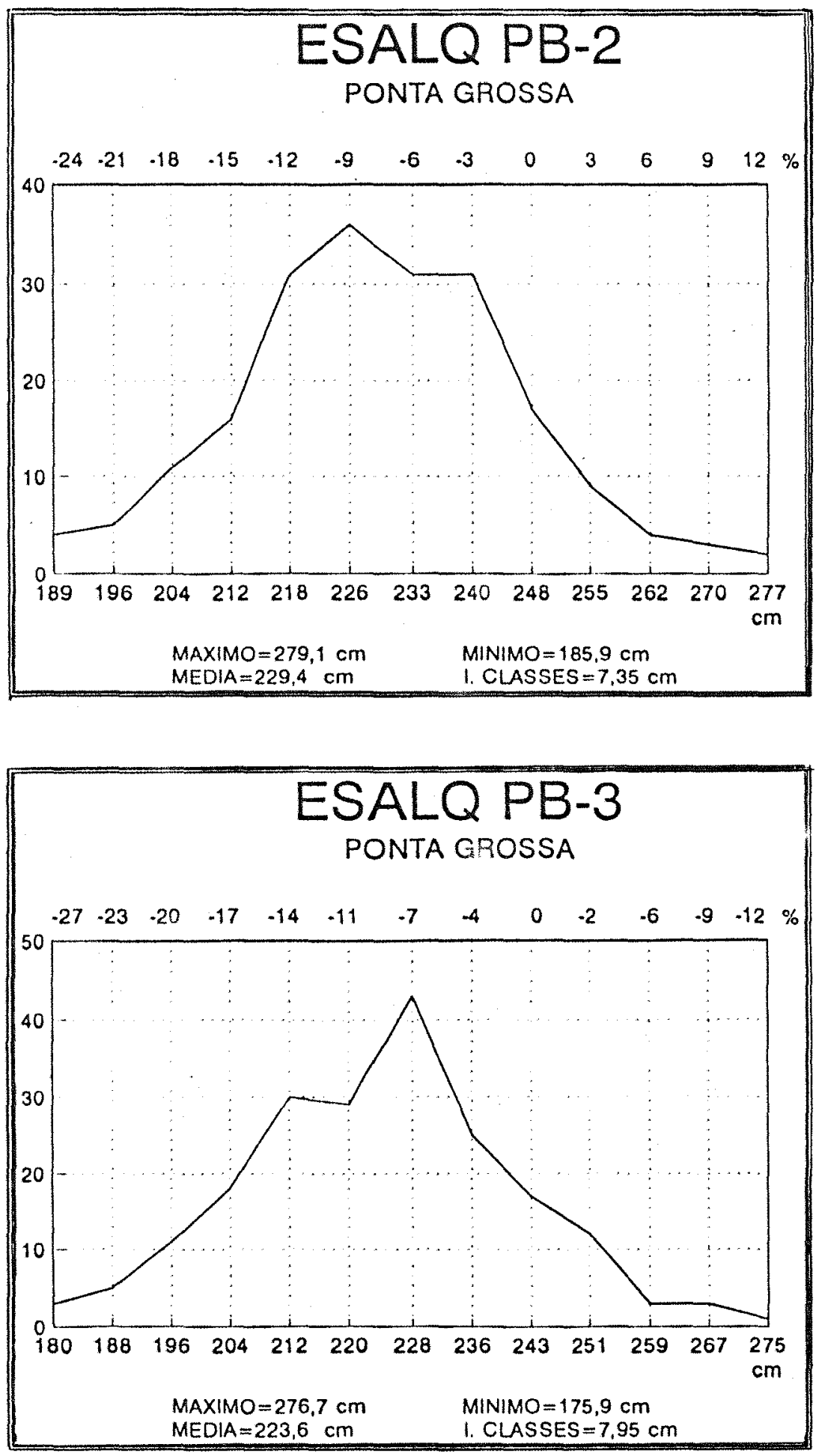

Figura 3. Distribuições abservadas das progênies $S_{1}$, e seus desvios percen tuais em relação as respectivas populações $S_{D}$, para altura de planta $(\mathrm{cm})$ em Ponta Grossa. 

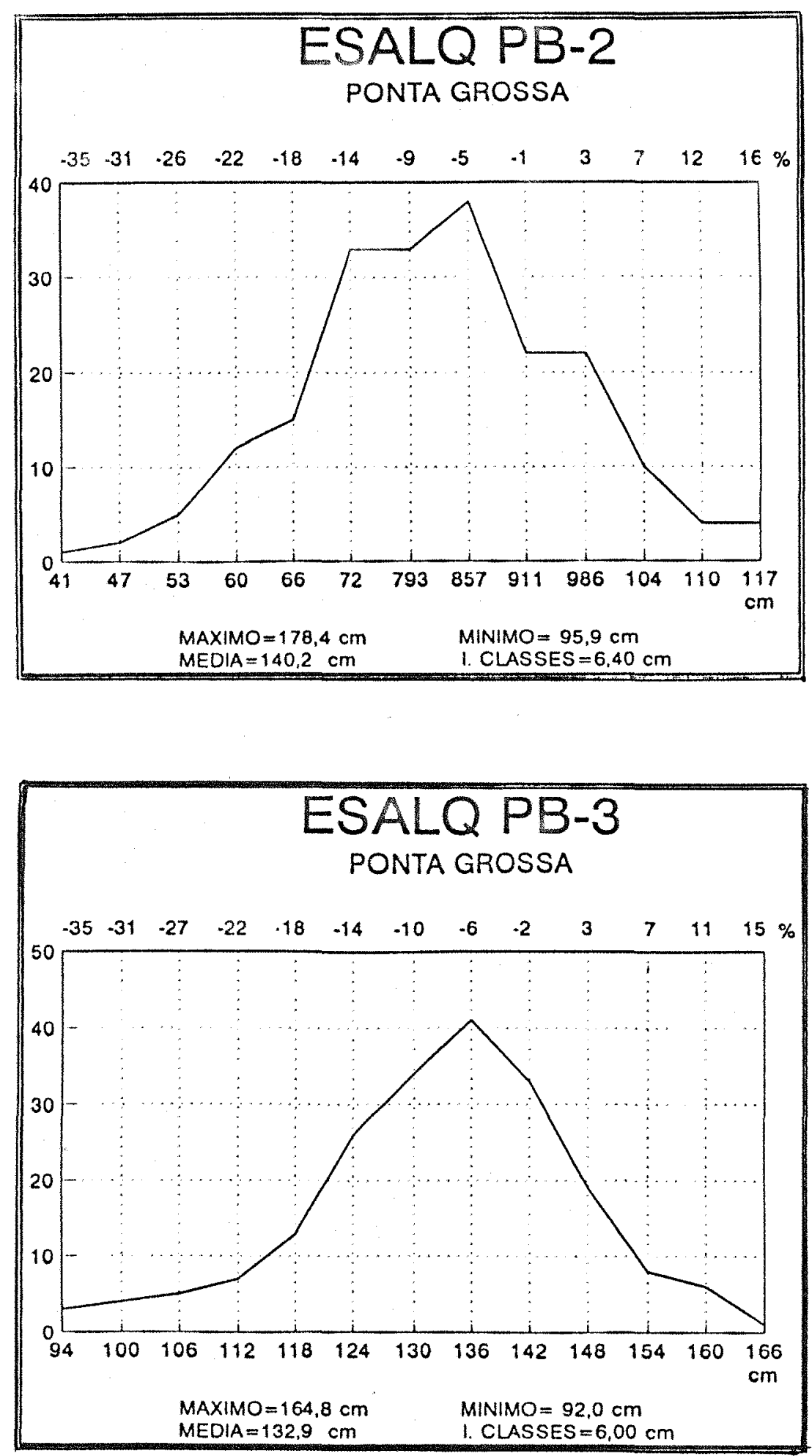

Figura 4. Distribuiçōes observadas das progēnies $S_{1}$ e seus desvios percen tuais em relação as respectivas populaçōes $S_{0}$. para altura de espiga $(\mathrm{cm})$, em Ponta Grossa. 

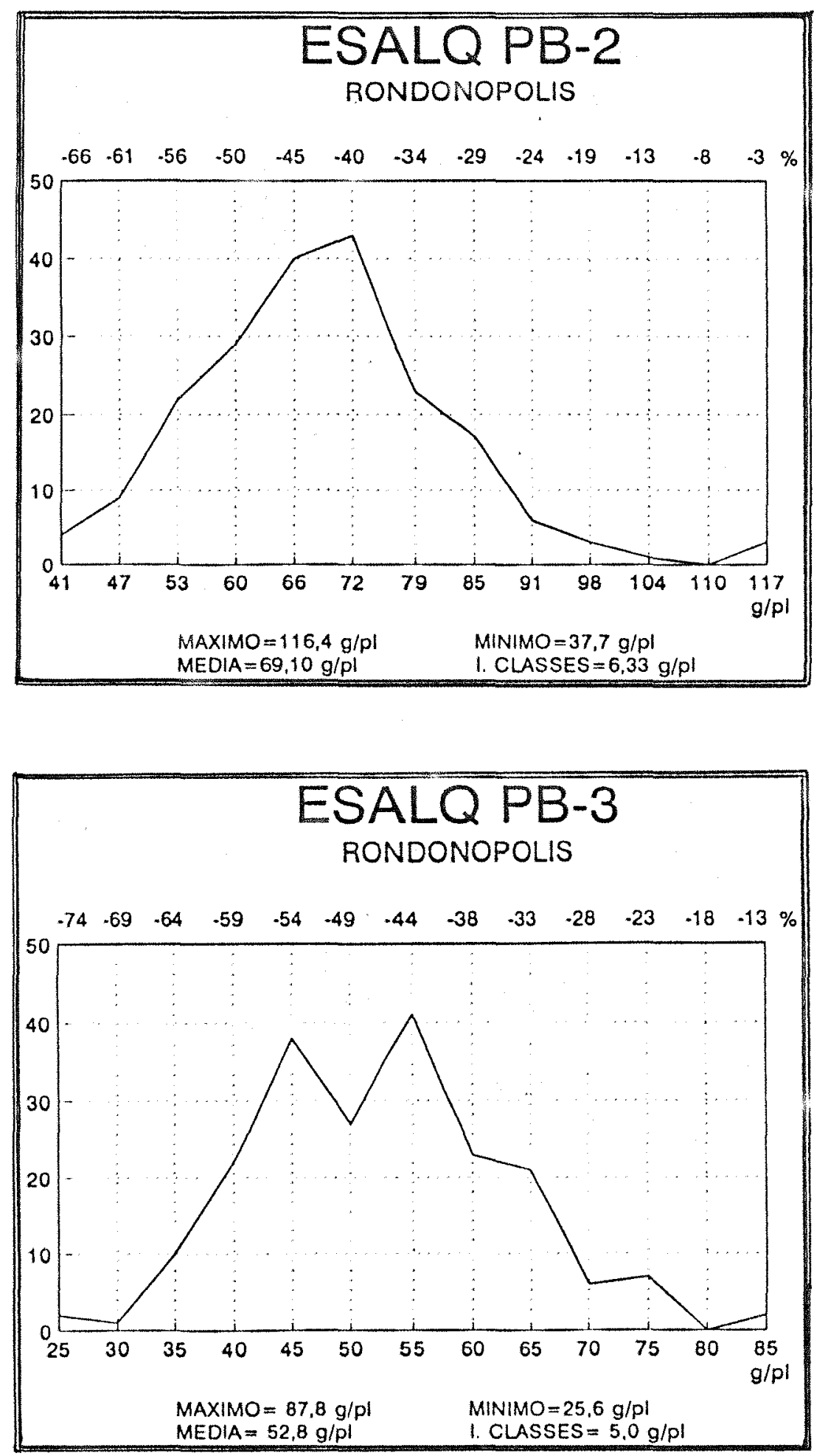

Figura 5. Distribuições observadas das progénies $S_{1}$ e seus desvios percen. tuais em relação as respectivas populações $S_{O^{\prime}}$ para produção de gräos $(g / p l)$, em Rondonöpolis. 

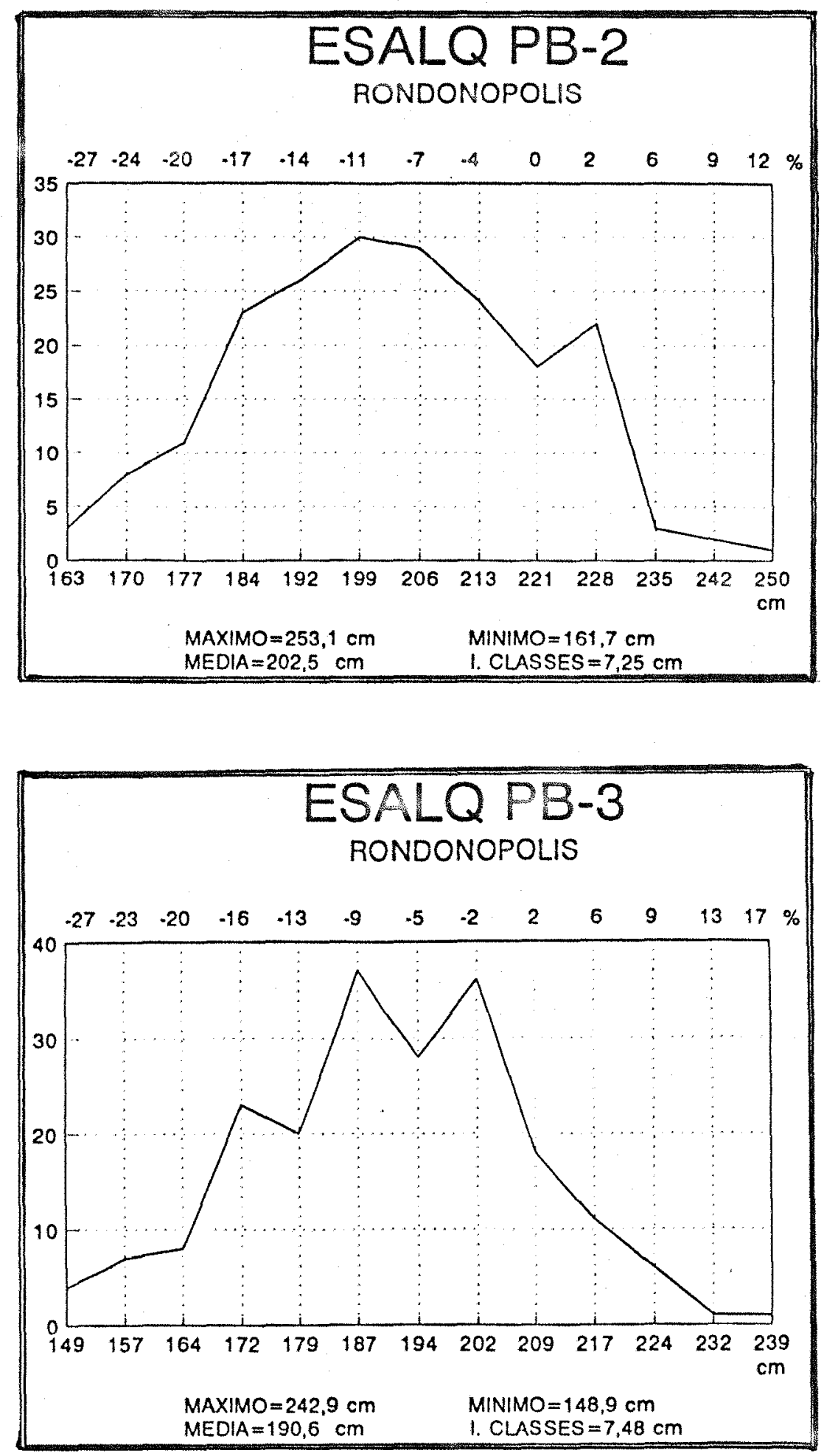

Figura 6. Distribuiçōes observadas das progēnies $S_{1}$ e seus desvios percen tuais em relação as respectivas populações $S_{0}$, para altura de planta $(\mathrm{cm})$, em Rondonöpolis. 

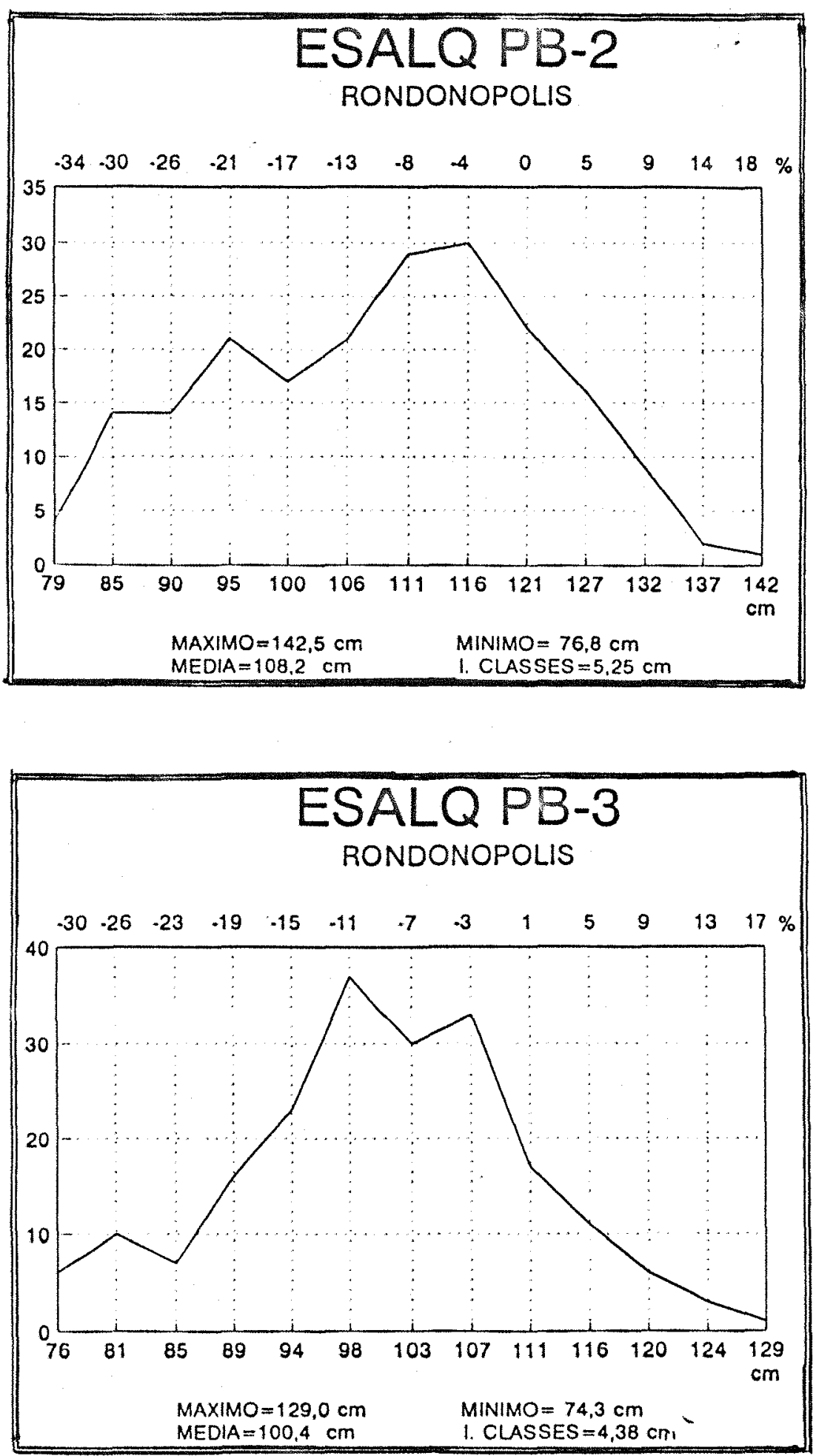

Figura 7. Distribuiçöes observadas das progênies $S_{1}$ e seus desvios percen tuais en relação as respectivas populações $S_{0}$, para altura de espiga $(\mathrm{cm})$, em Rondonópolis. 


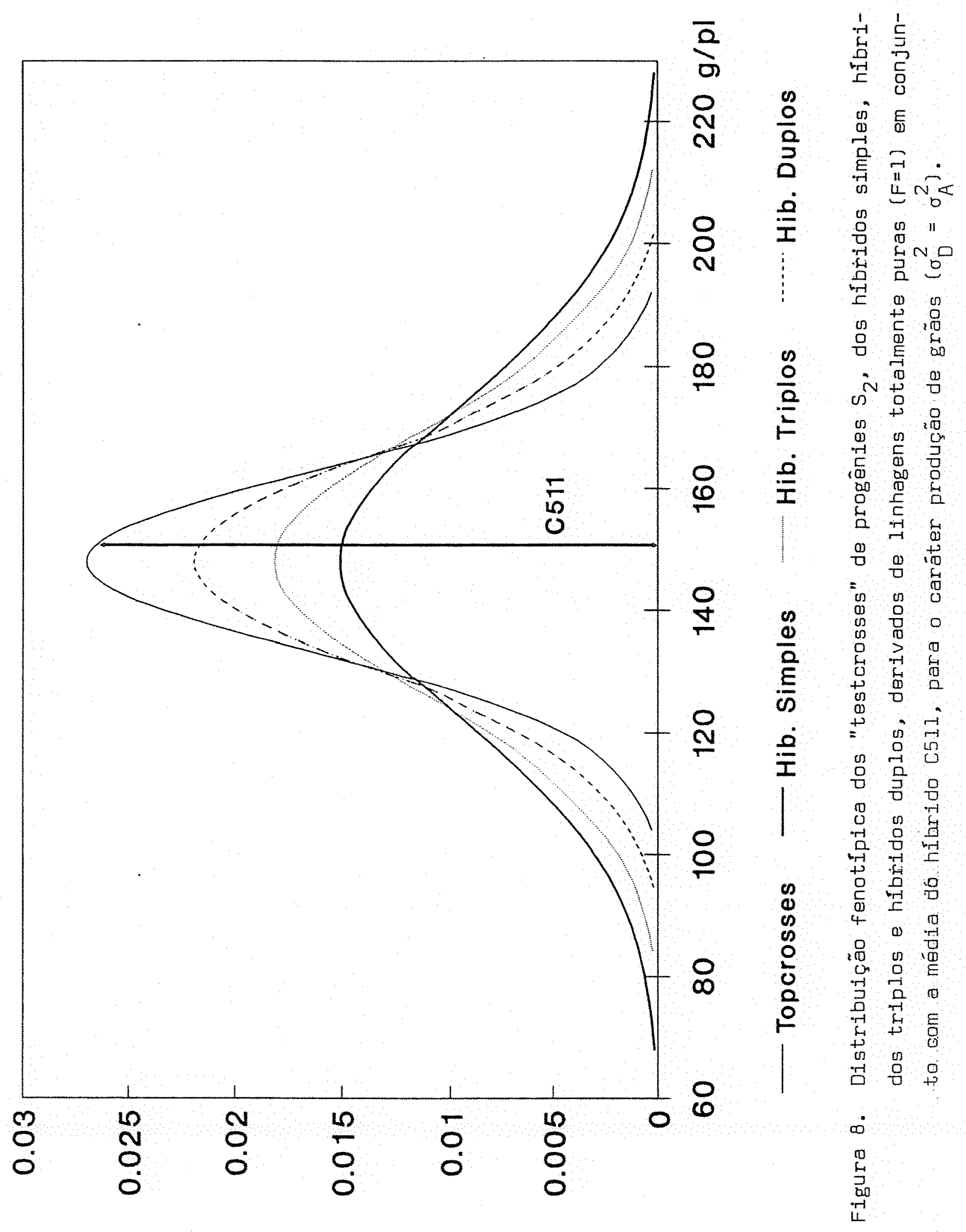




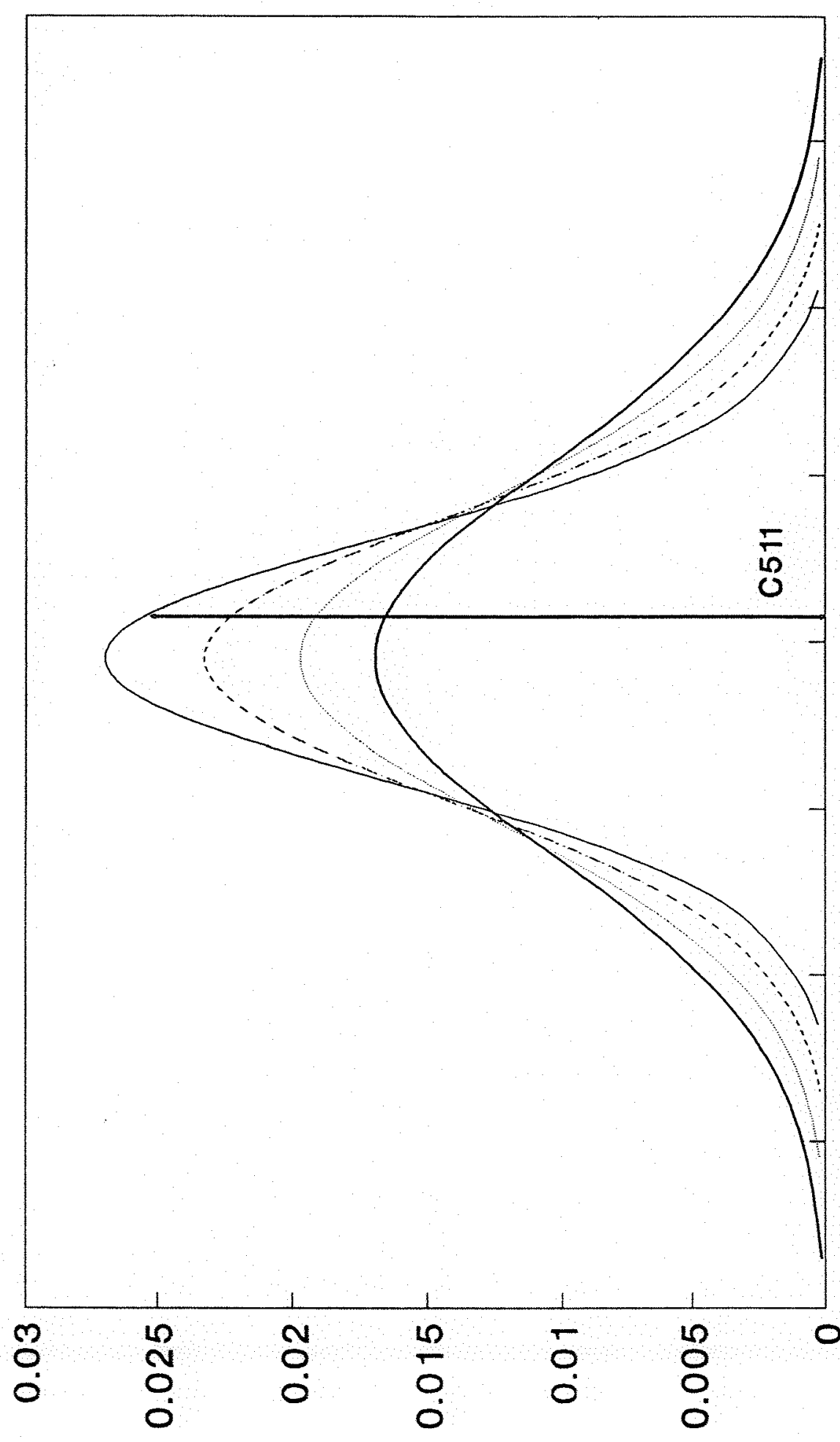

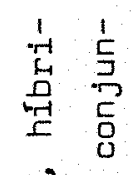

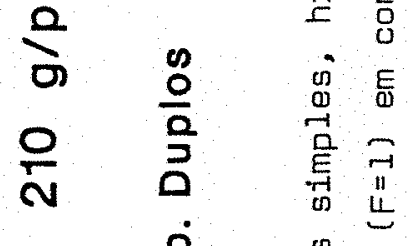

으 号

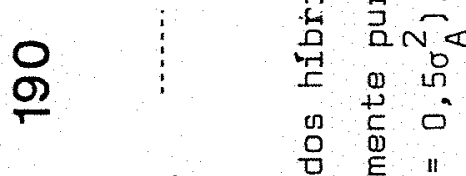

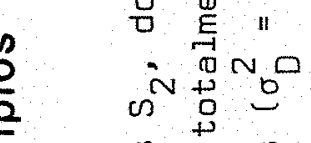

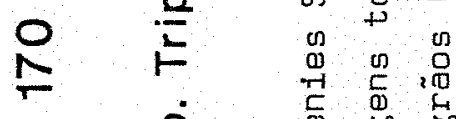

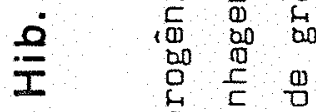

8

10

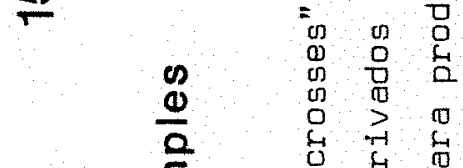

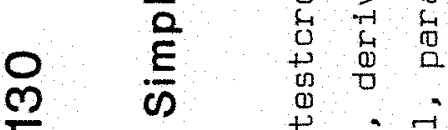

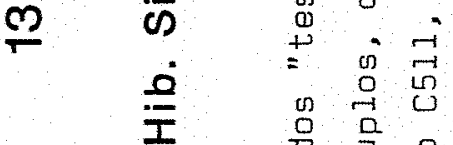

$\begin{array}{lllll} & 0 & 0 & 0 & 0 \\ 0 & 0 & 0 & 0 \\ 0 & 0 & 0 & 0 \\ 0 & 0 & 0 & 0 \\ 0 & 0\end{array}$

$\quad$ D

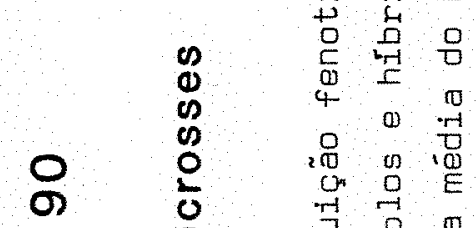

$\begin{array}{lllll}0 & \frac{1}{0} & 0 & 0 & E \\ 0 & 0 & 0 & 0 \\ 0 & 0 & & 0\end{array}$

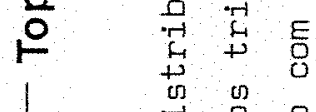

0

ती

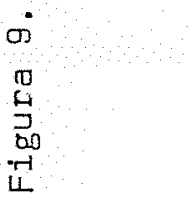




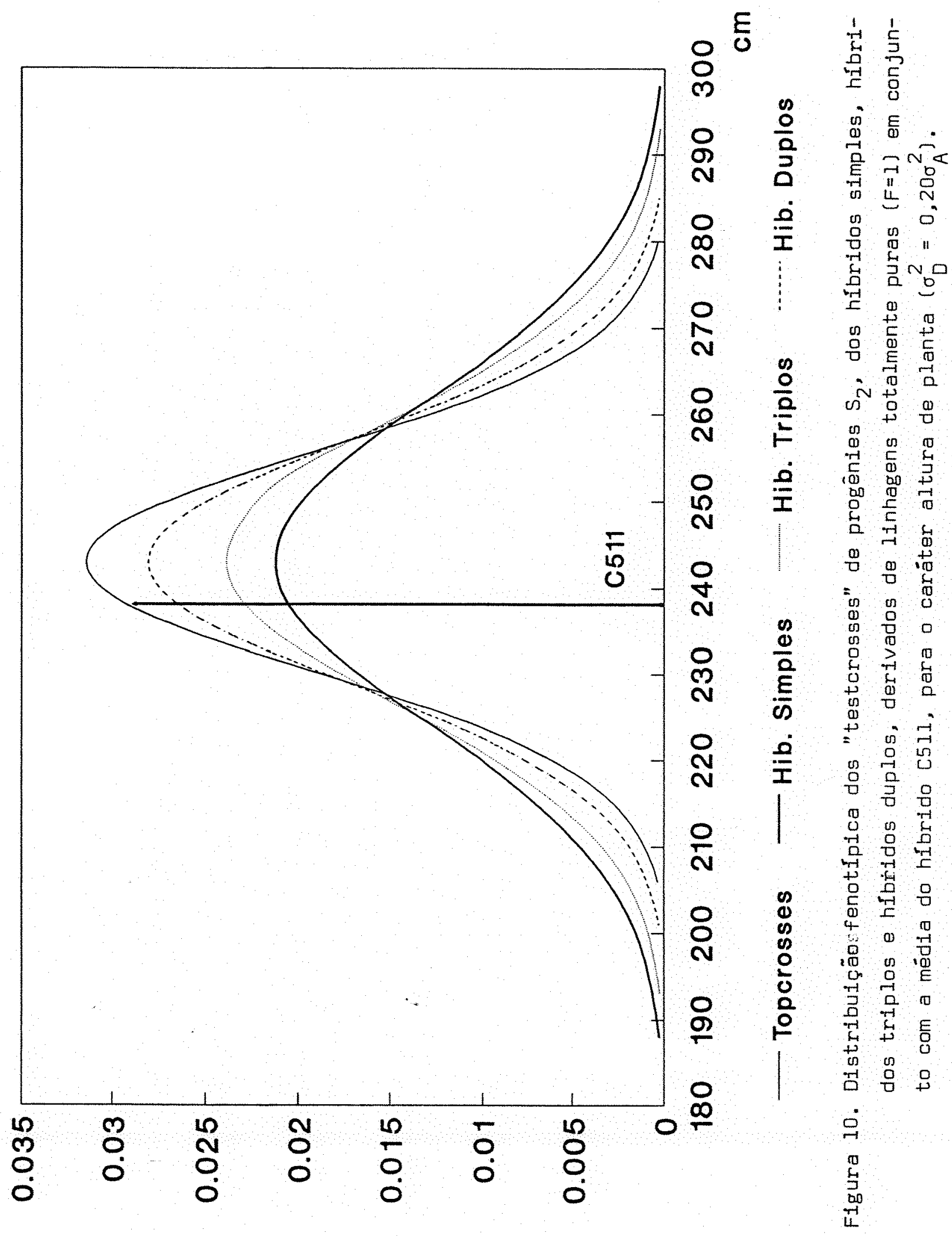




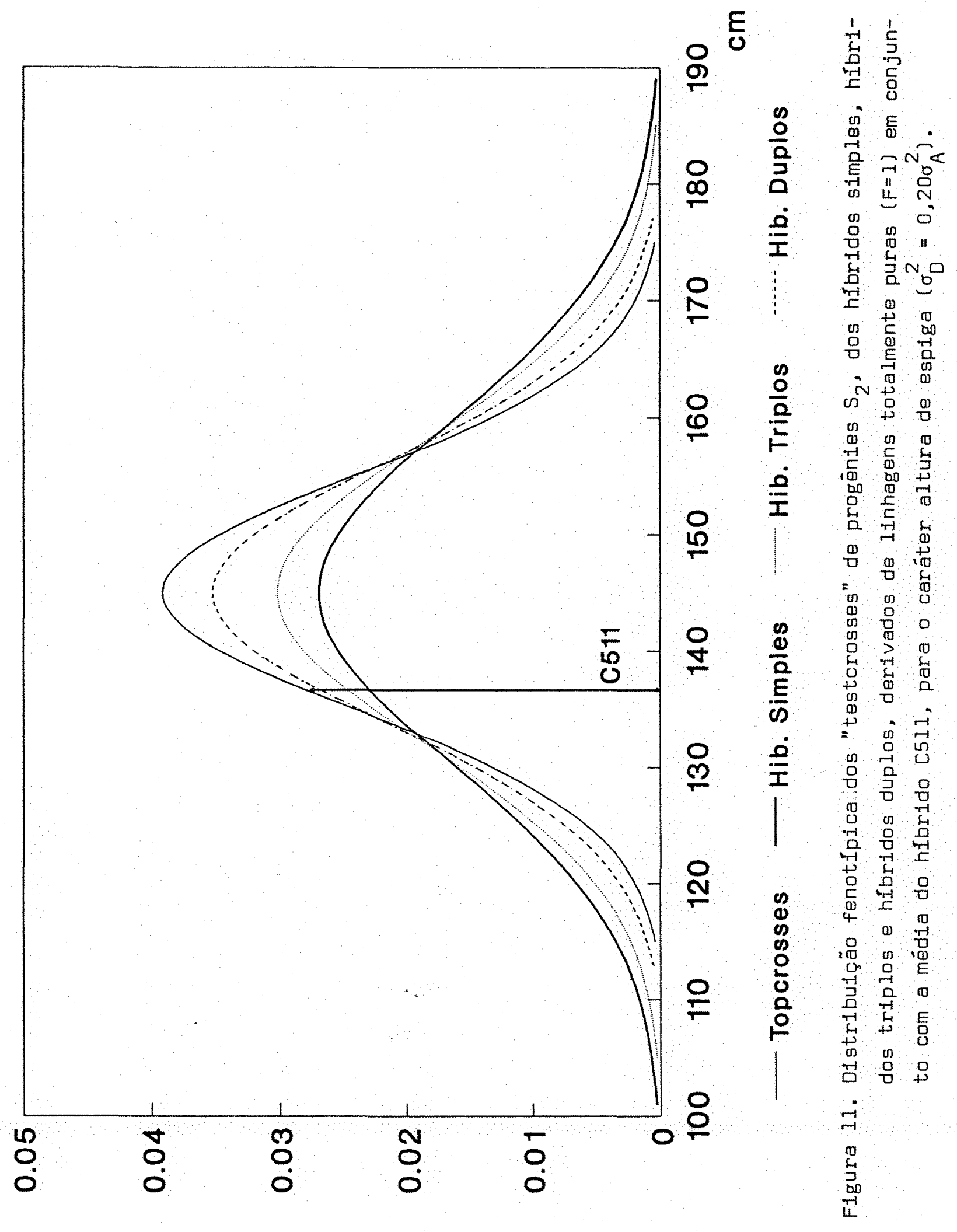


APENDI CES 
APENDICE 1. Mêdias de produção (PRO), altura de planta (APL e altura de es piga (AEL do conjunto de $20 \%$ dos "testcrosses" 12 maís produtivos.

\begin{tabular}{|c|c|c|c|c|c|c|c|c|}
\hline \multirow{2}{*}{ Trat. } & \multicolumn{2}{|c|}{ PRO } & \multicolumn{2}{|c|}{$A P$} & \multicolumn{2}{|c|}{$A E$} & \multicolumn{2}{|c|}{$A E / A P$} \\
\hline & $(g / p 1)$ & $(\%)$ & $(\mathrm{cm})$ & $(\%)$ & $(\mathrm{cm})$ & $(\%)$ & & $(\%)$ \\
\hline 1.18 & 172 & 118,3 & 245 & 104,9 & 147 & 109,6 & 0,60 & 104,5 \\
\hline 1.24 & 170 & 117,1 & 262 & 112,2 & 162 & 120,7 & 0,62 & 107,7 \\
\hline 1.33 & 166 & 114,5 & 255 & 109,2 & 155 & 115,5 & 0,61 & 105,8 \\
\hline 1.66 & 166 & 114,2 & 250 & 107,0 & 152 & 113,3 & 0,61 & 105,9 \\
\hline 1.12 & 164 & 112,9 & 270 & 115,6 & 162 & 120,7 & 0,60 & 104,5 \\
\hline 1.71 & 163 & 111,9 & 270 & 115,6 & 165 & 123,0 & 0,61 & 106,4 \\
\hline 1.32 & 161 & 110,8 & 255 & 109,2 & 155 & 115,5 & 0,61 & 105,8 \\
\hline 1.22 & 161 & 110,8 & 247 & 105,7 & 155 & 115,5 & 0,63 & 109,3 \\
\hline 1.14 & 161 & 110,8 & 262 & 112,2 & 155 & 115,5 & 0,59 & 103,0 \\
\hline 1.63 & 161 & 110,8 & 270 & 115,6 & 155 & 115,5 & 0,57 & 100,0 \\
\hline 1.08 & 159 & 109,4 & 252 & 107,9 & 155 & 115,5 & 0,62 & 107,1 \\
\hline 1.54 & 158 & 108,4 & 255 & 109,2 & 160 & 119,3 & 0,63 & 109,2 \\
\hline 1.79 & 156 & 107,6 & 262 & 112,2 & 157 & 117,0 & 0,60 & 104,3 \\
\hline 1.35 & 156 & 107,0 & 235 & 100,6 & 140 & 104,3 & 0,60 & 103,7 \\
\hline 1.19 & 155 & 106,3 & 227 & 97,2 & 132 & 98,4 & 0,58 & 101,3 \\
\hline 1.62 & 154 & 106,1 & 242 & 103,6 & 142 & 105,8 & 0,59 & 102,2 \\
\hline C511 & 145,4 & 100,0 & 233 & 100,0 & 134 & 100,0 & 0,575 & 100,0 \\
\hline
\end{tabular}


APENDICE 2. Médias de produção (PROL, altura de planta LAPl e altura de es piga (API, do conjunto de $20 \%$ dos "testcrosses" 21 maịs produtivos.

\begin{tabular}{|c|c|c|c|c|c|c|c|c|}
\hline \multirow{2}{*}{ Trat. } & \multicolumn{2}{|l|}{ PRO } & \multicolumn{2}{|c|}{$A P$} & \multicolumn{2}{|c|}{$A E$} & \multicolumn{2}{|c|}{$A E / A P$} \\
\hline & {$[g / p 1]$} & $(\%)$ & $(\mathrm{cm})$ & $(\%)$ & $(\mathrm{cm})$ & $(\%)$ & & $(\%)$ \\
\hline 2.27 & 195 & 122,5 & 237 & 98,5 & 120 & 100,9 & 0,59 & 102,3 \\
\hline 2.71 & 184 & 115,5 & 230 & 95,6 & 140 & $100 ; 9$ & 0,61 & 105,5 \\
\hline 2.64 & 182 & 114,6 & 265 & 110,2 & 160 & 115,3 & 0,60 & 104,7 \\
\hline 2.10 & 182 & 114,3 & 265 & 110,2 & 167 & 120,4 & 0,63 & 109,2 \\
\hline 2.25 & 178 & 112,1 & 240 & 99,8 & 140 & 100,9 & 0,58 & 101,1 \\
\hline 2.21 & 175 & 110,2 & 250 & 104,0 & 155 & 111,7 & 0,62 & 107,5 \\
\hline 2.23 & 175 & 109,9 & 250 & 104,0 & 152 & 109,5 & 0,61 & 105,4 \\
\hline 2.56 & 171 & 107,3 & 242 & 100,6 & 145 & 104,5 & 0,60 & 103,9 \\
\hline 2.26 & 170 & 107,1 & 262 & 108,9 & 162 & 116,8 & 0,62 & 107,2 \\
\hline 2.87 & 170 & 107,0 & 257 & 106,9 & 155 & 111,7 & 0,60 & 104,5 \\
\hline 2.81 & 170 & 106,8 & 250 & 104,9 & 150 & 108,1 & 0,60 & 104,0 \\
\hline 2.28 & 168 & 105,8 & 237 & 98,5 & 135 & 97,3 & 0,57 & 98,7 \\
\hline 2.08 & 168 & 105,5 & 242 & 100,6 & 142 & 102,3 & 0,59 & 101,7 \\
\hline 2.44 & 166 & 104,6 & 250 & 104,0 & 150 & 108,1 & 0,60 & 104,0 \\
\hline 2.0 .5 & 166 & 104,6 & 245 & 101,9 & 150 & 108,1 & 0,61 & 106,1 \\
\hline 2.20 & 166 & 104,1 & 242 & 100,6 & 140 & 100,9 & 0.58 & 100,3 \\
\hline 2.65 & 166 & 104,1 & 242 & 100,6 & 145 & 104,5 & 0,60 & 103,9 \\
\hline 2.74 & 164 & 103,1 & 237 & 98,5 & 147 & 105,9 & 0,62 & 107,5 \\
\hline C511 & 159,2 & 100,0 & 240,5 & 100,0 & 138,8 & 100,0 & 0,577 & 100,0 \\
\hline
\end{tabular}


APENDICE 3. Esquema adaptado de seleção recorrente recíproca avaliando "testcrosses" de plantas $\mathrm{s}_{1}$ prọ̣ ficas e recombinando progénies $\mathrm{S}_{2}$, em ciclo mínimo de dois anos.

\begin{tabular}{|c|c|c|c|}
\hline FASE & $\begin{array}{l}\text { EPOCA } \\
\text { SEMEADURA }\end{array}$ & INSTALAÇÃO & OBJETIVO \\
\hline 1 & $\begin{array}{l}\text { Verão } \\
\text { Ano } 1\end{array}$ & $\begin{array}{l}\text { Um campo plantas } S_{0} \\
\text { por população }\end{array}$ & Autofecundação para obtenção de $\mathrm{PS}_{1}$ \\
\hline 2 & $\begin{array}{l}\text { Inverno } \\
\text { Ano } 1\end{array}$ & $\begin{array}{l}\text { Um campo PS por } \\
\text { população }\end{array}$ & $\begin{array}{c}\text { Obtenção de dols tipos de progénies } \\
\text { a) PS : autofecundação da segunda espiga } \\
\text { b) PMI-inter: cruzamento primelra espiga com } \\
\text { mistura de pólen da populaçäo } \\
\text { recíproca. }\end{array}$ \\
\hline 3 & $\begin{array}{l}\text { Verão } \\
\text { Ano } 2\end{array}$ & $\begin{array}{l}\text { Experimentos para avaliação } \\
\text { PMI-inter }\end{array}$ & $\begin{array}{l}\text { Avaliação da capacidade combinatórla para } \\
\text { a) S.R.Recíproca } \\
\text { b) S.Híbridos }\end{array}$ \\
\hline \multirow[t]{2}{*}{4} & Inverno & $\begin{array}{l}\text { a) Um lote isolado por } \\
\text { populaçäo com semente } \\
\text { remanescente } \text { PS }_{2} \text { sele- } \\
\text { cionadas }\end{array}$ & $\begin{array}{l}\text { Recombinação e obtenção das populaçōes } \\
\text { melhoradas }\end{array}$ \\
\hline & Ano 2 & $\begin{array}{l}\text { b) Um campo } \mathrm{PS}_{2} \text { por } \\
\text { populaçäo }\end{array}$ & Autofecundação para obtenção $\mathrm{PS}_{3}$ \\
\hline \multirow[t]{2}{*}{5} & Veräo & a) Idem Fase 1 & Idem Fase 1 \\
\hline & Ano 3 & $\begin{array}{l}\text { b) Um campo PS } 3 \text { por } \\
\text { população }\end{array}$ & Autofecundação para obtenção de linhagens $S_{4}$. \\
\hline
\end{tabular}

